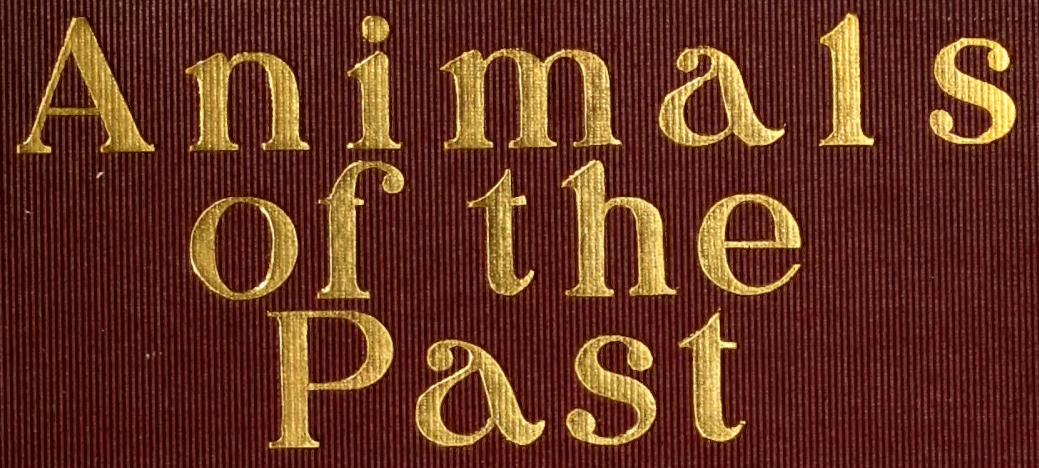

Frederic A.Lucas 

to 2. Coimen wich the remoles 



ANIMALS OF THE PAST 




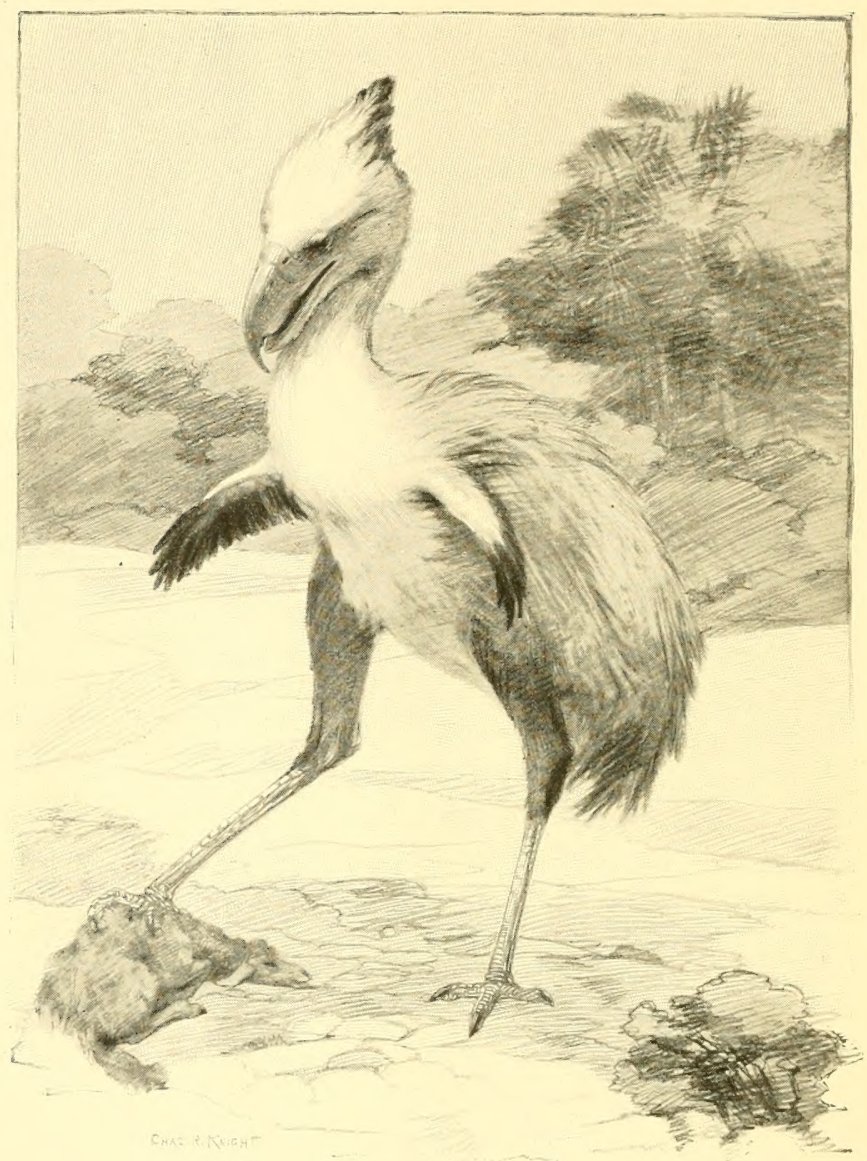

Phororhacos, a Patagonian Giant of the Miocene.

From a drawing by Charles R. Knight. 


\section{ANIMALS OF THE PAST}

BY

\section{FREDERIC A. LUCAS}

Curator of the Division of Comparative Anatomy,

United States National Museum

จ

FULLY ILLUSTRATED

NEW YORK

McCLURE, PHILLIPS \& CO.

1901 
Copyrigit, 1900, by S. S. McClute Co.

1901, BY McClure, PHillips \& Co.

Published November, 1901.

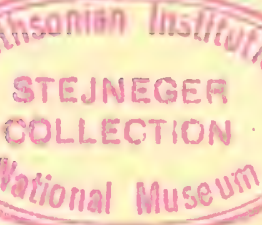




\section{TABLE OF CONTENTS}

\section{INTRODUCTORY AND EXPLANATORY}

Use of scientific names, xvi; estimates of age of earth, xvii; restorations by Mr. Knight, xviii; Works of Reference, xix.

\section{FOSSILS, AND HOW THEY ARE FORMED}

Definition of fossils, 1 ; fossils may be indications of animals or plants, 2; casts and impressions, 3; why fossils are not more abundant, 4; conditions under which fossils are formed, 5; enemies of bones, 6; Dinosaurs engulfed in quicksand, 8; formation of fossils, 9 ; petrified bodies frauds, 10 ; natural casts, 10; leaves, 13; incrustations, 14; destruction of fossils, 15 ; references, 17 .

\section{THE EARLIEST KNOWN VERTEBRATES}

Methods of interrogating Nature, 18; thickness of sedimentary rocks, 20; earliest traces of life, 21; early vertebrates difficult of preservation, 22 ; armored fishes, 23 ; abundance of early fishes, 25 ; destruction of fish, 26 ; carboniferous sharks, 29 ; known mostly from teeth and spines, 30 ; references, 32 .

\section{IMPRESSIONS OF THE PAST}

Records of extinct animals, 33 ; earliest traces of animal life, 34 ; formation of tracks, 35 ; tracks in all strata, 36 ; discovery of tracks, 37 ; tracks of Dinosaurs, 39 ; species named from tracks, 41 ; footprints aid in determining attitude of animals, 43 ; tracks at Carson City, 45 ; references, 47 . 


\section{RULERS OF THE ANCIENT SEAS}

The Mosasaurs, 49 ; history of the first known Mosasaur, 50 ; jaws of reptiles, 53 ; extinction of Mosasaurs, 55 ; the seaserpent, 56; Zeuglodon, 58 ; its habits, 59 ; Koch's Hydrarchus, 61 ; bones collected by Mr. Schuchert, 63; abundance of sharks, 64 ; the great Carcharodon, 65 ; arrangement of sharks' teeth, 67 ; references, 68 .

\section{BIRDS OF OLD}

Earliest birds, 70 ; wings, 71 ; study of young animals, 73 ; the curious Hoactzin, 74; first intimation of birds, 76 ; Archæopteryx, 77 ; birds with teeth, 78 ; cretaceous birds, 79 ; Hesperornis, 80 ; loss of power of flight, 81 ; covering of Hesperornis, 82 ; attitude of Hesperornis, 83 ; curious position of legs, 84 ; toothed birds disappointing, 85 ; early development of birds, 86 ; eggs of early birds, 87 ; references, 88.

\section{THE DINOSAURS}

Discovery of Dinosaur remains, 90 ; nearest relatives of Dinosaurs, 91 ; relation of birds to reptiles, 92 ; brain of Dinosaurs, 93 ; parallel between Dinosaurs and Marsupials, 95 ; the great Brontosaurus, 96 ; food of Dinosaurs, 97 ; habits of Diplodocus, 99 ; the strange Australian Moloch, 100; combats of Triceratops, 101 ; skeleton of Triceratops, 102 ; Thespesius and his kin, 104; the carnivorous Ceratosaurus, 106 ; Stegosaurus, the plated lizard, 106 ; references, 109.

\section{READING THE RIDDLES OF THE ROCKS}

Fossils regarded as sports of nature, 111 ; qualifications of a successful collector, 112 ; chances of collecting, 114 ; excavation of fossils, 115 ; strengthening fossils for shipment, 117 ; great size of some specimens, 118 ; the preparation of fossils, 119 ; mistakes of anatomists, 120 ; reconstruction of Triceratops, 121; distinguishing characters of bones, 122 ; 
the skeleton a problem in mechanics, 124; clothing the bones with flesh, 127 ; the covering of animals, 127 ; outside ornamentation, 129 ; probabilities in the covering of animals, 130 ; impressions of extinct animals, 131; mistaken inferences from bones of Mammoth, 133; coloring of large land animals, 134 ; color markings of young animals, 136 ; references, 137.

\section{FEATHERED GIANTS}

Legend of the Moa, 139 ; our knowledge of the Moas, 141 ; some Moas wingless, 142 ; deposits of Moa bones, 143 ; legend of the Roc, 144; discovery of Apyornis, 145; largesounding names, 146 ; eggs of great birds, 147 ; the Patagonian Phororhacos, 149; the huge Brontornis, 150; development of giant birds, 153 ; distribution of flightless birds, 154; relation between flightlessness and size, 156 ; references, 156 .

\section{THE ANCESTRY OF THE HORSE}

North America in the Eocene age, 160 ; appearance of early horses, 163 ; early domestication of the horse, 165 ; the toes of horses, 166"; Miocene horses small, 167 ; evidence of genealogy of the horse, 170 ; meaning of abnormalities, 170; changes in the climate and animals of the West, 174 ; references, 176.

\section{THE MAMMOTH}

The story of the killing of the Mammoth, 177 ; derivation of the word "mammoth," 178 ; mistaken ideas as to size of the Mammoth, 179; size of Mammoth and modern elephants, 180 ; finding of an entire Mammoth, 182; birthplace of the Mammoth, 184; beliefs concerning its bones, 185 ; the range of the animal, 186 ; theories concerning the extinction of the Mammoth, 188; Man and Mammoth, 189; origin of the Alaskan Live Mammoth Story, 190; traits of the Innuits, 192; an entire Mammoth recently found, 194; references, 195. 


\section{THE MASTODON}

Differences between Mastodon and Mammoth, 198; affinities of the Mastodon, 200 ; vestigial structures, 201 ; distribution of American Mastodon, 203 ; first noticed in North America, 204 ; thought to be carnivorous, 206; Koch's Missourium, 208 ; former abundance of Mastodons, 209; appearance of the animal, 210 ; its size, 211 ; was man contemporary with Mastodon? 213; the Lenape stone, 215; legend of the big buffalo, 216 ; references, 218 .

\section{WHY DO ANIMALS BECOME EXTINCT?}

Extinction sometimes evolution, 221 ; over-specialization as a cause for extinction, 222 ; extinction sometimes unaccountable, 223; man's capability for harm small in the past, 224; old theories of great convulsions, 226 ; changes in nature slow, 227 ; the case of Lingula, 228; local extermination, 229; the Moas and the Great Auk, 232 ; the case of large animals, 233 ; interdependence of living beings, 234; coyotes and fruit, 236 ; Shaler on the Miocene flora of Europe, 236 ; man's desire for knowledge, 238.

INDEX, - . . . . . . . . 243 


\section{NOTE ON THE ILLUSTRATIONS}

'The original drawings, made especially for this book, are by Charles R. Knight and James M. Gleeson, under the direction of Mr. Knight. 'The fact that the originals of these drawings have been presented to and accepted by the United States National Museum is evidence of their scientific value. Mr. Knight has been commissioned by the Smithsonian Institution, the United States National Museum, and the New York Museum of Natural History, to do their most important pictures of extinct animals. He is the one modern artist who can picture prehistoric animals with artistic charm of presentation as well as with full scientific accuracy. In this instance, the author has personally superintended the artist's work, so that it is as correct in every respect as present knowledge makes possible. Of the minor illustrations, some are by $\mathrm{Mr}$. Bruce Horsfall, an artist attached to the staff of the New York Museum of Natural History, and all have been drawn with the help of and under the author's supervision. 



\section{IIST OF ILLUSTRATIONS}

Phororhacos, a Patagonian Giant of the Miocene

From a Drawing by Charles R. Knight

Frontispiece Fig.

1. Diplomystus, an Ancient Member of the Shad Family . . . . . 4

From the fish-bed at Green River, Wyoming. From a specimen in the United States National Museum.

2. Bryozoa, from the Shore of the Devonian Sea that Covered Eastern New York . 10 From a specimen in Yale University ILuseum, prepared by Dr. Beecher.

3. Skeleton of a Radiolarian Very Greatly Enlarged . . . . . . . 17

4. Cephalaspis and Loricaria, an Ancient and a Modern Armored Fish . . . 24

5. Pterichthys, the Wing Fish . . . 32

6. Where a Dinosaur Sat Down . . . 38

7. Footprints of Dinosaurs on the Brownstone of the Connecticut Valley . . . 40 From a slab in the museum of Amherst College. 
Fig.

8. The Track of a Three-toed Dinosaur . 47

9. A Great Sea Lizard, Tylosaurus Dyspelor . 52 From a drawing by $J$. M. Gleeson.

10. Jaw of a Mosasaur, Showing the Joint that Increased the Swallowing Capacity of that Reptile . . . . . . 54

11. Koch's Hydrarchus. Composed of Portions of the Skeletons of Several Zeuglodons 62

12. A Tooth of Zeuglodon, One of the "Yoke Teeth," from which it derives the name . 69

13. Archæopteryx, the Earliest Known Bird . 70 From the specimen in the Berlin Mruseum.

14. Nature's Four Methods of Making a Wing : Bat, Pteryodactyl, Archæopteryx, and Modern Bird . . . . . 72

15. Young Hoactzins . . . . . 75

16. Hesperornis, the Great Toothed Diver 82 From a drawing by J. M. Gleeson.

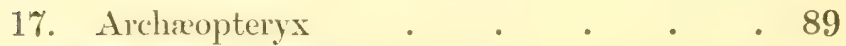
As Restored by Lr. Pycraft.

18. Thespesius, a Common Herbivorous Dinosaur of the Cretaceous a $\quad$ • . $\quad .90$ From a drawing by Charles R. Knight.

19. A Hind Leg of the Great Brontosaurus, the Largest of the Dinosaurs 96 
Fig.

20. A Single Vertebra of Brontosaurus 97

21. Moloch, a Modern Lizard that Surpasses the

Stegosaurs in All but Size . . 100 From a drawing by $J$. MI. Gleeson.

22. Skeleton of Triceratops . . . . 103

23. The Horned Ceratosaurus, a Carnivorous

Dinosaur . . . . . 106 From a drawing by J. M. Gleeson.

24. Stegosaurus, an Armored Dinosaur of the Jurassic . . . . . . 108 From a drawing by Charles R. Knight.

25. Skull of Ceratosaurus . . . 110 From a specimen in the United States National MIuseum.

26. Triceratops, He of the Three-horned Face 126 From a statuette by Charles R. Knight.

27. A Hint of Buried Treasures . . . 137

28. Relics of the Moa . . . . . 140

29. Eggs of Feathered Giants, Epyornis, Ostrich, Moa, Compared with a Hen's Egg . . . . . . . 148

30. Skull of Phororhacos Compared with that of the Race-horse Lexington . . 151

31. Leg of a Horse Compared with that of the Giant Moa . . . . . 152 
Fig. $\quad$ Page

32. The Three Giants, Phororhacos, Moa, Ostrich . . . . . . . 158

33. Skeleton of the Modern Horse and of His

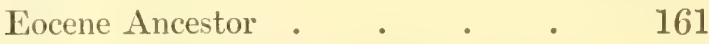

34. The Development of the Horse . . 168

35. The Mammoth . . . . 176 From a drawing by Charles R. Knight.

36. Skeleton of the Mammoth in the Royal Museum of St. Petersburg . . . 183

37. The Mammoth . . . . . . 196 As engraved by a Primitive Artist on a Piece of Mammoth-Tusk.

38. Tooth of Mastodon and of Mammoth _ 199

39. The Missourium of Koch . . . . 207 From a Tracing of the Figure Illustrating Koch's Description.

40. The Mastodon . . . . . . 210 From a drawing by $J$. M. Gleeson.

41. The Lenape Stone, Reduced . 219 


\section{INTRODUCTORY AND EXPLANA- TORY}

At the present time the interest in the ancient life of this earth is greater than ever before, and very considerable sums of money are being capended to dispatch carefully planned expeditions to various parts of the world systematically to gather the fossil remains of the animals of the past. That this interest is not merely confined to a fere scientific men, but is shared by the general public, is shown by the numerous articles, including many telegrams, in the columns of the daily papers. The object of this book is to tell some of the interesting, facts concerning a few of the better linown or more remarkable of these extinct inhabitants of the ancient world; also, if possible, to ease the strain on these renerable animals, caused by stretching them so often beyond their due proportions.

The book is admittedly somerchat on the lines 
xvi INTRODUCTORY AND EXPLANATORY

of MI. Hutchinson's "Extinct Monsters" and "Creatures of Other Days," but it is hoped that it may be considered zeith books as with boats, a good plan to build after a good model. The information scattered through these pages has been derived from varied sources; some has of necessity been taken from standard books, a part has been gathered in the course of museum reorl and offecial correspondence; for much, the author is indebted to his personal fricuds, and for a part, he is under obligations to fivends he has never met, acho have limdly responded to his inquiries. The endearor has been conscientiously made to caxclude all misinformation; it is, nevertheless, entirely probable that some mistalies may have crept in, and due apology for these is hereby made beforehand.

The author expects to be talien to task for the use of scientific names, and the reader may perhaps sympathian with the old lady zoho said that the discovery of all these strange amimals did not surprise her so much as the fact that anyone should hinow their names when they reere found. The real trouble is that there are no common names for these animals. Then, too, 
people who call for easier names do not stop to reflect that, in many cases, the scientific names are no harder than others, simplyy less familiar, and, when domesticated, the'y cease to be hard: weitness mammoth, elephant, rhinoceros, giraffic, boa constrictor, all of rehich are scientific names. And if', for cexample, we were to call the Hyracotherinm a Higrax beast it roould not be a name, but a description, and not a bit more intelligible.

Again, it is impossible to indicate the period at achich these creatures lived without using the scientific term for it - Jurassic, Eocene, Pliocene, as the case may be-becanse there is no other way of doing it.

Some readers will doubtless feel disappointed because they are not told how many years ago these animals liverd. The question is often astied How longa ago did this or that animal line? But wehen the least estimate puts the age of the earth at only 10,000,000 years, while the longest makes it 6,000,000,000, it doess seem as if it were hardly worth rehile to name any figmes. Lien when we get well toward the present period we find the time that has olapsed since the beginning of 
xviii INTRODUCTORY AND EXPLANATORY

the Jurassic, when the Dinosanrs held carmival, serriously put at from 15,000,000 to 6,000,000 years; while from the begimning of the Eocene, when the mammals began to gain the supremacy, until nowe, the figures wary, from $3,000,0100$ to 5, (1)00, (1)00 years. So the question of age will be left for the reader to settle to his or her satisfaction.

The restorations of extinct animals may be considered as giving as acenrate representations of these creatures as it is possible to make; they were either drawn by Mr. En nishte, whose name is guarantee that the? are of the highest quality, or by MIr. Glecson, with the aid of Mr. Knight's criticism. That they are infallibly correct is out of the question; for, as Dr. Woodicard werites in the preface to "Eutinct Monsters," "restorations are ever liable to emendation, and the present . . . will certainly prove no exception to the rule." As a striking instance of this, it was found necessary at the last moment to change the figure of Hesperornis, the original life-like portrait proving to be incorrect in attitude, a fact that avould have long escenped detection but for the Pan-American Exposition. 
The connection between the two is explained on page 76 . However, the reader may rest assured that these restorations are infinitely more nearly correct than many figures of living animals that have appeared reithin the last twenty-five years, and are even now doing duty.

The endeavor has been made to indicate, at the end of each chapter, the museums in which the best examples of the animals described may be seen, and also some book or article in which further information may be obtained. As this book is intended for the general reader, references to purely technical articles have, so far as possible, been avoided, and none in foreign languages mentioned.

For important works of reference on the subject of paleontology, the reader may consult "A Manual of Paleontology," by Alleyne Nicholson and R. Lydcklier, a work in tro volumes dealing with invertebrates, wertebrates, and plants, or "A Text-Book of Paleontology," by Karl von Zittel, English edition, only the first volume of which has so far been published. An admirable book on the vertebrates is "Outlines 
$\mathrm{xx}$ INTRODUCTORY AND EXPLANATORY

of Vertebrate Paleontology," by Arthur Smith Woodward. It is to be understood that these are not at all "popular" in their scope, but intended for students who are already well advanced in the study of zoölogy. 
ANIMALS OF THE PAST 



\section{I}

FOSSILS, AND HOW THEY ARE FORMED

"How of a thousand snakes each one Was changed into a coil of stone."

Fossils are the remains, or even the indications, of animals and plants that have, through natural agencies, been buried in the earth and preserved for long periods of time. This may seem a rather meagre definition, but it is a difficult matter to frame one that will be at once brief, exact, and comprehensive ; fossils are not necessarily the remains of extinct animals or plants, neither are they, of necessity, objects that have become petrified or turned into stone.

Bones of the Great Auk and Rytina, which are quite extinct, would hardly be considered as fossils; while the bones of many species of animals, still living, would properly come in that category, having long ago been buried by natural causes and often been changed into 
stone. And yet it is not essential for a specimen to have had its animal matter replaced by some mineral in order that it may be classed as a fossil, for the Siberian Mammoths, found entombed in ice, are very properly spoken of as fossils, although the flesh of at least one of these animals was so fresh that it was eaten. Likewise the mammoth tusks brought to market are termed fossil-ivory, although differing but little from the tusks of modern elephants.

Many fossils indeed merit their popular appellation of petrifactions, because they have been changed into stone by the slow removal of the animal or vegetable matter present and its replacement by some mineral, usually silica or some form of lime. But it is necessary to include 'indications of plants or animals' in the above definition because some of the best fossils may be merely impressions of plants or animals and no portion of the objects themselves, and yet, as we shall see, some of our most important information has been gathered from these same imprints.

Nearly all our knowledge of the plants that flourished in the past is based on the impres- 
FOSSILS, AND HOW THEY ARE FORMED 3

sions of their leaves left on the soft mud or smooth sand that later on hardened into enduring stone. Such, too, are the trails of creeping and crawling things, casts of the burrows of worms and the many footprints of the reptiles, great and small, that crept along the shore or stalked beside the waters of the ancient seas. The creatures themselves have passed away, their massive bones even are lost, but the prints of their feet are as plain to-day as when they were first made.

Many a crustacean, too, is known solely or mostly by the cast of its shell, the hard parts having completely vanished, and the existence of birds in some formations is revealed merely by the casts of their eggs; and these natural casts must be included in the category of fossils.

Impressions of vertebrates may, indeed, be almost as good as actual skeletons, as in the case of some fishes, where the fine mud in which they were buried has become changed to a rock, rivalling porcelain in texture; the bones have either dissolved away or shattered into dust at the splitting of the rock, but the 
imprint of each little fin-ray and every threadlike bone is as clearly defined as it would have been in a freshly prepared skeleton. So fine, indeed, may have been the mud, and so quiet for the time being the waters of the ancient sea or lake, that not only have prints of bones and leaves been found, but those of feathers and of the skin of some reptiles, and even of such soft and delicate objects as jelly fishes. But for these we should have little positive knowledge of the outward appearance of the creatures of the past, and to them we are occasionally indebted for the solution of some moot point in their anatomy.

The reader maty possibly wonder why it is that fossils are not more abundant; why, of the vast majority of animals that have dwelt upon the earth since it became fit for the habitation of living beings, not a trace remains. 'This, too, when some objects - the tusks of the Mammoth, for example - have been sufficicntly well preserved to form staple articles of commerce at the present time, so that the carved handle of my lady's parasol may have formed part of some animal that flourished at the very dawn 


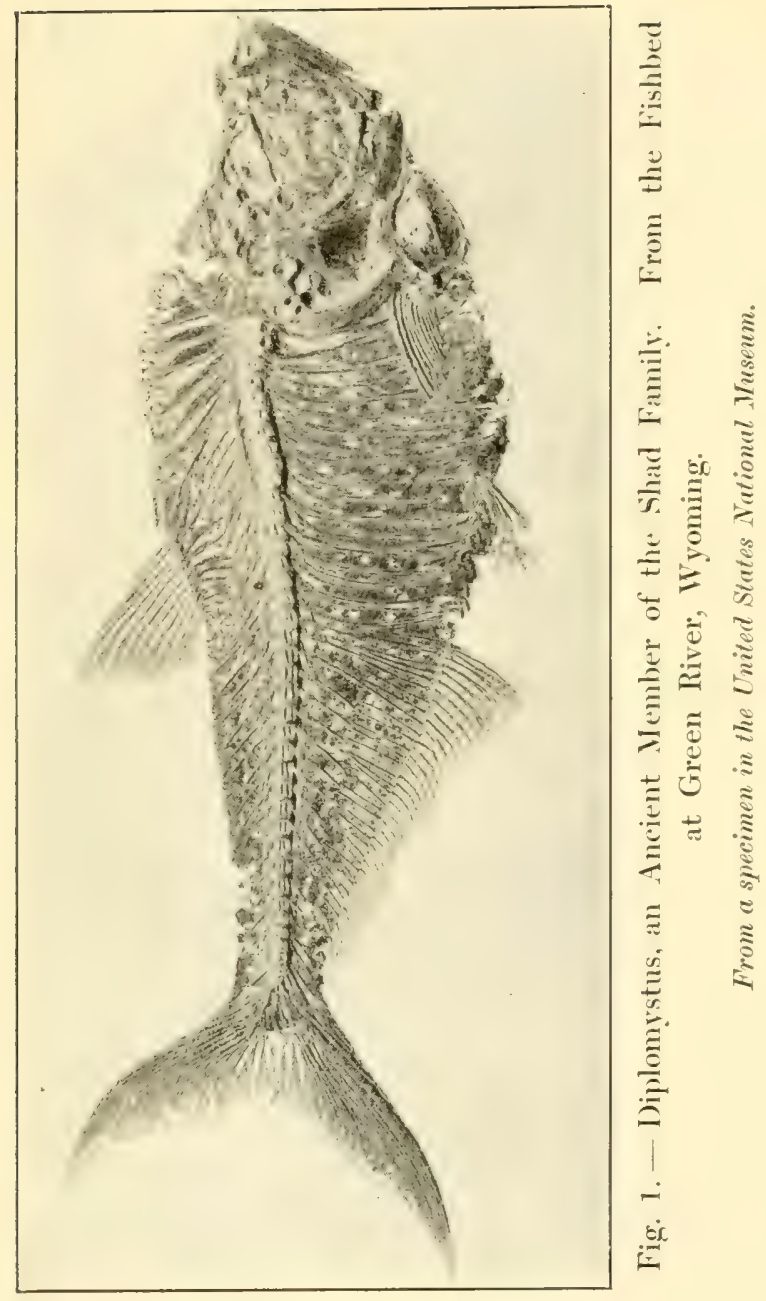



of the human race, and been gazed upon by her grandfather a thousand times removed. The answer to this query is that, unless the conditions were such as to preserve at least the hard parts of any creature from immediate decay, there was small probability of its becoming fossilized. 'These conditions are that the objects must be protected from the air, and, practically, the only way that this happens in nature is by having them covered with water, or at least buried in wet ground.

If an animal dies on dry land, where its bones lie exposed to the summer's sun and rain and the winter's frost and snow, it does not take these destructive agencies long to reduce the bones to powder; in the rare erent of a climate devoid of rain, mere changes of temperature, by producing expansion and contraction, will sooner or later cause a bone to crack and crumble.

Usually, too, the work of the elements is aided by that of animals and plants. Every one has seen a dog make way with a pretty good-sized bone, and the Hyena has still greater capabilities in that line; and ever since verte- 
brate life began there have been carnivorous animals of some kind to play the rôle of bonedestroyers. Even were there no carnivores, there were probably then, as now, rats and mice a-plenty, and few suspect the havoc small rodents may play with a bone for the grease it contains, or merely for the sake of exercising their teeth. Now and then we come upon a fossil bone, long since turned into stone, on which are the marks of the little cutting teeth of field mice, put there long, long ago, and yet looking as fresh as if made only last week. 'These little beasts, however, are indirect rather than direct agents in the destruction of bones by gnawing off the outer layers, and thus permitting the more ready entrance of air and water. Plants, as a rule, begin their work after an object has become partly or entirely buried in the soil, when the tiny rootlets find their way into fissures, and, expanding as they grow, act like so many little wedges to force it asunder.

Thus on dry land there is small opportunity for a bone to become a fossil ; but, if a creature so perishes that its body is swept into the 
ocean or one of its estuaries, settles to the muddy bottom of a lake or is caught on the sandy shoals of some river, the chances are good that its bones will be preserved. They are poorest in the ocean, for unless the body drifts far out and settles down in quiet waters, the waves pound the bones to pieces with stones or scour them away with sand, while marine worms may pierce them with burrows, or echinoderms cut holes for their habitations; there are more enemies to a bone than one might imagine.

Suppose, howerer, that some animal has sunk in the depths of a quiet lake, where the wash of the wares upon the shore wears the sand or rock into mud so fine that it floats out into still water and settles there as gently as dew upon the grass. Little by little the bones are covered by a deposit that fills every groove and pore, preserving the mark of every ridge and furrow; and while this may take long, it is merely a matter of time and farorable circumstance to bury the bones as deeply as one might wish. Scarce a reader of these lines but at some time has cast anchor in some quict 
pond and pulled it up, thickly covered with sticky mud, whose existence would hardly be suspected from the sparkling waters and pebbly shores. If, instead of a lake, our animal had gone to the bottom of some estuary into which poured a river turbid with mud, the process of entombment would have been still more rapid, while, had the creature been engulfed in quicksand, it would have been the quickest method of all; and just such accidents did take place in the early days of the earth as well as now. At least two examples of the great Dinosaur Thespesius have been found with the bones all in place, the thigh bones still in their sockets and the ossified tendons running along the backbone as they did in life. This would hardly have happened had not the body been surrounded and supported so that every part was held in place and not crushed, and it is difficult to see any better agency for this than burial in quicksand.

If such an event as we have been supposing took place in a part of the globe where the land was gradually sinking - and the crust of the earth is ever rising and falling - the mud 
FOSSILS, AND HOW THEY ARE FORMED 9 and sand would keep on accumulating until an enormously thick layer was formed. The lime or silica contained in the water would tend to cement the particles of mud and grains of sand into a solid mass, while the process would be aided by the pressure of the overlying sediment, the heat created by this pressure, and that derived from the earth beneath. During this process the animal matter of bones or other objects would disappear and its place be taken by lime or silica, and thus would be formed a layer of rock containing fossils. The exact manner in which this replacement is effected and in which the chemical and mechanical changes occur is very far from being definitely known - especially as the process of "fossilization" must at times have been very complicated.

In the case of fossil wood greater changes have taken place than in the fossilization of bone, for there is not merely an infiltration of the specimen but a complete replacement of the original vegetable by mineral matter, the interior of the cells being first filled with silica and their walls replaced later on. So com- 
pletely and minutely may this change occur that under the microscope the very cellular structure of the wood is visible, and as this varies according to the species, it is possible, by microscopical examination, to determine the relationship of trees in cases where nothing but fragments of the trunk remain.

The process of fossilization is at best a slow one, and soft substances such as flesh, or even hom, decay too rapidly for it to take place, so that all accounts of petrified bodies, human or otherwise, are either based on deliberate frauds or are the result of a very erroneous misinterpretation of facts. That the impression or cast of a body might be formed in nature, somewhat as casts have been made of those who perished at Pompeii, is true; but, so far, no authentic case of the kind has come to light, and the reader is quite justified in disbelieving any report of "a petrified man."

Natural casts of such hard bodies as shells are common, formed by the dissolving away of the original shell after it had become enclosed in mud, or even after this had changed to stone, and the filling up of this space by the 


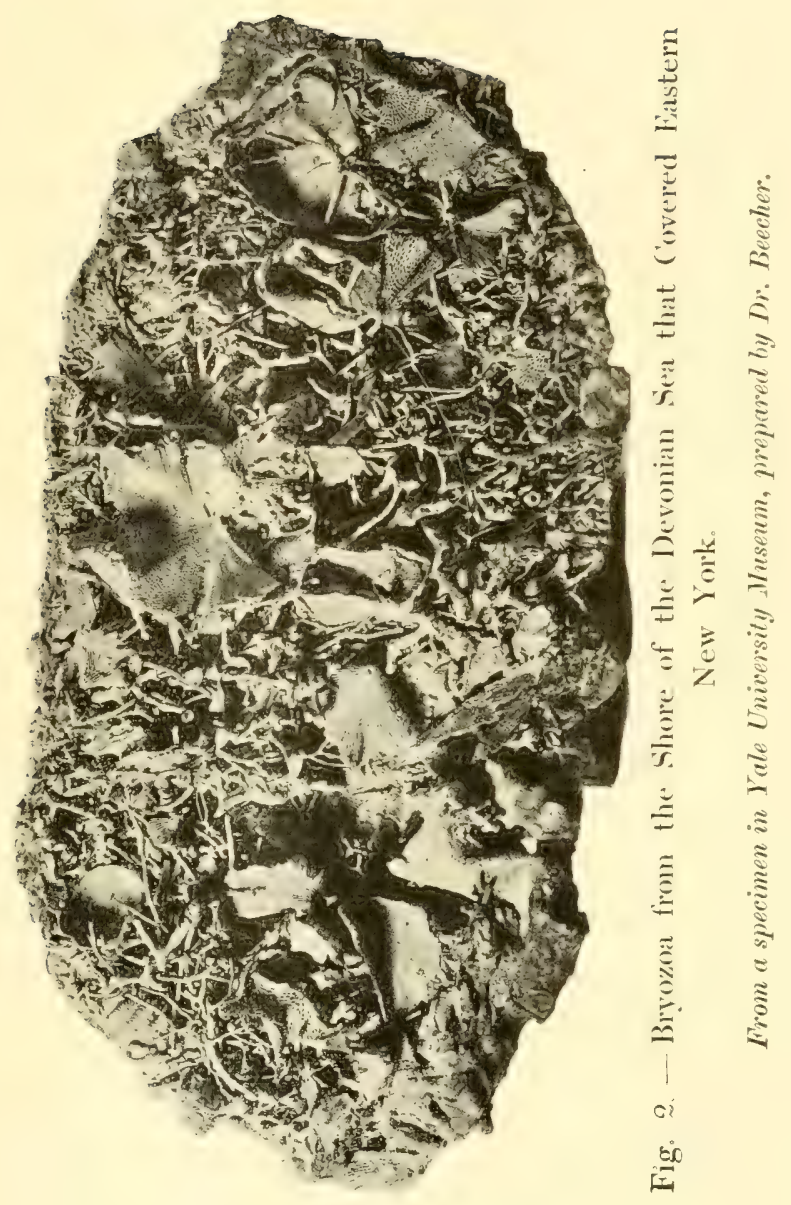



FOSSILS, AND HOW THEY ARE FORMED 11

filtering in of water charged with lime or silica, which is there deposited, often in crystalline form. In this way, too, are formed casts of eggs of reptiles and birds, so perfect that it is possible to form a pretty accurate opinion as to the group to which they belong.

Sometimes it happens that shells or other small objects imbedded in limestone have been dissolved and replaced by silica, and in such cases it is possible to eat away the enveloping rock with acid and leave the silicified casts. By this method specimens of shells, corals, and bryozoans are obtained of almost lace-like delicacy, and as perfect as if only yesterday gathered at the sea-shore. Casts of the interior of shells, showing many details of structure, are common, and anyone who has seen clams dug will understand how they are formed by the entrance of mud into the empty shell.

Casts of the kernels of nuts are formed in much the same way, and Professor E. H. Barbour has thus described the probable manner in which this was done. When the nuts were dropped into the water of the ancient lake the kernel rotted away, but the shell, being tough 
and hard, would probably last for years under farorable circumstances. Throughout the marls and clays of the Bad Lands (of South Dakota) there is a large amount of potash. This is dissolved by water, and then acts upon quartz, carrying it away in solution. 'This would find its way by infiltration into the interior of the nut. At the same time with this process, carrying lime carbonate in solution was going on, so that doubtless the stone kernels, consisting of pretty nearly equal parts of lime and silica, were deposited within the nuts. These kernels, of course, became hard and flinty in time, and capable of resisting almost any amount of weathering. Not so the organic shell; this eventually would decay away, and so leave the filling or kernel of chalcedony and lime.*

"Fossil leaves" are nothing but fine casts, made in natural moulds, and all have seen the first stages in their formation as they

* Right here is the weak spot in Professor Barbour's explanation, and an illustration of our lack of knowledge. For it is difficult to see why the more enduring husk should not have become mineralized cqually with the cavity within. 
watched the leaves sailing to the ground to be covered by mud or sand at the next rain, or dropping into the water, where sooner or later they sink, as we may see them at the bottom of any quiet woodland spring.

Impressions of leaves are among the early examples of color-printing, for they are frequently of a darker, or even different, tint from that of the surrounding rock, this being caused by the carbonization of vegetable matter or to its action on iron that may have been present in the soil or water. Besides complete mineralization, or petrifaction, there are numerous cases of incomplete or semi-fossilization, where modern objects, still retaining their phosphate of lime and some animal matter even, are found buried in rock. This takes place when water containing carbonate of lime, silica, or sometimes iron, flows over beds of sand, cementing the grains into solid but not dense rock, and at the same time penetrating and uniting with it such things as chance to be buried. In this way was formed the "fossil man" of Guadeloupe, West Indies, a skeleton of a modern Carib lying in recent concretionary 
limestone, together with shells of existing species and fragments of pottery. In a similar way, too, human remains in parts of Florida have, through the infiltration of water charged with iron, become partially converted into limonite iron ore; and yet we know that these bones have been buried within quite recent times.

Sometimes we hear of springs or waters that "turn things into stone," but these tales are quite incorrect. Waters there are, like the celebrated hot springs of Auvergne, France, containing so much carbonate of lime in solution that it is readily deposited on objects placed therein, coating them more or less thickly, according to the length of time they are allowed to remain. This, however, is merely an encrustation, not extending into the objects. In a similar way the precipitation of solid material from waters of this description forms the porous rock known as tufa, and this often encloses moss, twigs, and other substances that are in no way to be classed with fossils.

But some streams, flowing orer limestone rocks, take up considerable carbonate of lime, and this may be deposited in water-soaked logs, 
replacing more or less of the woody tissue and thus really partially changing the wood into stone.

The rery rocks themselves may consist largely of fossils; chalk, for example, is mainly made up of the disintegrated shells of simple marine animals called foraminifers, and the beautiful flint-like "skeletons" of other small creatures termed radiolarians, minute as they are, have contributed extensively to the formation of some strata.

Even after an object has become fossilized, it is far from certain that it will remain in good condition until found, while the chance of its being found at all is exceedingly small. When we remember that it is only here and there that nature has made the contents of the rocks accessible by turning the strata on edge, heaving them into cliffs or furrowing them with valleys and canyons, we realize what a vast number of pages of the fossil record must remain not only unread, but unseen. The wonder is, not that we know so little of the history of the past, but that we have learned so much, for not only is nature care- 
less in keeping the records - preserving them mostly in scattered fragments - but after they have been laid away and sealed up in the rocks they are subject to many accidents. Some specimens get badly flattened by the weight of subsequently deposited strata, others are cracked and twisted by the movements of the rocks during periods of upheaval or subsidence, and when at last they are brought to the surface, the same sun and rain, snow and frost, from which they once escaped, are ready to renew the attack and crumble even the hard stone to fragments. Such, very briefly, are some of the methods by which fossils may be formed, such are some of the accidents by which they may be destroyed ; but this description must be taken as a mere outline and as applying mainly to vertebrates, or backboned animals, since it is with them that we shall have to deal. It may, however, show why it is that fossils are not more plentiful, why we have mere hints of the existence of many animals, and why myriads of creatures may have flourished and passed away without so much as leaving a trace of their presence behind. 


\section{REFERENCES}

A very zaluable and interesting article by Dr. Charles A. White, entitled "The Relation of Biology to Geological Investigation," will be found in the Report of the United States Nutional Museum for 1592. This comprises a scries of essangs on the nature and scientific uses of fossil remains, their origin, relutive chronological ralue and other questions pertaining to them. The United States N'ational .Museum has published a pamphlet, part $h$, Bulletin 39, containing directions for collecting and preparing fossils, by Charles Schuchert; and another, part $B$, Bulletin 39, collecting recent and fossil plants, by $F$. H. Knowelton.

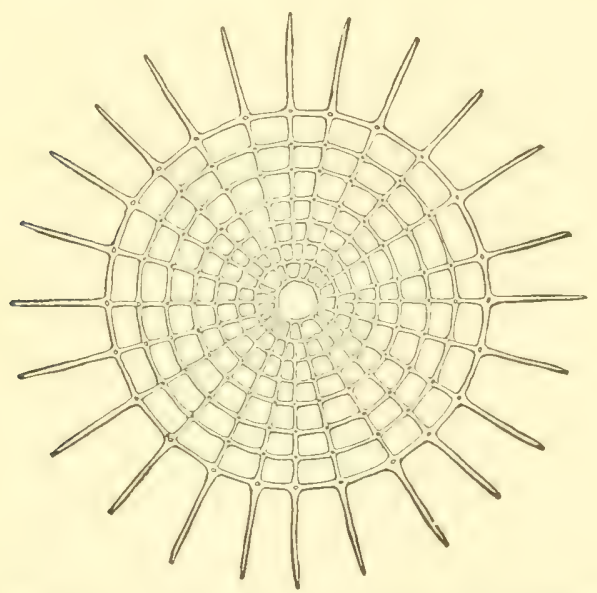

Fig. 3.-Skeleton of a Radiolarian Very Greatly Enlarged. 


\section{II}

THE EARLIEST KNOWN VERTEBRATES

"We are the ancients of the earth

And in the morning of the times."

There is a universal, and perfectly natural, desire for information, which in ourselves we term thirst for knowledge and in others call curiosity, that makes mankind desire to know how everything began and causes much speculation as to how it all will end. This may take the form of a wish to know how a millionaire made his first ten cents, or it may lead to the questions -What is the oldest animal? or, What is the first known member of the great group of backboned animals at whose head man has placed himself? and, What did this, our primeval and many-times-removed ancestor, look like? The question is one that has ever been full of interest for naturalists, and Nature has been interrogated in various ways in the hope that she 
might be persuaded to yield a satisfactory answer. The most direct way has been that of tracing back the history of animal life by means of fossil remains, but beyond a certain point this method cannot go, since, for reasons stated in various places in these pages, the soft bodies of primitive animals are not preserved. To supplement this work, the embryologist has studied the early stages of animals, as their development throws a side-light on their past history. And, finally, there is the study of the varied forms of invertebrates, some of which have proved to be like vertebrates in part of their structure, while others have been revealed as vertebrates in disguise. So far these various methods have yielded various answers, or the replies, like those of the Delphic Oracle, have been variously interpreted so that vertebrates are considered by some to have descended from the worms, while others have found their beginnings in some animal allied to the King Crab.

Every student of genealogy knows only too well how difficult a matter it is to trace a family pedigree back a few centuries, how soon the family names become changed, the line of de- 
scent obscure, and how soon gaps appear whose filling in requires much patient research. How much more difficult must it be, then, to trace the pedigree of a race that extends, not orer centuries, but thousands of centuries; how wide must be some of the gaps, how very different may the founders of the family be from their descendants! The words old and ancient that we use so often in speaking of fossils appeal to us somewhat raguely, for we speak of the ancient cirilizations of (rreece and Rome, and call a family old that can show a pedigree running back four or five hundred years, when such as these are but affairs of yesterday compared with even recent fossils.

Perhaps we may better appreciate the meaning of these words by recalling that, since the dawn of vertebrate life, sufficient of the earth's surface has been worn away and washed into the sea to form, were the strata piled directly one upon the other, fifteen or twenty miles of rock. This, of course, is the sum total of sedimentary rocks, for such a thickness as this is not to be found at any one locality; because, during the various ups and downs that this world of 
ours has met with, those portions that chanced to be out of water would receive no deposit of mud or sand, and hence bear no corresponding stratum of rock. 'The reader may think that there is a great deal of difference between fifteen and twenty miles, but this liberal margin is due to the difficulty of measuring the thickness of the rocks, and in Europe the sum of the measurable strata is much greater than in North America.

The earliest traces of animal life are found deeper still, beneath something like eighteen to twenty-five miles of rock, while below this level are the strata in which dwelt the earliest living things, organisms so small and simple that no trace of their existence las been left, and we infer that they were there because any given group starts in a modest way with small and simple individuals.

At the bottom, then. of twenty miles of rocks the seeker for the progenitor of the great family of backboned animals finds the scant remains of fish-like animals that the cautious naturalist, who is much given to "hedging," terms, not vertebrates, but prevertebrates or 
the forerunners of backboned animals. The earliest of these consist of small bony plates, and traces of a cartilaginous backbone from the Lower Silurian of Colorado, believed to represent relatives of Chimara and species related to those better-known forms Holoptychius and Osteolepis, which occur in higher strata. 'There are certainly indications of vertebrate life, but the remains are so imperfect that little more can be said regarding them, and this is also true of the small conical teeth which oceur in the Isower Silurian of St. Petersburg, and are thought to be the teeth of some animal like the lamprey.

A little higher up in the rocks, though not in the scale of life, in the I cower Old Red Sandstone of England, are found more numerous and better preserved specimens of another little fish-like creature, rarely if ever exceeding two inches in length, and also related (probably) to the hag-fishes and lampreys that live to-day.

'These early vertebrates are not only small, but they were cartilaginous, so that it was essential for their preservation that they should 
be buried in soft mud as soon as possible after death. Eren if this took place they were later on submitted to the pressure of some miles of orerlying rock until, in some cases, their remains have been pressed out thinner than a sheet of paper, and so thoroughly incorporated into the surrounding stone that it is no easy matter to trace their shadowy outlines. With such drawbacks as these to contend with, it can scarcely be wondered at that, while some naturalists believe these little creatures to be related to the lamprey, others consider that they belong to a perfectly distinct group of animals, and others still think it possible that they may be the larval or early stages of larger and betterdeveloped forms.

Still higher up we come upon the abundant remains of numerous small fish-like animals, more or less completely clad in bony armor, indicating that they lived in troublous times when there was literally a fight for existence and only such as were well armed or well protected could hope to survive. A parallel case exists to-day in some of the rivers of South America, where the little cat-fishes would pos- 
sibly be eaten out of existence but for the fact that they are covered-some of them very completely - with plate-armor that enables them to defy their enemies, or renders them such poor eating as not to be worth the taking.
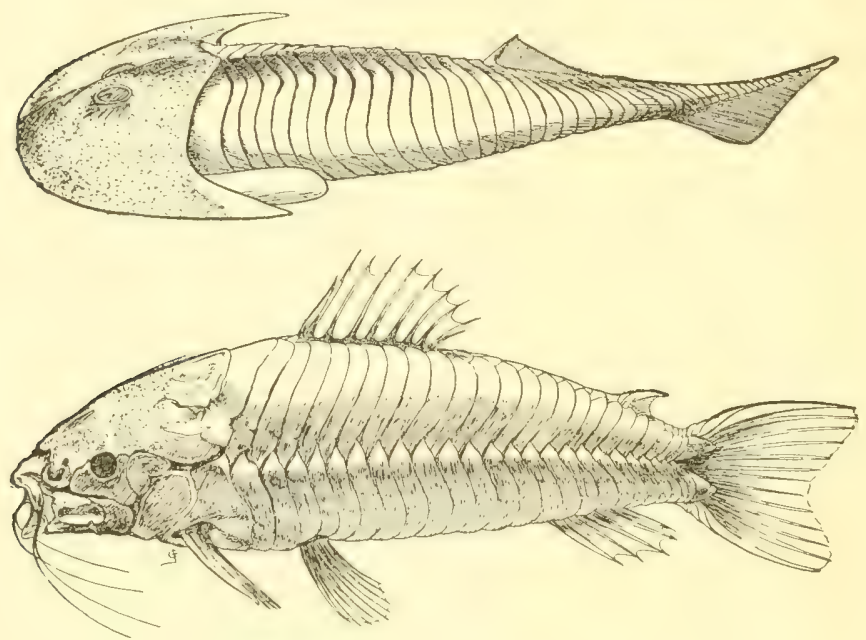

Fig. 4. - Cephalaspis and Loricaria, an Ancient and a Modern Armored Fish.

The arrangement of the plates or scales in the living Loricaria is very suggestive of the series of bony rings covering the body of the ancient Cephalaspis, only the latter, so far as we know, had no side-fins; but the creatures are in no 
wise related, and the similarity is in appearance only.

Pterichthys, the wing fish, was another small, quaint, armor-clad creature, whose fossilized remains were taken for those of a crab, and once described as belonging to a beetle. Certainly the buckler of this fish, which is the part most often preserved, with its jointed, bony arms, looks to the untrained eye far more like some strange crustacean than a fish, and even naturalists have pictured the animal as crawling over the bare sands by means of those same arms. These fishes and their allies were once the dominant type of life, and must have abounded in favored localities, for in places are great deposits of their protective shields jumbled together in a confused mass, and, save that they have hardened into stone, lying just as they were washed up on the ancient beach ages ago. How abundant they were may be gathered from the fact that it is believed their bodies helped consolidate portions of the strata of the English Old Red Sandstone. Says Mr. Hutchinson, speaking of the Caithness Flagstones, "They owe their peculiar tenacity and 
durability to the dead fishes that rotted in their midst while yet they were only soft mud. For just as a plaster cast boiled in oil becomes thereby denser and more durable, so the oily and other matter coming from decomposing fish operated on the surrounding sand or mud so as to make it more compact."

It may not be easy to explain how it came to pass that fishes dwelling in salt water, as these undoubtedly did, were thus deposited in great numbers, but we may now and then see how deposits of fresh-water fishes may have been formed. When rivers flowing through a stretch of level country are swollen during the spring floods, they overflow their banks, often carrying along large numbers of fishes. As the water subsides these may be caught in shallow pools that soon dry up, leaving the fishes to perish, and every year the Illinois game association rescues from the "back waters" quantities of bass that would otherwise be lost. Mr. F. S. Webster has recorded an instance that came under his observation in Texas, where thousands of gar pikes, trapped in a lake formed by an overflow of the Rio Grande, had 
been, by the drying up of this lake, penned into a pool about serenty-five feet long by twentyfive feet wide. 'The fish were literally packed together like sardines, layer upon layer, and a shot fired into the pool would set the entire mass in motion, the larger gars as they dashed about casting the smaller fry into the air, a score at a time. Mr. Webster estimates that there must have been not less than 700 or 800 fish in the pool, from a foot and a half up to seren feet in length, every one of which perished a little later. In addition to the fish in the pond, hundreds of those that had died previously lay about in erery direction, and one can readily imagine what a fish-bed this would have made had the occurrence taken place in the past.

From the better-preserved specimens that do now and then turn up, we are able to obtain a very exact idea of the construction of the bony cuirass by which Pterichthys and its American cousin were protected, and to make a pretty accurate reconstruction of the entire animal. These primitive fishes had mouths, for eating is a necessity; but these mouths were not associ- 
ated with true jaws, for the two do not, as might be supposed, necessarily go together. Neither did these animals possess hard backbones, and, while l'terichthys and its relatives had arms or fins, the hard parts of these were not on the inside but on the outside, so that the limb was more like the leg of a crab than the fin of a fish; and this is among the reasons why some naturalists have been led to conclude that rertebrates may have dereloped from crustaceans. l'teraspis, another of these little armored prevertebrates, had a less complicated covering, and looked very much like a small fish with its fore parts caught in an elongate clam-shell.

The fishes that we have so far been considering-orphans of the past they might be termed, as they have no living relatives - were little fellows; but their immediate successors, preserved in the Deronian strata, particularly of North America, were the giants of those days, termed, from their size and presumably fierce appearance, 'Titantichthys and Dinichthys, and are related to a fish, Ceratodus, still living in Australia.

We know practically nothing of the external appearance of these fishes, great and fierce 
though they may have been, with powerful jaws and armored heads, for they had no bony skeleton-as if they deroted their energies to preying upon their neighbors rather than to internal improvements. 'They attained a length of ten to eighteen feet, with a gape, in the large species called 'Titanichthys, of four feet, and such a fish might well be capable of devouring anything known to have lived at that early date.

Succeeding these, in Carboniferous times, came a host of shark-like creatures known mainly from their teeth and spines, for their skeletons were of cartilage, and belonging to types that have mostly perished, giving place to others better adipted to the changed conditions wrought by time. Almost the only living relative of these early fishes is a little shark, known as the Port Jackson Shark, living in Australian waters. I ike the old sharks, this one has a spine in front of his back fins, and, like them, he fortunately has a mouthful of diversely shaped teeth; fortunately, because through their aid we are enabled to form some idea of the manner in which some of the teeth found scat- 
tered through the rocks were arranged. For the teeth were not planted in sockets, as they are in higher animals, but simply rested on the jaws, from which they readily became detached when decomposition set in after death. To complicate matters, the teeth in different parts of the jaws were often so unlike one another that when found separately they would hardly be suspected of having belonged to the same animal. Besides teeth these fishes, for purposes of offence and defence, were usually armed with spines, sometimes of considerable size and strength, and often elaborately grooved and sculptured. As the soft parts perished the teeth and spines were left to be scattered by waves and currents, a tooth here, another there, and a spine somewhere else; so it has often happened that, being found separately, two or three quite different names have been given to one and the same animal. Now and then some specimen comes to light that escaped the thousand and one accidents to which such things were exposed, and that not only shows the teeth and spines but the faint imprint of the body and fins as well. And from such rare 
THE EARLIEST KNOWN VERTEBRATES 31 examples we learn just what teeth and spines go with one another, and sometimes find that one fish has received names enough for an entire school.

'These ancient sharks were not the large and powerful fishes that we have to-day - these came upon the scene later - but mostly fishes of small size, and, as indicated by their spines, fitted quite as much for defence as offence. Their rise was rapid, and in their turn they became the masters of the world, spreading in great numbers through the waters that covered the face of the earth; but their supremacy was of short duration, for they declined in numbers even during the Carboniferous Period, and later dwindled almost to extinction. And while sharks again increased, they never reached their former abundance, and the species that arose were swift, predatory forms, better fitted for the struggle for existence. 


\section{REFERENCES}

The early fishes make but little show in a museum, both on account of their small size and the conditions under which they have been prescrect. The Huseum of Comparative Zoölogy has a large collection of these ancient vertebrates, and there is a considerable mumber of fine teeth and spines of Carboniferous sharks in the United States National Museum.

Hugh Miller's "The Old Red Sandstone" contains some charming descriptions of his discoteries of Pterichthys and related forms, and this book will eier remain a classic.

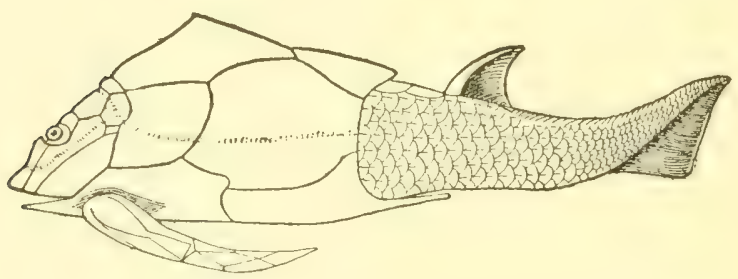

Fig. 5. - Pterichthys, the Wing Fish. 


\section{III}

\section{IMPRESSIONS OF THE PAST}

"The weird palimpsest, old and vast, Wherein thou hid'st the spectral past."

The Rev. H. N. Hutchinson commences one of his interesting books with Emerson's saying, "that Everything in nature is engaged in writing its own history;" and, as this remark cannot be improved on, it may well stand at the head of a chapter dealing with the footprints that the creatures of yore left on the sands of the sea-shore, the mud of a long-vanished lake bottom, or the shrunken bed of some water-course. Not only have creatures that walked left a record of their progress, but the worms that burrowed in the sand, the shell-fish that trailed over the mud when the tide was low, the stranded crab as he scuttled back to the sea - each and all left some mark to tell of their former presence. Even the rain that fell 
and the very wind that blew sometimes recorded the direction whence they came, and we may read in the rocks, also, accounts of freshets sweeping down with turbid waters, and of long periods of drouth, when the land was parched and lakes and rivers shrank beneath the burning sun.

All these things have been told and retold; but, as there are many who have not read Mr. Hutchinson's books and to whom Buckland is quite unknown, it may be excusable to add something to what has already been said in the first chapter of these impressions of the past.

The very earliest suggestion we have of the presence of animal life upon this globe is in the form of certain long dark streaks below the Cambrian of England, considered to be traces of the burrows of worms that were filled with fine mud, and while this interpretation may be wrong there is, on the other hand, no reason why it may not be correct. Plant and animal life must have had very lowly beginnings, and it is not at all probable that we shall find any trace of the simple and minute 
forms with which they started, " though we should not be surprised at finding hints of the presence of living creatures below the strata in which their remains are actually known to occur.

Worm burrows, to be sure, are hardly footprints, but tracks are found in Cambrian rocks just above the strata in which the supposed burrows occur, and from that time onward there are tracks a-plenty, for they have been made, wherever the conditions were farorable, ever since animals began to walk. All that was needed was a medium in which impressions could be made and so filled that there was imperfect adhesion between mould and matrix. 'Thus we find them formed not only by the sea-shore, in sands alternately dry and covered, but by the river-side, in shallow water, or even on land where tracks might be left in

* Within the last few years what are believed to be indications of bacteria have been described from carboniferous rodis. Naturally such announcements must be accepted with great caution, for while there is no reason why this may not be true, it is much more probable that definite evidence of the effects of bacteria on plants should be found than that these simple, singlecelled organisms should themselves have been detected. 
soft or moist earth into which wind-driven dust or sand might lodge, or sand or mud be swept by the mimic flood caused by a thunder shower.

So there are tracks in strata of every age; at first those of invertebrates: after the worm burrows the curious complicated trails of animals believed to be akin to the king crab; broad, ribbed, ribbon-like paths ascribed to trilobites; then faint scratches of insects, and the shallow, palmed prints of salamanders, and the occasional slender sprawl of a lizard; then footprints, big and little, of the horde of Dinosaurs and, finally, miles above the Cambrian, marks of mammals. Sometimes, like the tracks of salamanders and reptiles in the carboniferous rocks of Pennsylvania and Kansas, these are all we have to tell of the existence of air-breathing animals. Again, as with the iguanodon, the foot to fit the track may be found in the same layer of rock, but this is not often the case.

Although footprints in the rocks must often have been seen, they seem to have attracted little or no notice from scientific men until about 
1830 to 1835 , when they were almost simultaneously described both in Europe and America; even then, it was some time before they were generally conceded to be actually the tracks of animals, but, like worm burrows and trails, were looked upon as the impressions of sea-weeds.

The now famous tracks in the "brown stone" of the Connecticut Valley seem to have first been seen by I'liny Moody in 1802, when he ploughed up a specimen on his farm, showing small imprints, which later on were popularly called the tracks of Noah's raven. 'The discovery passed without remark until in $\mathbf{1 8 3 5}$ the footprints came under the observation of Dr. James Deane, who, in turn, called Professor Hitchcock's attention to them. 'The latter at once began a systematic study of these impressions, publishing his first account in 1836 and continuing his researches for many years, in the course of which he brought together the fine collection in Amherst College. At that time Dinosaurs were practically unknown, and it is not to be wondered at that these threetoed tracks, great and small, were almost uni- 
versally believed to be those of birds. So it is greatly to the credit of Dr. Deane, who also studied these footprints, that he was led to suspect that they might have been made by other animals. 'This suspicion was partly caused by the occasional association of four and five-toed prints with the three-toed impressions, and partly by the rare occurrence of

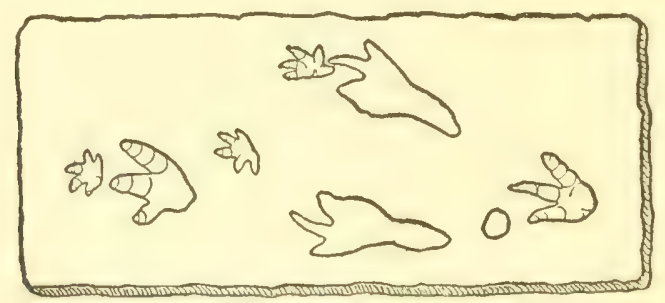

Fig. 6. - Where a Dinosaur Sat Down.

imprints showing the texture of the sole of the foot, which was quite different from that of any known bird.

In the light of our present knowledge we are able to read many things in these tracks that were formerly more or less obscure, and to see in them a complete verification of Dr. Deane's suspicion that they were not made by birds. We see clearly that the long tracks 
called Anomoepus, with their accompanying short fore feet, mark where some Dinosaur squatted down to rest or progressed slowly on all-fours, as does the kangaroo when feeding quietly; and we interpret the curious heartshaped depression sometimes seen back of the feet, not as the mark of a stubby tail, but as made by the ends of the slender pubes, bones that help form the hip-joints. 'Then, too, the mark of the inner, or short first, toe, is often very evident, although it was a long time before the bones of this toe were actually found, and many of the Dinosaurs now known to have four toes were supposed to have but three.

It seems strange, and it is strange, that while so many hundreds of tracks should have been found in the limited area exposed to view, so few bones have been found - our knowledge of the veritable animals that made the tracks

* It is to be noted that a leaping kangaroo touches the ground neither with his heel nor his tail, but that between jumps he rests momentarily on his toes only; hence impressions made by any creature that jumped like a kangaroo vould be very short. 
being a blank. A few examples have, it is true, been found, but these are only a tithe of those known to have existed; while of the great animals that strode along the shore, leaving tracks fifteen inches long and a yard apart pressed deeply into the hard sand, not a bone remains. The probability is that the strata containing their bones lie out to sea, whither their bodies were carried by tides and currents, and that we may never see more than the few fragments that were scattered along the seaside.

That part of the Valley of the Connecticut wherein the footprints are found seems to have been a long, narrow estuary running southward from 'Turner's Falls, Mass., where the tracks are most abundant and most clear. 'The topography was such that this estuary was subject to sudden and great fluctuations of the water-level, large tracts of shore being now left dry to bake in the sun, and again covered by turbid water which deposited on the bottom a layer of mud. Over and over again this happened, forming layer upon layer of what is now stone, sometimes the lapse of time be- 


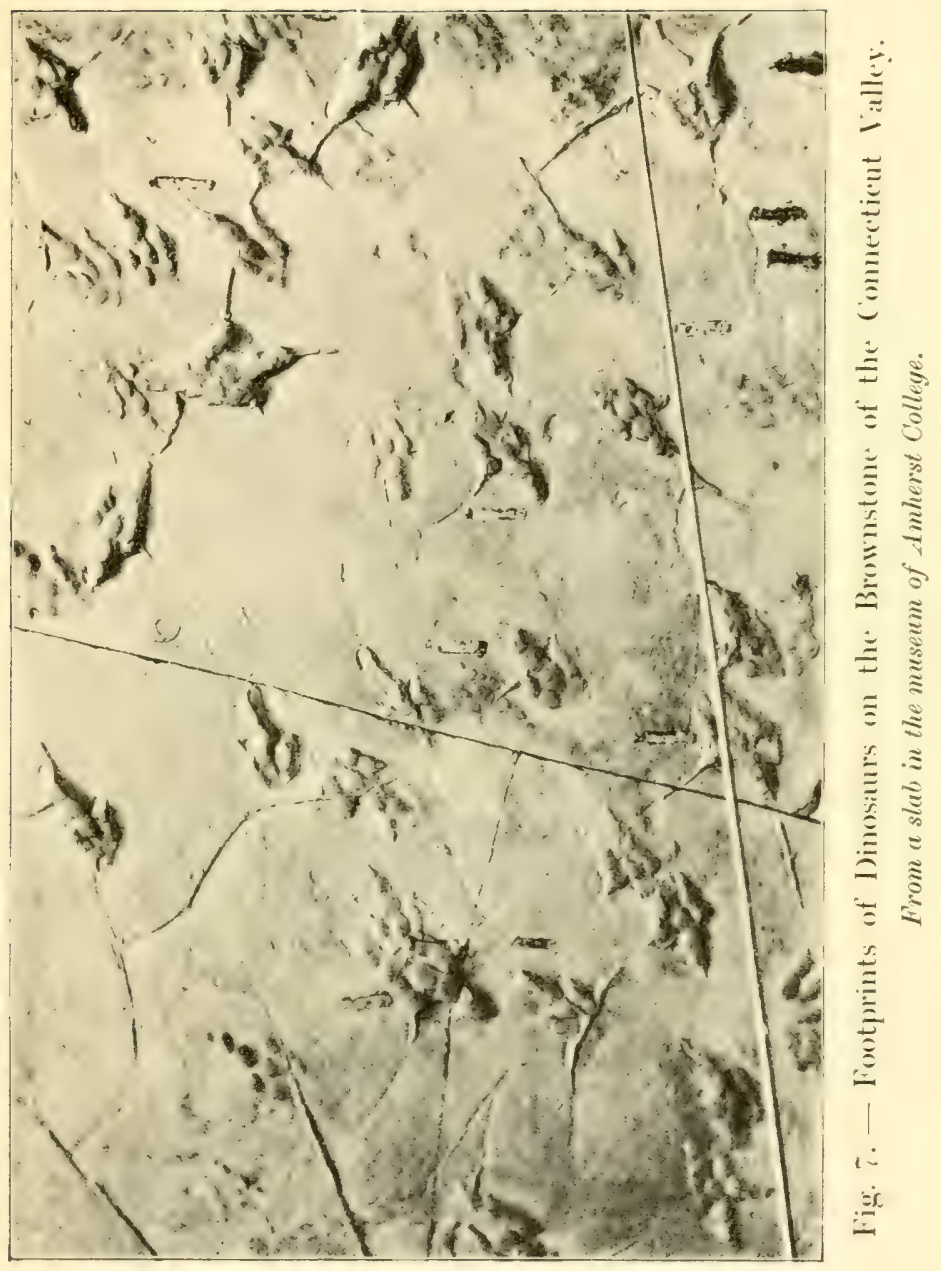



twreen the deposits being so short that the tracks of the big Dinosaurs extend through several sheets of stone; while again there was a period of drouth when the shore became so dry and firm as to retain but a single shallow impression.

Something of the wealth of animal life that roamed about this estuary may be gathered from the number of different footprints recorded on the sands, and these are so many and so raried that Professor Hitchcock in two extensive reports enumerated orer 150 species, representing various groups of animals. One little point must, however, be borne in mind, that mere size is no sure indication of differences in dealing with reptiles, for these longlived creatures grow almost continuously throughout life, so that one animal even may larve left his footprints orer and over in assorted sizes from one end of the valley to the other.

The slab shown in Fig. 7 is a remarkably fine example of these Connecticut River footprints; it shows in relief forty-eight tracks of the animal called Brontozoum sillimanium and 
six of a lesser species. It was quarried near Middletown, in 17\%8, and for sixty years did duty as a flagstone, fortunately with the face downwards. When taken up for repairs the tracks were discovered, and later on the slab, which measures three by five feet, was transferred to the museum of 1 mherst College.

There is an interesting parallel between the history of footprints in England and America, for they were noticed at about the same time, 1830 , in both countries; in each case the tracks were in rocks of 'Triassic age, and, in both instances, the animals that made them have never been found. In Fingland, however, the tracks first found were those ascribed to tortoises, though a little later Dinosaur footprints were discorered in the same locality. Oddly enough these numerous tracks all run one way, from west to east, as if the animals were migrating, or were pursuing some well-known and customary route to their feeding grounds.

For some reason 'Triassic rocks are particularly rich in footprints; for from strata of this same age in the Rhine Valley come those curious examples so like the mark of a stubby 
hand that Dr. Kaup christened the beast supposed to have made them Cheirotherium, beast with a hand, suggesting that they had been made by some gigantic opossum. As the tracks measure five by eight inches, it would have been rather a large specimen, but the mammals had not then arisen, and it is generally believed that the impressions were made by huge (for their lind) salamander-like creatures, known as labyrinthodonts, whose remains are found in the same strata.

Footprints may aid greatly in determining the attitude assumed by extinct animals, and in this way they have been of great service in furnishing proof that many of the Dinosaurs walked erect. The impressions on the sands of the old Connecticut estuary may be said to show this very plainly, but in England and Belgium is evidence still more conclusive, in the shape of tracks ascribed to the Iguanodon. These were made on soft soil into which the feet sank much more deeply than in the Connecticut sands, and the casts made in the natural moulds show the impression of toes very clearly. If the animals had walked flat-footed, 
as we do, the prints of the toes would have been followed by a long heel mark, but such is not the case; there are the sharply defined marks of the toes and nothing more, showing plainly that the Iguanodons walked, like birds, on the toes alone. More than this, had these 1)inosaurs dragged their tails there would have been a continuous furrow between the footprints; but nothing of this sort is to be found ; on the contrary, a fine scries of tracks, uncovered at Hastings, Fngland, made by several individuals and ruming for serenty-five feet, shows footprints only. Ilence it may be fairly concluded that these great creatures carried their tails clear of the ground, as shown in the picture of Thespesins, the weight of the tail counterbalancing that of the body. Where crocodilians or some of the short-limbed Dinosaurs have crept along there is, as we should expect, a continuous furrow between the imprints of the feet. 'This is what footprints tell us when their message is read aright; when improperly translated they only add to the enormous bulk of our ignorance.

Some years ago we were treated to accounts 
of wonderful footprints in the rock of the prison-yard at Carson City, Nev., which, according to the papers, not only showed that men existed at a much earlier period than the scientific supposed, but that they were men of giant stature. 'This was clearly demonstrated by the footprints, for they were such as might have been made by huge moccasined feet, and this was all that was necessary for the conclusion that they were made by just such feet. For it is a curious fact that the majority of mankind seem to prefer any explanation other than the most simple and natural, particularly in the case of fossils, and are always looking for a primitive race of gigantic men.

Bones of the Mastodon and Mammoth have again and again been eagerly accepted as those of giants; a salamander was brought forward as evidence of the deluge (homo diluvii testis); ammonites and their allies pose as fossil snakes, and the "petrified man" flourishes perennially. However, in this case the prints were recognized by naturalists as having most probably been made by some great ground sloth, such 
as the Mylodon or Morotherium, these animals, though belonging to a group whose headquarters were in P'atagonia, having extended their range as far north as Oregon. 'That the tracks seemed to have been made by a biped, rather than a quadruped, was due to the fact that the prints of the hind feet fell upon and obliterated the marks of the fore. Still, a little observation showed that here and there prints of the fore feet were to be seen, and on one spot were indications of a struggle between two of the big beasts. The mud, or rather the stone that had been mud, bears the imprints of opposing feet, one set deeper at the toes, the other at the heels, as if one animal had pushed and the other resisted. In the rock, too, are broad depressions bearing the marks of coarse hair, where one creature had apparently sat on its haunches in order to use its fore limbs to the best advantage. Other footprints there are in this prison-yard; the great round "spoor" of the mammoth, the hoofs of a deer, and the paws of a wolf (?), indicating that hereabout was some pool where all these creatures came to drink. More than this, 
we learn that when these prints were made, or shortly after, a strong wind blew from the southeast, for on that face of the ridges bounding the margin of each big footprint, we find sand that lodged against the squeezed-up mud and stuck there to serve as a perpetual record of the direction of the wind.

\section{REFERENCES}

Almost erery muscum has some specimen of the Connecticut Valley footprints, but the largest and finest collections are in the muscums of Amherst College, Muss., and Yale L'niversity, although, owing to lack of room, only a few of the Yale specimens are on cxhibition. The collection at Amherst comprises most of the types described by Professor E. Hitchcock in his "Ichnology of New England," a work in two fully illustrated quarto volumes. Other footprints are described and figured by Dr. J. Deane in "Ichnographs from the Sandstone of the Connecticut River."

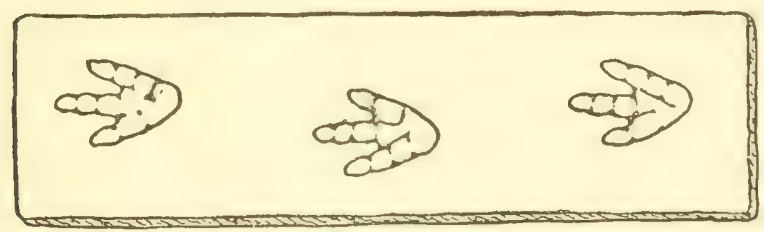

Fig. 8. - The Track of a Three-toed Dinosaur. 


\section{IV}

\section{RULERS OF THE ANCIENT SEAS}

"A time there was when the universe mas darkness and water, wherein certain animals of frightful and compound mien were generated. There were serpents, and other creatures with the mixed shapes of one another. . . ."-The Archaic Genesis.

History shows us how in the past nation after nation has arisen, increased in size and strength, extended its bounds and dominion until it became the ruling power of the world, and then passed out of existence, often so completely that nothing has remained save a few mounds of dirt marking the graves of former cities. And so has it been with the kingdoms of nature. Just as Greece, Carthage, and Rome were successively the rulers of the sea in the days that we call old, so, long before the advent of man, the seas were ruled by successive races of creatures whose bones now lie scattered over the beds of the ancient seas, even as the 
wrecks of galleys lie strewn over the bed of the Meditcramean. Hor a time the armorclad fishes held undisputed sway; then their reign was ended by the coming of the sharks, who in their tum gave way to the fish-lizards, the Ichthyosaurs and Plesiosaurs. 'These, however, were rather local in their rule; but the next group of reptiles to appear on the scene, the great marine reptiles called Mosasaurs, practically extended their empire around the world, from New Kealand to North America.

We properly call these reptiles great, for so they were; but there are degrees of greatness, and there is a universal tendency to think of the animals that have become extinct as much greater than those of the present day, to magnify the reptile that we never saw as well as the fish that "got away," and it may be safely said that the greatest of animals will shrink before a two-foot rule. As a matter of fact, no animals are known to have existed that were larger than the whales; and, while there are now no reptiles that can compare in bulk with the Dinosaurs, there were few Mosasaurs that exceeded in size a first-class Crocodile. 
An occasional Mosasaur reaches a length of forty feet, but such are rare indeed, and one even twenty-five feet long is a large specimen, ${ }^{*}$ while the great Mugger, or Man-eating Crocodile, grows, if permitted, to a length of twentyfive or even thirty feet, and need not be ashamed to match his bulk and jaws against those of most Mosasaurs.

The first of these sea-reptiles to be discovered has passed into history, and now reposes in the .Jardin des Plantes, Paris, after changing hands two or three times, the original owner being dispossessed of his treasure by the subtleties of law, while the next holder was deprived of the specimen by main force. 'Thus the story is told by M. Faujas St. Fond, as rendered into English, in Mantell's "Petrifactions and their 'Teachings": "Some workmen, in blasting the rock

* It is surprising to find Professor Cope placing the length of the Mosasaurs at 70, 80, or 100 feet, as there is not the slightest basis for eren the lonest of these figures. Professor Iilliston, the best anthority on the subject, states, in his volume on the "Cretaceous Reptiles of Kansas," that there is not in existence any specimen of " Mosasaur indicating a greater length than 45 feet. 
in one of the carerns of the interior of the mountain, perceived, to their astonishment, the jaws of a large animal attached to the roof of the chasm. The discorery was immediately made known to M. Hoffinam, who repaired to the spot, and for weeks presided over the arduous task of scparating the mass of stone containing these remains from the surrounding rock. His labors were rewarded by the successful extrication of the specimen, which he conveyed in triumph to his house. 'This extraordinary discovery, howerer, soon became the subject of general conversation, and excited so much interest that the canon of the cathedral which stands on the mountain resolved to claim the fossil, in right of being lord of the manor, and succeeded, after a long and harassing lawsuit, in obtaining the precious relic. It remained for years in his possession, and Hoffman died without regaining his treasure. At length the French Revolution broke out, and the armies of the Republic advanced to the gates of Maestricht. 'The town was bombarded; but, at the suggestion of the commit. tee of savans who accompanied the French 
troops to select their share of the plunder, the artillery was not suffered to play on that part of the city in which the celebrated fossil was known to be preserved. In the meantime, the canon of St. Peter's, shrewdly suspecting the reason why such peculiar favor was shown to his residence, removed the specimen and concealed it in a vault; but, when the city was taken, the French authorities compelled him to give up his ill-gotten prize, which was immediately transmitted to the Jardin des Plantes, at Paris, where it still forms one of the most interesting objects in that magnificent collection." And there it remains to this day.

The seas that rolled over western Kansas were the headquarters of the Mosasaurs, and hundreds - aye, thousands - of specimens have been taken from the chalk bluffs of that region, some of them in such a fine state of preservation that we are not only well acquainted with their internal structure, but with their outward appearance as well. They were essentially swimming lizards - great, overgrown, and distant relatives of the Monitors 


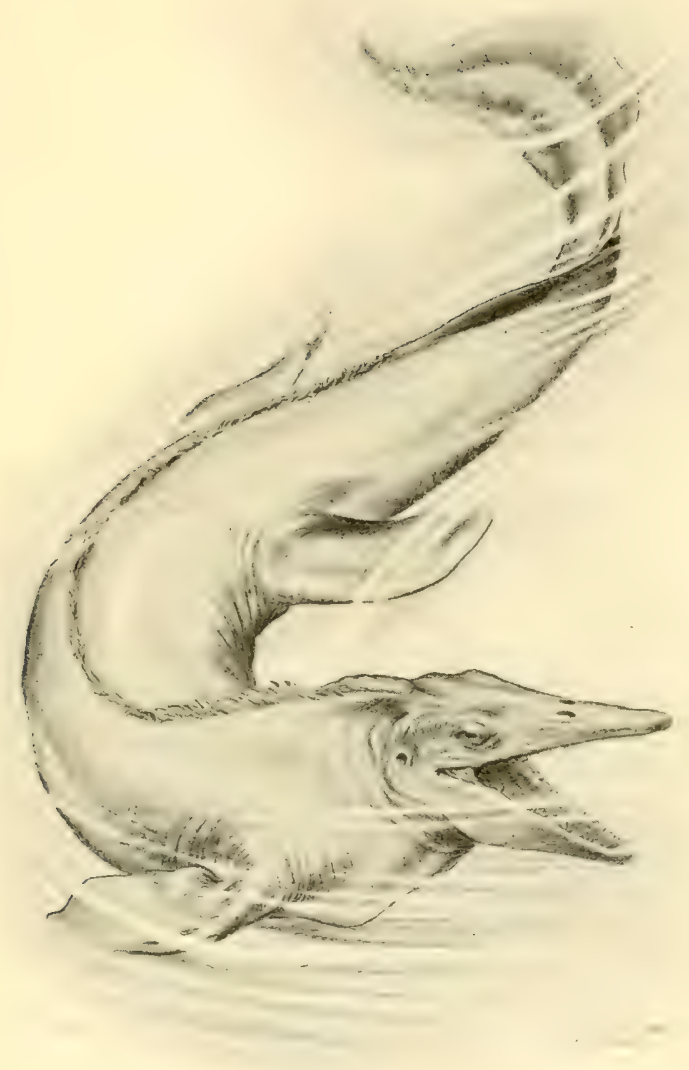

Fig. 9.-A Great Sea Lizard, Tylosanrus Dyspelor. From a draving by J. M. Gleeson. 

of Africa and Asia, especially adapted to a roving, predatory life by their powerful tails and paddle-shaped feet. Their cup-and-ball vertebræ indicate great flexibility of the body, their sharp teeth denote ability to capture slippery prey, and the structure of the lower jaw shows that they probably ate in a hurry and swallowed their food entire, or bolted it in great chunks. The jaws of all reptiles are made up of a number of pieces, but these are usually so spliced together that each half of the jaw is one inflexible, or nearly inflexible, mass of bone. In snakes, which swallow their prey entire, the difficulty of swallowing animals greater in diameter than themselves is surmounted by having the two halves of the lower jaw loosely joined at the free ends, so that these may spread wide apart and thus increase the gape of the mouth. 'This is also helped by the manner in which the jaw is joined to the head. The pelican solves the problem by the length of his mandibles, this allowing so much spring that when open they bow apart to form a nice little landing net. In the Mosasaurs, as in the cormorants, among birds, there 
is a sort of joint in each half of the lower jaw which permits it to bow outward when opened, and this, aided by the articulation of the jaw with the cranium, adds greatly to the swallowing capacity. 'Thus in nature the same end is attained by very different methods. 'To bor. row a suggestion from Professor Cope, if the reader will extend his arms at full length, the palms touching, and then bend his ellows outward he will get a very good idea of the ac-

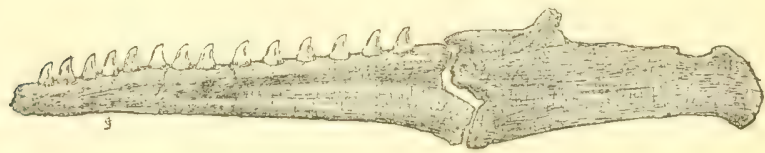

Fig. 10. - Jaw of a Mosasaur, Showing the Joint that Increased the Swallowing Capacity of that Reptile.

tion of a Mosasaur's jaw. The western sea was a lively place in the day of the great Mosasaurs, for with them swam the king of turtles, Archelon, as Mr. Mieland has fitly named him, a creature a dozen feet or more in length, with a head a full yard long, while in the shallows prowled great fishes with massive jaws and teeth like spikes.

'There, too, was the great, toothed diver, 
Hesperornis (see page 83), while over the waters flew pterodactyls, with a spread of wing of twenty feet, largest of all flying creatures; and, not improbably - nay, very probably-fish-eaters, too; and when each and all of these were seeking their dimners, there were troublous times for the small fry in that old Kansan sea.

And then there came a change; to the south, to the west, to the north, the land was imperceptibly but surely rising, perhaps only an inch or two in a century, but still rising, until "The Ocean in which flourished this abundant and vigorous life was at last completely inclosed on the west by elevations of sea-bottom, so that it only communicated with the Atlantic and Pacific at the Gulf of Mexico and the Arctic Sea."

The continued elevation of both eastern and western shores contracted its area, and when ridges of the sea-bottom reached the surface, forming long, low bars, parts of the water-area were included, and comnection with salt-water prevented. Thus were the living beings imprisoned and subjected to many new risks to 
life. The stronger could more readily capture the weaker, while the fishes would gradually perish through the constant freshening of the water. With the death of any considerable class, the balance of food-supply would be lost, and many large species would disappear from the scene. 'The most omnivorous and enduring would longest resist the approach of starvation, but would finally yield to inexorable fate - the last one caught by the shifting bottom among shallow pools, from which his exhausted energies could not extricate him." *

Like the "Fossil man" the sea-serpent flourishes perennially in the newspapers and, despite the fact that he is now mainly regarded as a joke, there have been many attempts to habilitate this mythical monster and place him on a foundation of firm fact. The most earnest of these was that of M. Oudemans, who expressed his belief in the existence of some rare and huge seal-like creature whose occasional appearance in southern waters gave rise

* Cope: "The V'ertebrata of the Cretaceous Formations of the ITest," p.50, being the "Report of the C'nited States Geological Survey of the Territories," Vol. II. 
to the best authenticated reports of the seaserpent. Among other possibilities it has been suggested that some animal beliered to be extinct had really lived over to the present day. Now there are a few waifs, spared from the wrecks of ancient faunas, stranded on the shores of the present, such as the Australian Ceratodus and the Gar Pikes of North America, and these and all other creatures that could be mustered in were used as proofs to sustain this theory. If, it was said, these animals have been spared, why not others? If a fish of such ancient lineage as the Gar Pike is so common as to be a nuisance, why may there not be a few Plesiosaurs or a Mosasaur somewhere in the depths of the ocean? The argument was a good one, the more that we may "suppose" almost anything, but it must be said that no trace of any of these creatures has so far been found outside of the strata in which they have long been known to occur, and all the probabilities are opposed to this theory. Still, if some of these creatures hal been spared, they might well have passed for sea-serpents, even though $Z$ euglodon, the one most like a 
serpent in form, was the one most remotely related to snakes.

Zeuglodon, the yoke-tooth, so named from the shape of its great cutting teeth, was indeed a strange animal, and if we wonder at the Greenland Whale, whose head is one-third its total length, we may equally wonder at Zeuglodon, with four feet of head, ten feet of body, and forty feet of tail. No one, seeing the bones of the trunk and tail for the first time, would suspect that they belonged to the same animal, for while the vertebra of the body are of moderate size, those of the tail are, for the bulk of creature, the longest known, measuring from fifteen to eighteen inches in length, and weighing in a fossil condition fifty to sixty pounds. In life, the animal was from fifty to seventy feet in length, and not more than six or eight feet through the deepest part of the body, while the tail was much less; the head was small and pointed, the jaws well armed with grasping and cutting teeth, and just back of the head was a pair of short paddles, not unlike those of a fur seal. It is curious to speculate on 
the labits of a creature in which the tail so obviously wagged the dog and whose articulations all point to great freedom of movement up and down. 'This may mean that it was an active diver, descending to great depths to prey upon squid, as the Sperm- IThale does to-day, while it seems quite certain that it must have reared at least a third of its great length out of water to take a comprehensive view of its surroundings. And if size is any indication of power, the great tail, which obviously ended in flukes like those of a whale, must have been capable of propelling the beast at a speed of twenty or thirty miles an hour. Something of the kind must have been needed in order that the small head might provide food enough for the great tail, and it has been suggested that inability to do this was the reason why Zeuglodon became extinct. On the other hand, it has been ingeniously argued that the huge tail served to store up fat when food was plenty, which was drawn upon when food became scarce. The fur seals do something similar to this, for the males come on shore in May rolling in blubber, and depart in Septem- 
ber lean and hungry after a three months' fast.

Zeuglodons must have been very numerous in the old Gulf of Mexico, for bones are found abundantly through portions of our Southern States; it was also an inhabitant of the old seas of southern Europe, but, as we shall see, it gave place to the great fossil shark, and this in turn passed out of existence. Still, common though its bones may be, stories of their use for making stone walls - and these stories are still in circulation - resolve themselves on close scrutiny into the occasional use of a big vertebra to support the corner of a corn-crib.

The scientific name of Zeuglodon is Basilosaurus, cetoides, the whale-like king lizard-the first of these names, Busilosanms, having been given to it by the original describer, Dr. Harlan, who supposed the animal to have been a reptile. Now it is a primary rule of nomenclature that the first name given to an animal must stick and may not be changed, even by the act of a zoölogical congress, so Zeuglodon must, so far as its name is concerned, masquerade as a reptile for the rest of its paleon- 
tological life. 'This, however, really matters very little, because scientific names are simply verbal handles by which we may grasp animals to describe them, and Dr. Le Conte, to show how little there may be in a name, called a beetle Gyascutus. Owen's name of Zeuglodon, although not tenable as a scientific name, is too good to be wasted, and being readily remembered and easily pronounced may be used as a popular name.

One might think that a creature sixty or seventy feet long was amply long enough, but Dr. Albert Koch thought otherwise, and did with Zeuglodon as, later on, he did with the Mastodon, combining the vertebre of several individuals until he had a monster 114 feet long! This he exhibited in Europe under the name of Hydrarchus, or water king, finally disposing of the composite creature to the Museum of Dresden, where it was promptly reduced to its proper dimensions. 'The natural make-up of Zeuglodon is sufficiently composite without any aid from man, for the head and paddles are not unlike those of a seal, the ribs are like those of a manatee, and the shoul- 


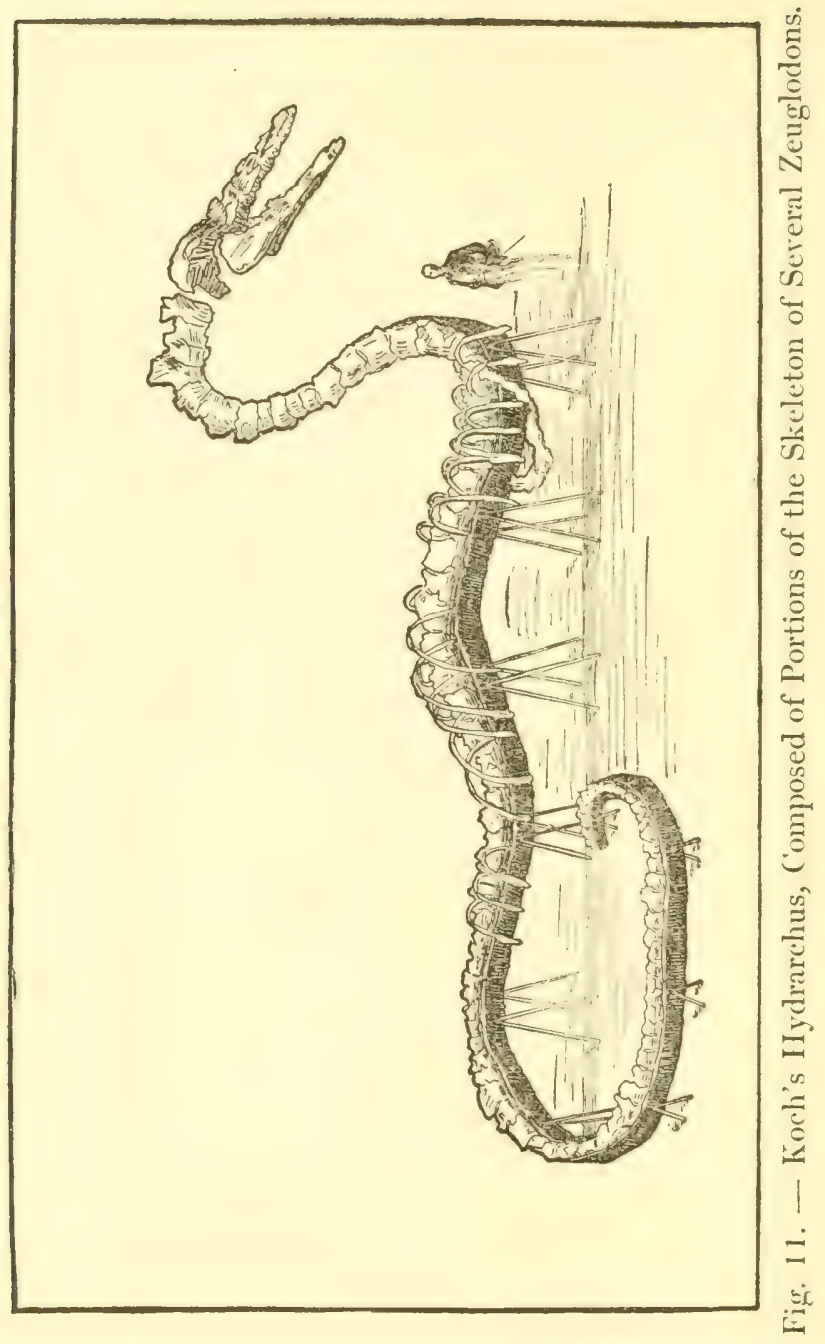


der blades are precisely like those of a whale, while the vertebrx are different from those of any other animal, even its own cousin and lesser contemporary Dorudon. 'There were also tiny hind legs tucked away beneath skin, but these, as well as many other parts of the animal's structure were unknown, until Mr. Charles Schuchert collected a series of specimens for the National Museum, from which it was possible to restore the entire skeleton. Owing to a rather curious circumstance the first attempt at a restoration was at fault; among the bones originally obtained by Mr. Schuchert there were none from the last half of the tail, an old gully having cut off the hinder portion of the backbone and destroyed the vertebræ. Not far away, however, was a big lump of stone containing several vertebræ of just the right size, and these were used as models to complete the papier-maché skeleton shown at Atlanta, in 1894. But a year after Mr. Schuchert collected a series of vertebræ, beginning with the tip of the tail, and these showed conclusively that the first lot of tail vertebræ belonged to a creature still unde- 
scribed and one probably more like a whale than Zeuglodon himself, whose exact relationships are a little uncertain, as may be imagined from what was said of its structure. Mixed with the bones of Zeuglodon was the shell of a turtle, nearly three feet long, and part of the backbone of a great water-snake that must have been twenty-five feet long, both previously quite unknown. One more curious thing about Zeuglodon bones remains to be told, and then we are done with him; ordinarily a fossil bone will break indifferently in any direction, but the bones of Zeuglodon are built, like an onion, of concentric layers, and these have a great tendency to peel off during the preparation of a specimen.

And now, as the wheels of time and change rolled slowly on, sharks again came uppermost, and the warmer Eocene and Miocene oceans appear to have fairly teemed with these sea wolves. There were small sharks with slender teeth for catching little fishes, there were larger sharks with saw-like teeth for cutting slices out of larger fishes, and there were sharks 
that might almost have swallowed the biggest fish of to-day whole, sharks of a size the waters had never before contained, and fortunately do not contain now. We know these monsters mostly by their teeth, for their skeletons were cartilaginous, and this absence of their remains is probably the reason why these creatures are passed by while the adjectives huge, immense, enormous are lavished on the Mosasaurs and Plesiosaurs - animals that the great-toothed shark, Carcharodon megalodon, might well have eaten at a meal. For the gaping jaws of one of these sharks, with its hundreds of gleaming teeth must, at a moderate estimate, have measured not less than six feet across.

The great White Shark, the man-eater, so often found in story books, so rarely met with in real life, attains a length of thirty feet, and a man just makes him a good, satisfactory lunch. Now a tooth of this shark is an inch and a quarter long, while a tooth of the huge Megalodon is commonly three, often four, and not infrequently five inches long. Applying the rule of three to such a tooth as this would gire a shark 120 feet long, bigger than most 
whales, to whom a man would be but a mouthful, just enough to whet his sharkship's appetite. Even granting that the rule of three unduly magnifies the dimensions of the brute, and making an ample reduction, there would still remain a fish between seventy-five and one hundred feet long, quite large enough to satisfy the most ambitious of tuna fishers, and to have made bathing in the Miocene ocean unpopular. Contemporary with the greattoothed shark was another and closely related species that originated with him in Eocene times, and these two may possibly have had something to do with the extinction of Zeuglodon. 'This species is distinguished by having on either side of the base of the great triangular cutting teeth a little projection or cusp, like the "ear" on a jar, so that this species has been named auriculatus, or eared. The edges of the teeth are also more saw-like than in those of its greater relative, and as the species must have attained a length of fifty or sixty feet it may, with its better armature, have been quite as formidable. And, as perhaps the readers of these pages may know, the 
supply of teeth never ran short. Back of each tooth, one behind another arranged in serried ranks, lay a reserve of six or seven smaller, but growing teeth, and whenever a tooth of the front row was lost, the tooth immediately behind it took its place, and like a well-trained soldier kept the front line unbroken. 'Thus the teeth of sharks are continually developing at the back, and all the teeth are steadily pushing forward, a very simple mechanical arrangement causing the teeth to lie flat until they reach the front of the jaw and come into use.

Once fairly started in life, these huge sharks spread themselves throughout the warm seas of the world, for there was none might stand before them and say nay. They swarmed along our southern coast, from Maryland to Texas; they swarmed everywhere that the water was sufficiently warm, for their teeth occur in Tertiary strata in many parts of the world, and the deep-sea dredges of the Challenger and Albatross have brought up their teeth by scores. And then - they perished, perished as utterly as did the hosts of Sennacherib. Why? We do 
not know. Did they devour everything large enough to be eaten throughout their habitat, and then fall to eating one another? Again, we do not know. But perish they did, while the smaller white shark, which came into being at the same time, still lives, as if to emphasize the fact that it is best not to overdo things, and that in the long run the victory is not always to the largest.

\section{REFERENCES}

The finest Mosasaur skeleton ever discovered, an almost complete skcleton of 'Tylosturus dyspelor, $29 \mathrm{fcet}$ in length, may be seen at the head of the staircase leading to the Hull of Palcontology, in the American MIuscum of Nutural History, New York. Another good specimen may be seen in the I'ale University Huscum, which probably has the largest collection of Mosasaurs in cxistence. Another fine collection is in the Iruseum of the State University of Kansas, at Lawerence.

'T'he best Zenglodon, the first to show the restigial hind leges and to make clear other portions of the structure, is in the United States National Museum.

The great sharks are known in this country by their teeth only, and, as these are common in the phosphate 
beds, specimens may be seen in almost amy collection. In the United States National Muscum, the jares of a trectrefoot blue shark are show'n for comparison. The largest tooth in that collection is 53 inches high and 5 inches across the base. It takes five tecth of the blue shark to fill the same number of inches.

The Mosasaur:s are descrilned in detail by Professor s:. W. Williston, in Vol. IV. of the "I'nizersity Geological Surrey of Kansas." There is a technical-and, conscquently, uninteresting - account of Zeuglodon in $\mathrm{V}$ ol. I.VIII. of the "Procedings of the L'nited States $N$ ' $($ tional Museum," page 32\%.

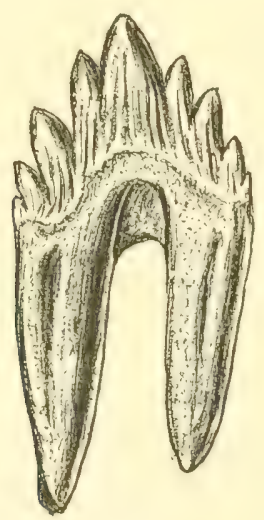

Fig. 12. - A Tooth of Zeuglodon, one of the "Yoke Teeth," from which it derives the name. 


\section{V \\ BIRDS OF OLD}

"With head, hands, wings, or feet, pursues his way, And swims, or sinks, or wades, or creeps, or flies."

When we come to discuss the topic of the earliest bird - not the one in the proverb - our choice of subjects is indeed limited, being restricted to the famous and oft-described Archæopteryx from the quarries of Solenhofen, which at present forms the starting-point in the history of the feathered race. Bird-like, or at least feathered, creatures, must have existed before this, as it is improbable that feathers and flight were acquired at one bound, and this lends probability to the view that at least some of the tracks in the Connecticut Valley are really the footprints of birds. Not birds as we now know them, but still creatures wearing feathers, these being the distinctive badge and livery of the order. For we may well speak 


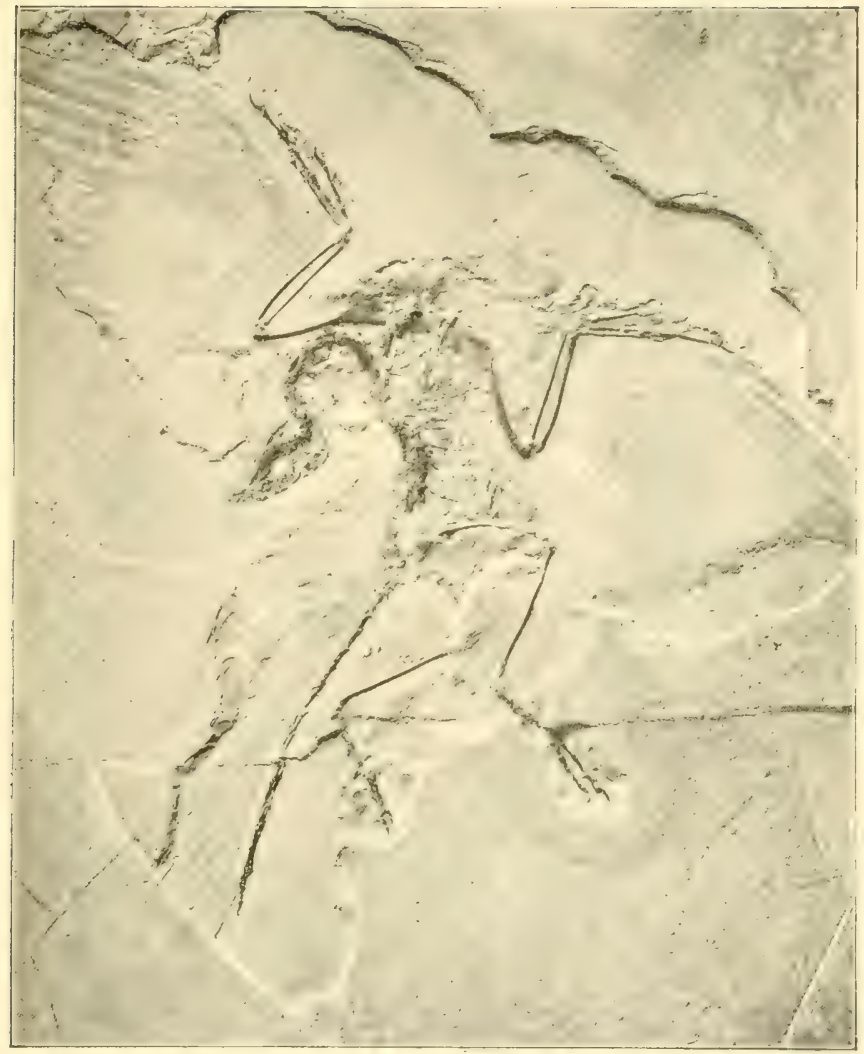

Fig. 13. - Archæopteryx, the Earliest Known Bird. From the specimen in the Berlin Iluseum. 

of the feathered race, the exclusive prerogative of the bird being not flight but feathers; no bird is without them, no other creature wears them, so that birds may be exactly defined in two words, feathered animals. Reptiles, and even mammals, may go quite naked or cover themselves with a defensive armor of bony plates or horny scales; but under the blaze of the tropical sun or in the chill waters of arctic seas birds wear feathers only, although in the penguins the feathers have become so changed that their identity is almost lost.

So far as flight goes, there is one entire order of mammals, whose members, the bats, are quite as much at home in the air as the birds themselves, and in bygone days the empire of the air belonged to the pterodactyls; even frogs and fishes have tried to fly, and some of the latter have nearly succeeded in the attempt. As for wings, it may be said that they are made on very different patterns in such animals as the pterodactyl, bat, and bird, and that while the end to be achieved is the same, it is reached by very different methods. The wing membrane of a bat is spread between his out- 


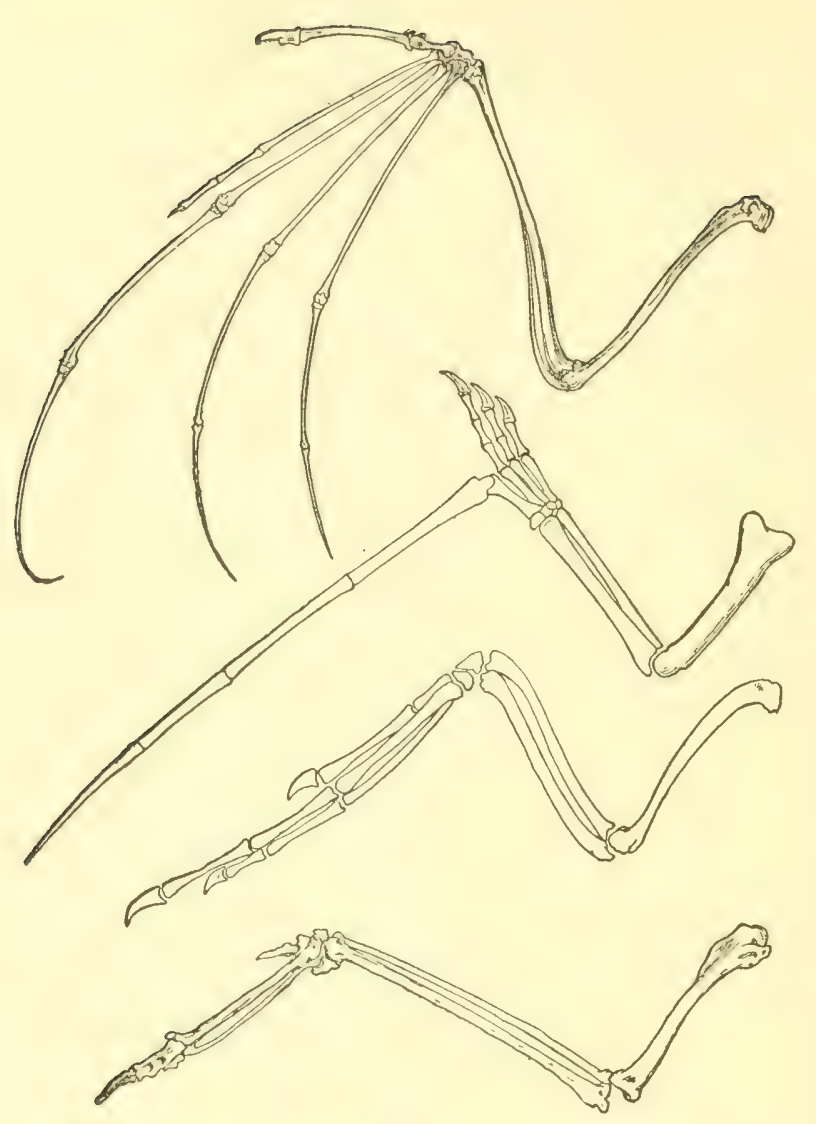

Fig. 14. - Nature's Four Methods of Making a Wing. Bat, Pterodactyl, Archaeopteryx, and Modern Bird. 
stretched fingers, the thumb alone being left free, while in the pterodactyl the thumb is wanting and the membrane supported only by what in us is the little finger, a term that is a decided misnomer in the case of the pterodactyl. In birds the fingers have lost their individuality, and are modified for the attachment or support of the wing feathers, but in Archæopteryx the hand had not reached this stage, for the fingers were partly free and tipped with claws.

We get some side lights on the structure of primitive birds by studying the young and the carlicr stages of living species, for in a very general way it may be said that the development of the individual is a sort of rough sketch or hasty outline of the development of the class of which it is a member; thus the transitory stages through which the chick passes before hatching give us some idea of the structure of the adult birds or bird-like creatures of long ago. Now, in embryonic birds the wing ends in a sort of paw and the fingers are separate, quite different from what they become a little later on, and not unlike their condition in 
Archæopteryx, and even more like what is found in the wing of an ostrich.

Then, too, there are a few birds still left, such as the ostrich, that have not kept pace with the others, and are a trifle more like reptiles than the vast majority of their relatives, and these help a little in explaining the structure of early birds. Among these is a queer bird with a queer name, Hoactzin, found in South America, which when young uses its little wings much like legs, just as we may suppose was done by birds of old, to climb about the branches. Mr. Quelch, who has studied these curious birds in their native wilds of British Guiana, tells us that soon after hatching, the nestlings begin to crawl about by means of their legs and wings, the well-dereloped claws on the thumb and finger being constantly in use for hooking to surrounding objects. If they are drawn from the nest by means of their legs, they hold on firmly to the twigs, both with their bill and wings; and if the nest be upset they hold on to all objects with which they come in contact by bill, feet, and wings, making considerable use of the bill, with the help 
of the clawed wings, to raise themselves to a higher level.

Thus, by putting these various facts together

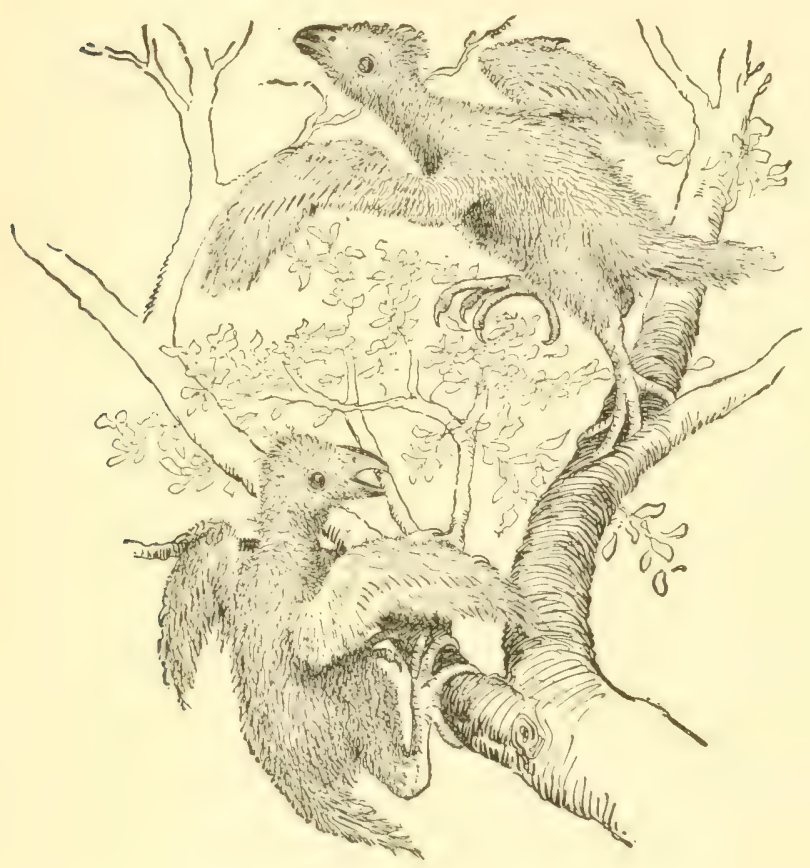

Fig. 15. - Young Hoactzins.

we obtain some pretty good ideas regarding the appearance and habits of the first birds. The immediate ancestors of birds, their exact point 
of departure from other vertebrates, is yet to be discovered; at one time it was considered that they were the direct descendants of Dinosaurs, or that at least both were derived from the same parent forms, and while that view was almost abandoned, it is again being brought forward with much to support it. It has also been thought that birds and those flying reptiles, the pterodactyls, have had a common ancestry, and the possibility of this is still entertained. Be that as it may, it is safe to consider that back in the past, earlier than the Jurassic, were creatures neither bird nor reptile, but possessing rudimentary feathers and having the promise of a wing in the structure of their fore legs, and some time one of these animals may come to light; until then Archxopteryx remains the earliest known bird.

In the Jurassic, then, when the Dinosaurs were the lords of the earth and small mammals just beginning to appear, we come upon traces of full-fledged birds. The first intimation of their presence was the imprint of a single feather found in that ancient treasure-house, the Solenhofen quarries; but as Hercules was revealed 
by his foot, so the bird was made erident by the feather whose discovery was announced August 15, 1861. And a little later, in September of the same year, the bird itself turned up, and in 1877 a second specimen was found, the two representing two species, if not two distinct genera. 'These were very different from any birds now living - so different, indeed, and bearing such evident traces of their reptilian ancestry, that it is necessary to place them apart from other animals in a separate division of the class birds.

Archæopteryx was considerably smaller than a crow, with a stout little head armed with sharp teeth (as scarce as hens' teeth was no joke in that distant period), while as he fluttered through the air he trailed after him a tail longer than his body, beset with feathers on either side. Everyone knows that nowadays the feathers of a bird's tail are arranged like the sticks of a fan, and that the tail opens and shuts like a fan. But in Archæopteryx the feathers were arranged in pairs, a feather on each side of every joint of the tail, so that on a small scale the tail was something like that of 
a kite; and because of this long, lizard-like tail this bird and his immediate kith and kin are placed in a group dubbed Saururæ, or lizard tailed.

Because impressions of feathers are not found all around these specimens some have thought that they were confined to certain portions of the body - the wings, tail, and thighs - the other parts being naked. 'There seems, however, no good reason to suppose that such was the case, for it is extremely improbable that such perfect and important feathers as those of the wings and tail should alone have been developed, while there are many reasons why the feathers of the body might have been lost before the bird was corered by mud, or why their impressions do not show.

It was a considerable time after the finding of the first specimen that the presence of teeth in the jaws was discovered, partly because the British Museum specimen was imperfect, ${ }^{*}$ and partly because no one suspected that birds had ever possessed teeth, and so no one ever looked

* The skull was lacking, and a part of the upper jaw lying to one side was thought to belong to a fish. 
for them. When, in 1877 , a more complete example was found, the existence of teeth was unmistakably shown; but in the meantime, in February, 1873, Professor Marsh had announced the presence of teeth in Hesperomis, and so to him belongs the credit of being the discoverer of birds with teeth.

The next birds that we know are from our own country, and although separated by an interval of thousands of years from the Jurassic Archieopteryx, time enough for the members of one group to have quite lost their wings, they still retain teeth, and in this respect the most bird-like of them is quite unlike any modern bird. These come from the chalk beds of western Kansas, and the first specimens were obtained by Professor Marsh in his expeditions of $\mathbf{1 8 7 0}$ and 1871 , but not until a few years later, after the material had been cleaned and was being studied, was it ascertained that these birds were armed with teeth. 'The smaller of these birds, which was apparently not unlike a small gull in general appearance, was, saving its teeth, so thoroughly a bird that it may be passed by without further notice, but the larger was remark- 
able in many ways. Hesperornis, the western bird, was a great diver, in some ways the greatest of the divers, for it stood higher than the king penguin, though more slender and-graceful in general build, looking somewhat like an overgrown, absolutely wingless loon.

'The penguins, as everyone knows, swim with their front limbs - we can't call them wings which, though containing all the bones of a wing, have become transformed into powerful paddles; Hesperornis, on the other hand, swam altogether with its legs - swam so well with them, indeed, that through disuse the wings dwindled away and vanished, save one bone. 'This, however, is not stating the theory quite correctly ; of course the matter cannot be actually proved. IIesperornis was a large bird, upwards of five feet in length, and if its ancestors were equally bulky their wings were quite too large to be used in swimming under water, as are those of such short-winged forms as the Auks which fly under the water quite as much as they fly over it. Hence the wings were closely folded upon the body so as to offer the least possible resistance. and being disused, they 
and their muscles dwindled, while the bones and muscles of the legs increased by constant use. By the time the wings were small enough to be used in so dense a medium as water the muscles had become too feeble to move them, and so degeneration proceeded until but one bone remained, a mere vestige of the wing that had been. 'The penguins retain their great breast muscles, and so did the Great Auk, because their wings are used in swimming, since it requires even more strength to move a small wing in water than it does to move a large wing in the thimer air. As for our domesticated fowls - the turkeys, chickens, and ducks - there has not been sufficient lapse of time for their muscles to dwindle, and besides artificial selection, the breeding of fowls for food has kept up the mere size of the muscles, although these lack the strength to be found in those of wild birds.

As a swimming bird, one that swims with its legs and not with its wings, IIesperornis has probably nerer been equalled, for the size and appearance of the bones indicate great power, while the bones of the foot were so joined to 
those of the leg as to turn edgewise as the foot was brought forward and thus to offer the least possible resistance to the water. It is a remarkable fact that the leg bones of Hesperornis are hollow, remarkable because as a rule the bones of aquatic animals are more or less solid, their weight being supported by the water; but those of the great diver were almost as light as if it had dwelt upon the dry land. That it did not dwell there is conclusively shown by its build, and above all by its feet, for the foot of a ruming bird is modified in quite another way.

The bird was probably covered with smooth, soft feathers, something like those of an Apteryx; this we know because Professor IVilliston found a specimen showing the impression of the skin of the lower part of the leg as well as of the feathers that covered the "thigh" and head. While such a covering seems rasther inadequate for a bird of such exclusively aquatic habits as Hesperornis must have been, there seems no getting away from the facts in the case in the shape of Professor Williston's specimen, and we have in the Snake 13ird, one of 


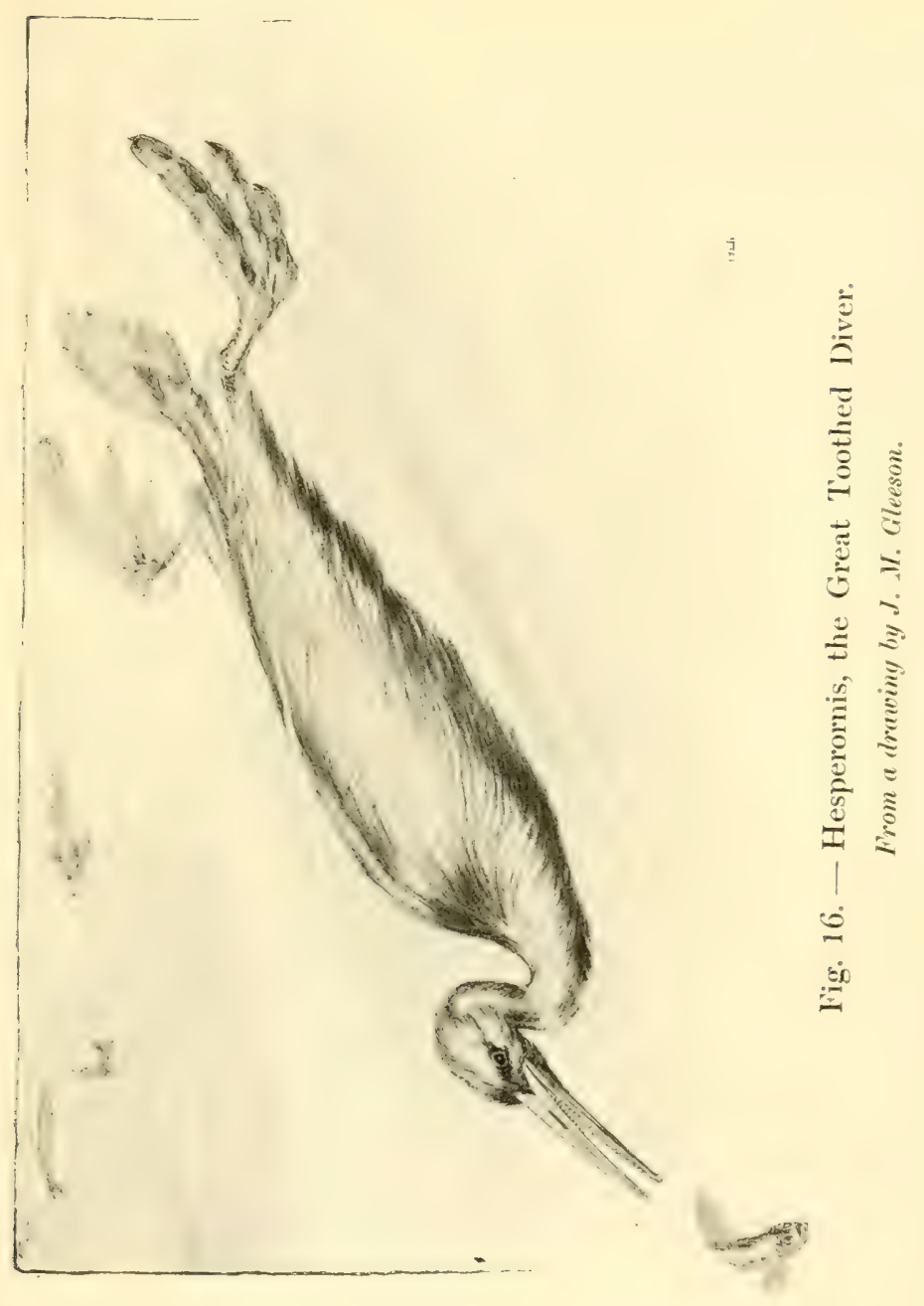



the most aquatic of recent birds, an instance of similarly poor covering. As all know who have seen this bird at home, its feathers shed the water very imperfectly, and after long-continued submersion become saturated, a fact which partly accounts for the habit the bird has of hanging itself out to dry,

The restoration which Mr. Gleeson has drawn differs radically from any yet made, and is the result of a careful study of the specimen belonging to the United States National Museum. No one can appreciate the peculiarities of Hesperornis and its remarkable departures from other swimming birds who has not seen the skeleton mounted in a swimming attitude. 'The great length of the legs, their position at the middle of the body, the narrowness of the body back of the hip joint, and the disproportionate length of the outer toe are all brought out in a manner which a picture of the bird squatting upon its haunches fails utterly to show. As for the tail, it is evident from the size and breadth of the bones that something of the kind was present; it is also evident that it was not like that of an ordinary bird, and so 
it has been drawn with just a suggestion of Archæopteryx about it.

'The most extraordinary thing about Hesperornis, however, is the position of the legs relative to the body, and this is something that was not even suspected until the skeleton was mounted in a swimming attitude. As anyone knows who has watched a duck swim, the usual place for the feet and legs is beneath and in a line with the body. But in our great extinct diver the articulations of the leg bones are such that this is impossible, and the feet and lower joint of the legs (called the tarsus) must have stood out nearly at right angles to the body, like a pair of oars. This is so peculiar and anomalous an attitude for a bird's legs that, although apparently indicated by the shape of the bones, it was at first thought to be due to the crushing and consequent distortion to which the bones had been subjected, and an endeavor was made to place the legs in the ordinary position, even though this was done at the cxpense of some little dislocation of the joints. But when the mounting of the skeleton had advanced further it became more 
evident that Hesperornis was not an ordinary bird, and that he could not have swum in the usual manner, since this would have brought his great knee-caps up into his body, which would have been uncomfortable. And so, at the cost of some little time and trouble, ${ }^{*}$ the mountings were so changed that the legs stood out at the sides of the body, as shown in the picture.

A final word remains to be said about toothed birds, which is, that the visitor who looks upon one for the first time will probably be disappointed. 'The teeth are so loosely implanted in the jaw that most of them fall out shortly after death, while the few that remain are so small as not to attract observation.

By the time the Eocene Period was reached, even before that, birds had become pretty much what we now see them, and very little

* The mounting of fossil bones is quite a different matler from the wiring of an ordinary skcleton, since the bones are not only so hard that they cammot be bored and nired like those of a recent animal, but they are so britlle and heavy that often they will not sustain their own weight. Hence such bones must be supported from the outside, and to do this so that the mountings will be strong enough to support their weight, allow the bones to be remoned for study, and yet be inconspicuous, is a difficult task. 
change has taken place in them since that time; they seem to have become so exactly adapted to the conditions of existence that no further modification has taken place. This may be expressed in another way, by saying that while the Mammals of the Eocene have no near relatives among those now living, entire large groups having passed completely out of existence, the few birds that we know might, so far as their appearance and affinities go, have been killed yesterday.

Were we to judge of the former abundance of birds by the number we find in a fossil state, we should conclude that in the early days of the world they were remarkably scarce, for bird bones are among the rarest of fossils. But from the high degree of development evidenced by the few examples that have come to light, and the fact that these represent various and quite distinct species, ${ }^{*}$ we are led

* But three birds, besides a stray feather or two, are so far known from the Eocene of North America. One of these is a forl not very unlike some of the small curassons of South America; another is a little bird, supposed to be related to the sparrons, while the third is a large bird of uncertain relationships. 
to conclude that birds were abundant enough, but that we simply do not find them.

Several eggs, too - or, rather, casts of eggs - have lately been found in the Cretaceous and Miocene strata of the $\mathrm{W}^{\top}$ est ; and, as eggs and birds are usually associated, we are liable at any time to come upon the bones of the birds that laid them.

'To the writer's mind no thoroughly satisfactory explanation has been given for the scarcity of bird remains; but the reason commonly adranced is that, owing to their lightness, dead birds float for a much longer time than other animals, and hence are more exposed to the ravages of the weather and the attacks of carrion-feeding animals. It has also been said that the power of flight enabled birds to escape calamities that caused the death of contemporary animals; but all birds do not fly ; and birds do fall victims to storms, cold, and starvation, and even perish of pestilence, like the Cormorants of Bering Island, whose ranks have twice been decimated by disease.

It is true that where carnivorous animals abound, dead birds do disappear quickly; and 
my friend Dr. Stejneger tells me that, while hundreds of dead sea-fowl are cast on the shores of the Commander Islands, it is a rare thing to find one after daylight, as the bodies are devoured by the Arctic foxes that prowl about the shores at night. But, again, as in the Miocenc of Southern France and in the Pliocene of Oregon, remains of birds are fairly numerous, showing that, under proper conditions, their bones are preserved for future reference, so that we may hope some day to come upon specimens that will enable us to round out the history of bird life in the past.

\section{REFERENCES}

The first discovered specimen of Archaopteryx, Archaopteryx macrera, is in the British Museum, the second more complete example is in the Royal Lluseum of Natural History, Berlin. The largest collection of toothed birds, including the types of Hesperomis, Ichthyornis and others, is in the Yale University Huseum, at New Harien. The U'nited States National Mhuseum at Washington has "fine mounted skeleton of Hesperornis, and the State I'nizersity of Kansas, at Lawrence, has the example showing the impressions of feathers. 
For scientific descriptions of these birds the reader is referred to Owen's paper "On the Archeoptery, of zon Meyer, with a Description of the Fossil Remains, ctc.," in the "Transactions of the Philosophical Society of London for 1863," page 33, and "Odontornithes, a Monograph of the Extinct Toothed Birds of North America," by $O$. C. Marsh. Much popular and scientific information concerning the carly birds is to be found in Ncwton's "Dictionary of Birds," and "The Story of Bird Life," by W. P. Pycraft; the "Structure and Life of Birds," by F. W. Headley; "The Story of the Birds," by J. Neroton Baskett.

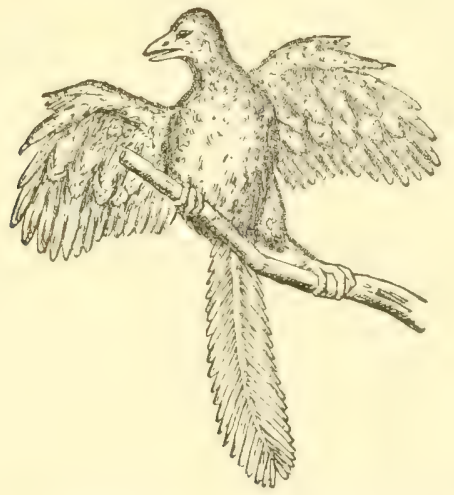

Fig. 17. - Archæopteryx as Restored by Mr. Pycraft. 


\section{VI}

\section{THE DINOSAURS}

"Shapes of all sorts and sizes, great and small."

A few million years ago, geologists and physicists do not agree upon the exact number, although both agree upon the millions, when the Rocky Mountains were not yet born and the now bare and arid western plains a land of lakes, rivers, and luxuriant vegetation, the region was inhabited by a race of strange and mighty reptiles upon whom science has bestowed the appropriate name of Dinosaurs, or terrible lizards.

Our acquaintance with the Dinosaurs is comparatively recent, dating from the early part of the nineteenth century, and in America, at least, the date may be set at 1818 , when the first Dinosaur remains were found in the $\checkmark$ alley of the Connecticut, although they naturally were not recognized as such, nor had the 


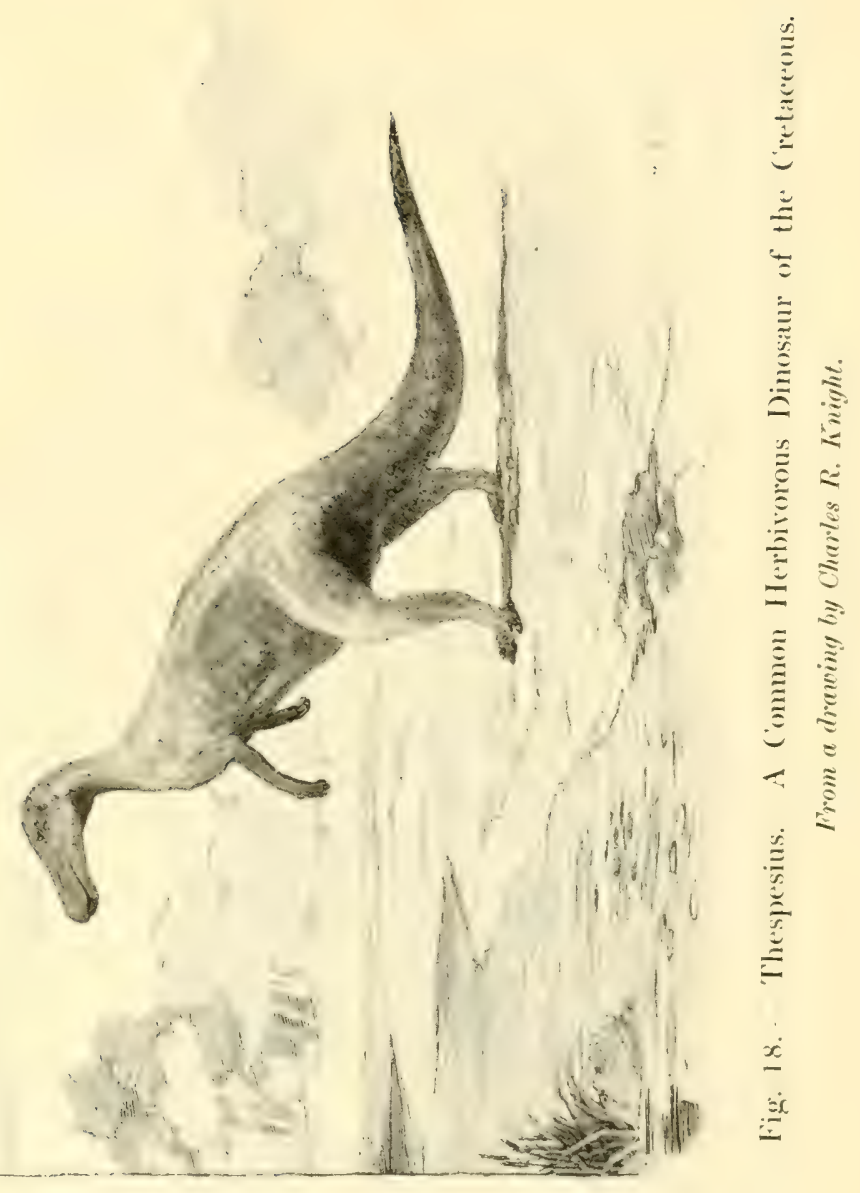



term been devised. The first Dinosaur to be formally recognized as representing quite a new order of reptiles was the carnivorous Megalosiur, found near Oxford, England, in 1824.

For a long time our knowledge of Dinosaurs was very imperfect and literally fragmentary, depending mostly upon scattered teeth, isolated vertebre, or fragments of bone picked up on the surface or casually encountered in some mine or quarry. Now, howerer, thanks mainly to the labors of American palicontologists, thanks also to the rich deposits of fossils in our Western States, we have an extensive knowledge of the Dinosaurs, of their size, structure, habits, and general appearance.

There are to-day no animals living that are closely related to them; none have lived for a long period of time, for the Dinosaurs came to an end in the Cretaccous, and it can only be said that the crocodiles, on the one hand, and the ostriches, on the other, are the nearest existing relatives of these great reptiles.

For, though so different in outward appear. ance, birds and reptiles are structurally quite 
closely allied, and the creeping snake and the bird on which it preys are relatives, although any intimate relationship between them is of the serpent's making, and is strongly objected to by the bird.

But if we compare the skeleton of a Dinosaur with that of an ostrich - a young one is preferable - and with those of the earlier birds, we shall find that many of the barriers now existing between reptiles and birds are broken down, and that they have many points in common. In fact, save in the matter of clothes, wherein birds differ from all other animals, the two great groups are not so very far apart.

'The Dinosaurs were by no means confined to North America, although the western United States scem to have been their headquarters, but ranged pretty much over the world, for their remains have been found in every continent, even in far-off New Zealand.

In point of time they ranged from the Trias to the Upper Cretaceous, their golden age, marking the culminating point of reptilian life, being in the Jurassic, when huge forms stalked by the sea-shore, browsed amid the swamps, or 
disported themselves along the reedy margins of lakes and rivers.

'They had their day, a day of many thousand years, and then passed away, giving place to the superior race of mammals which was just springing into being when the huge Dinosaurs were in the heyday of their existence.

And it does seem as if in the dim and distant past, as in the present, brains were a potent factor in the struggle for supremacy; for, though these reptiles were giants in size, dominating the earth through mere brute force, they were dwarfs in intellect.

The smallest human brain that is thought to be compatible with life itself weighs a little over ten ounces, the smallest that can exist with reasoning powers is two pounds; this in a creature weighing from 120 to 150 pounds.

What do we find among Dinosaurs? Thespesius, or Claosaurus, which may have walked where Baltimore now stands, was twenty-five feet in length and stood a dozen feet high in his bare feet, had a brain smaller than a man's clenched fist, weighing less than one pound. 
Brontosaurus, in some respects the biggest brute that ever walked, was but little better off, and 'Triceratops, and his relatives, creatures having twice the bulk of an elephant, weighing probably over ten tons, possessed a brain weighing not over two pounds!

How much of what we term intelligence could such a creature possess - what was the extent of its reasoning powers? Judging from our own standpoint and the small amount of intellect apparent in some humans with much larger brains, these big reptiles must have known just about enough to have eaten when they were hungry, anything more was superfluous.

However, intelligence is one thing, life another, and the spinal cord, with its supply of nerve-substance, doubtless looked after the mere mechanical functions of life; and while even the spinal cord is in many cases quite small, in some places, particularly in the sacral region, it is subject to considerable enlargement. This is notably true of Stegosaurus, where the sacral enlargement is twenty times the bulk of the puny brain - a fact noted by 
Professor Marsh, and seized upon by the newspapers, which announced that he had discovered a Dinosaur with a brain in its pelvis.

In their great variety of size and shape the Dinosaurs form an interesting parallel with the Marsupials of Australia. For just as these are, as it were, an epitome of the class of mammals, mimicking the herbivores, carnivores, rodents and even monkeys, so there are carnivorous and herbivorous Dinosaurs Dinosaurs that dwelt on land and others that habitually resided in the water, those that walked upright and those that crawled about on all fours; and, while there are no hints that any possessed the power of flight, some members of the group are very bird-like in form and structure, so much so that it has been thought that the two may have had a common ancestry.

The smallest of the Dinosaurs whose acquaintance we have made were little larger than chickens; the largest claim the distinction of being the largest known quadrupeds that have walked the face of the earth, the giants not only of their day, but of all time, 


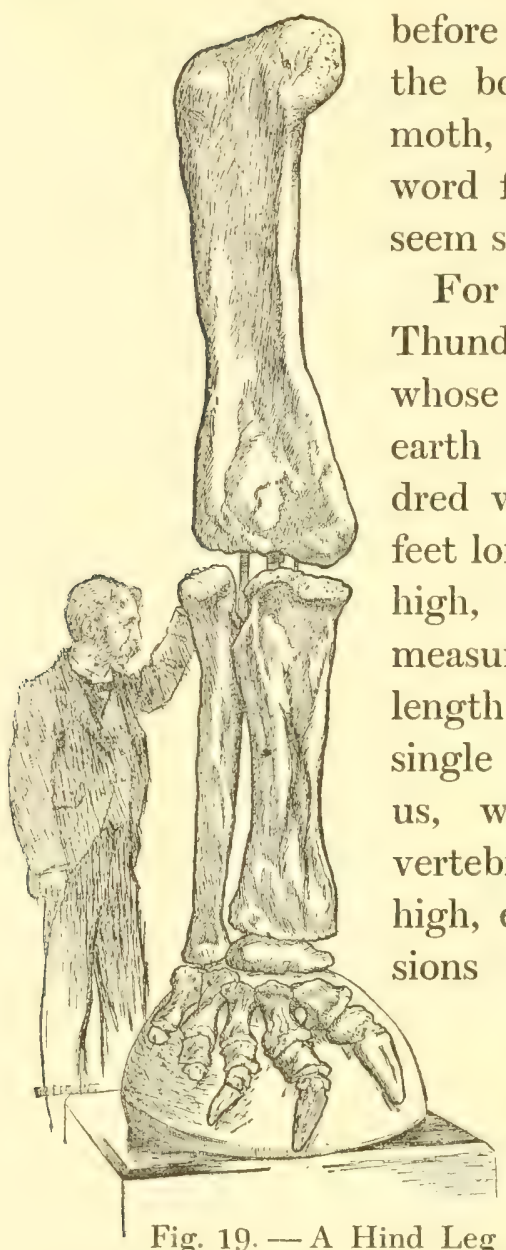

of the Great Brontosaurus, the Largest of the Dinosaurs. 
large, though rather short, body, very long neck and tail, and, for the size of the animal, a very small head. In fact, the head was so small and, in the case of Diplodocus, so poorly provided with teeth that it must have been quite a task, or a longcontinued pleasure, according to the state of its digestive apparatus, for the animal to have eaten its daily meal.

An elephant weighing $\mathbf{5}$ tons eats 100 pounds of hay and 25 pounds of grain for his day's ration; but, as this food is in a comparatively concentrated form, it
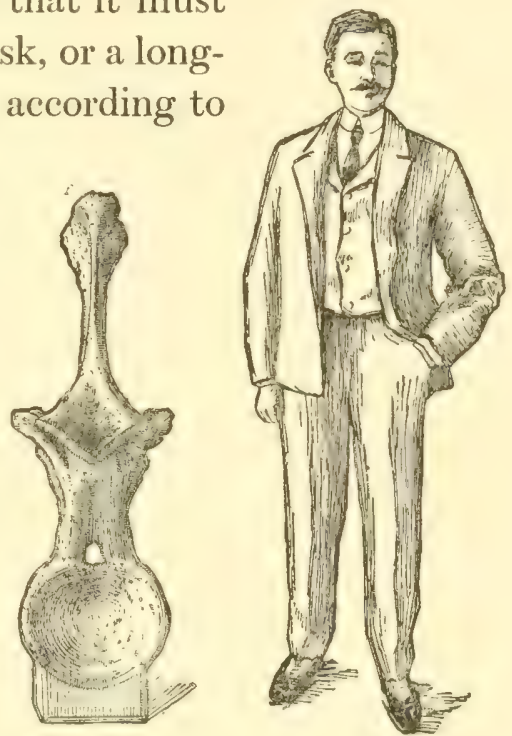

Fig. 20. - A Single Vertebra of Brontosaurus. would require at least twice this weight of green fodder.

It is a difficult matter to estimate the weight of a live Diplodocus or a Brontosaurus, but it 
is pretty safe to say that it would not be far from 20 tons, and that one would devour at the very least something over 700 pounds of leaves or twigs or plants each day - more, if the animal felt really hungry.

But here we must, even if reluctantly, curb our imagination a little and consider another point: the cold-blooded, sluggish reptiles, as we know them to-day, do not waste their energies in rapid movements, or in keeping the temperature of their bodies above that of the air, and so by no means require the amount of food needed by more active, warm-blooded animals. Alligators, turtles, and snakes will go for weeks, even months, without food, and while this applies more particularly to those that dwell in temperate climes and during their winter hibernation practically suspend the functions of digestion and respiration, it is more or less true of all reptiles. And as there is little reason for supposing that reptiles behaved in the past any differently from what they do in the present, these great Dinosaurs may, after all, not have been gifted with such ravenous appetites as one might fancy. Still, 
it is dangerous to lay down any hard and fast laws concerning animals, and he who writes about them is continually obliged to qualify his remarks - in sporting parlance, to hedge a little, and in the present instance there is some reason, based on the arrangement of vertebræ and ribs, to suppose that the lungs of Dinosaurs were somewhat like those of birds, and that, as a corollary, their blood may have been better aërated and warmer than that of living reptiles. But, to return to the question of food.

From the peculiar character of the articulations of the limb-bones, it is inferred that these animals were largely aquatic in their habits, and fed on some abundant species of water plants. One can readily see the advantage of the long neck in browsing off the regetation on the bottom of shallow lakes, while the animal was submerged, or in rearing the head aloft to scan the surrounding shores for the approach of an enemy. Or, with the tail as a counterpoise, the entire body could be reared out of water and the head be raised some thirty feet in the air. 
Triceratops, he of the three-horned face, had a remarkable skull which projected backward over the neck, like a fireman's helmet, or a sunbonnet worn hind side before, while over each eye was a massive horn directed forward, a third, but much smaller horn being sometimes present on the nose.

'The little "Horned 'Toad," which isn't a toad at all, is the nearest suggestion we have to-day of 'Triceratops; but, could he realize the ambition of the frog in the fable and swell himself to the dimensions of an ox, he would even then be but a pigmy compared with his ancient and distant relative.

So far as mere appearance goes he would compare very well, for while so much is said about the strange appearance of the Dinosaurs, it is to be borne in mind that their peculiarities are enhanced by their size, and that there are many lizards of to-day that lack only stature to be even more bialrre; and, for example, were the Australian Moloch but big enough, he could give even Stegosaurus "points" in more ways than one.

Standing before the skull of Triceratops, 


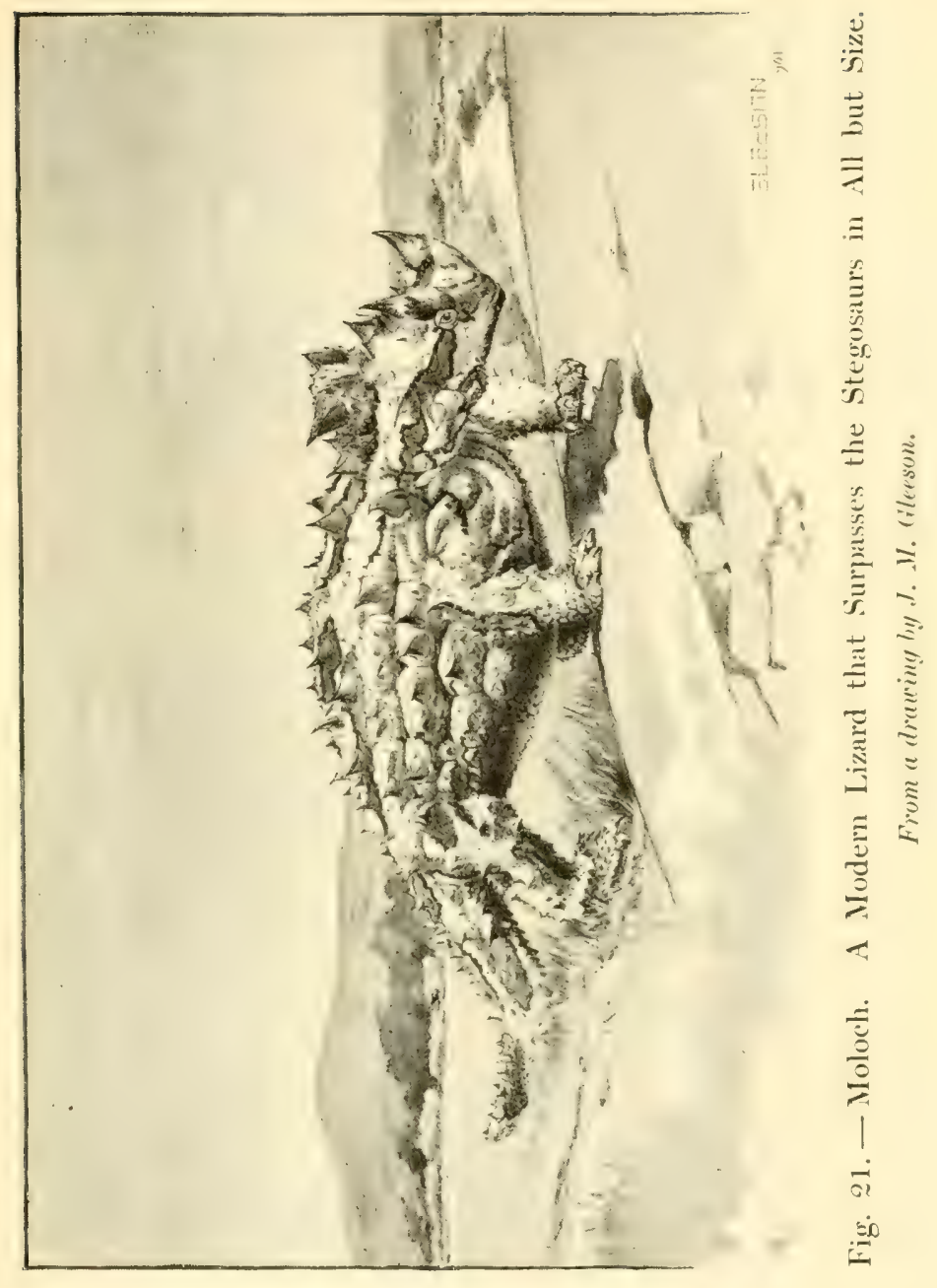



looking him squarely in the face, one notices in front of each eye a thick guard of projecting bone, and while this must have interfered with vision directly ahead it must have also furnished protection for the eye. So long as Triceratops faced an adversary he must have been practically invulnerable, but as he was the largest animal of his time, upward of twenty-five feet in length, it is probable that his combats were mainly with those of his own kind and the subject of dispute some fair female upon whom two rival suitors had cast covetous eyes. What a sight it would have been to have seen two of these big brutes in mortal combat as they charged upon each other with all the impetus to be derived from ten tons of infuriate flesh! We may picture to ourselves horn clashing upon horn, or glancing from each bony shield until some skilful stroke or unlucky slip placed one combatant at the mercy of the other, and he went down before the blows of his adversary " as falls on Mount Alvernus a thunder-smitten oak."

A pair of Triceratops horns in the National Museum bears witness to such encounters, for 
one is broken midway between tip and base; and that it was broken during life is evident from the fact that the stump is healed and rounded over, while the size of the horns shows that their owner reached a ripe old age.

For, unlike man and the higher vertebrates, reptiles and fishes do not have a maximum standard of size which is soon reached and rarely exceeded, but continue to grow throughout life, so that the size of a turtle, a crocodile, or a Dinosaur tells something of the duration of its life.

Before quitting 'Triceratops let us glance for a moment at its skeleton. Now among other things a skeleton is the solution of a problem in mechanics, and in Triceratops the head so dominates the rest of the structure that one might almost imagine the skull was made first and the body adjusted to it. The great head seems made not only for offence and defence; the spreading frill serves for the attachment of muscles to sustain the weight of the skull, while the work of the muscles is made easier by the fact that the frill reaches so far back of the junction of head with neck as to largely 
counterbalance the weight of the face and jaws. When we restored the skull of this animal it was found that the centre of gravity lay back of the eye. Several of the bones of the neck are united in one mass to furnish a firm attachment for the muscles that support and move the skull, but as the movements of the neck are already restricted by the overhanging frill, this loss of motion is no additional disadvantage.

To support all

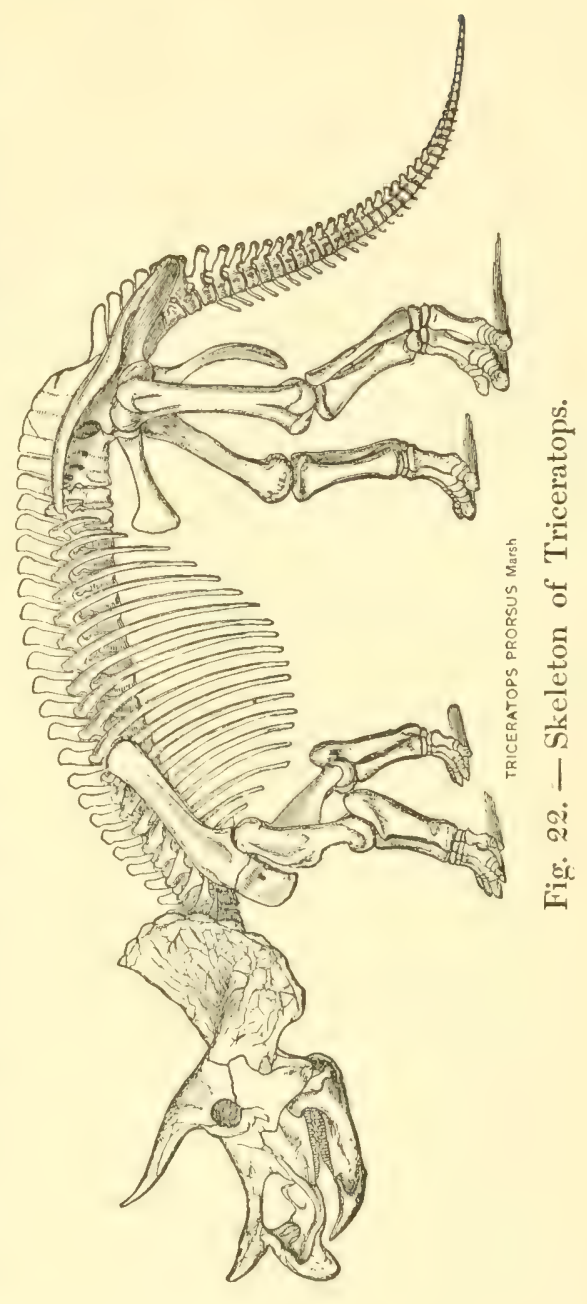


this weight of skull and body requires very massive legs, and as the fore legs are very short, this enables 'Triceratops to browse comfortably from the ground by merely lowering the front of the head.

'These forms we have been considering were the giants of the group, but a commoner species, 'Thespesius, though less in bulk than those just mentioned, was still of goodly proportions, for, as he stalked about, the top of his head was twelve feet from the ground.

Thespesius and his kin seem to have been comparatively abundant, for they have a wide distribution, and many specimens, some almost perfect, have been discovered in this country and abroad. No less than twenty-nine Iguanodons, a European relative of Thespesius, were found in one spot in mining for coal at Bernissart, Belgium. Here, during long years of Cretaceous time, a river slowly cut its way through the coal-bearing strata to a depth of 750 fect, a depth almost twice as great as the deepest part of the gorge of Niagara, and then, this being accomplished, began the work of filling up the valley it had excavated. 
It was then a sluggish stream with marshy borders, a stream subject to frequent floods, when the water, turbid with mud and laden with sand, orerflowed its banks, leaving them, as the waters subsided, covered thickly with mud. Here, amidst the luxuriant vegetation of a semi-tropical climate, lived and died the Iguanodons, and here the pick of the miner rescued them from their long entombment to form part of the treasures of the museum at Brussels.

Like other reptiles, living and extinct, Thespesius was continually renewing his teeth, so that as fast as one tooth was worn out it was replaced by another, a point wherein 'Thespesius had a decided advantage over ourselves. On the other hand, as there was a reserve supply of something like 400 teeth in the lower jaw alone, what an opportunity for the toothache!

And then we have a multitude of lesser Dinosaurs, including the active, predatory species with sharp claws and double-edged teeth. Megalosaurus, the first of the Dinosaurs to be really known, was one of these carnivorous 
species, and from our West comes a near relative, Ceratosaurus, the nose-horned lizard, a queer beast with tiny fore legs, powerful, sharpclawed hind fect, and well-armed jaws. A most formidable foe he seems, the more that the hollow bones speak of active morements, and Professor Cope pictured him, or a near relatire, vigorously engaged in combat with his fellows, or preying upon the huge but helpless herbivores of the marshes, leaping, biting, and tearing his enemy to pieces with tooth and claw.

Professor Osborn, on the other hand, is inclined to consider him as a reptilian hyena, feeding upon carrion, although one can but feel that such an armament is not entirely in the interests of peace.

I ast, but by no means least, are the Stegosaurs, or plated lizards, for not only were they beasts of goodly size, but they were among the most singular of all known animals, singular even for Dinosaurs. They had diminutive heads, small fore legs, long tails armed on either side near the tip, with two pairs of large spines, while from these spines to the neck 


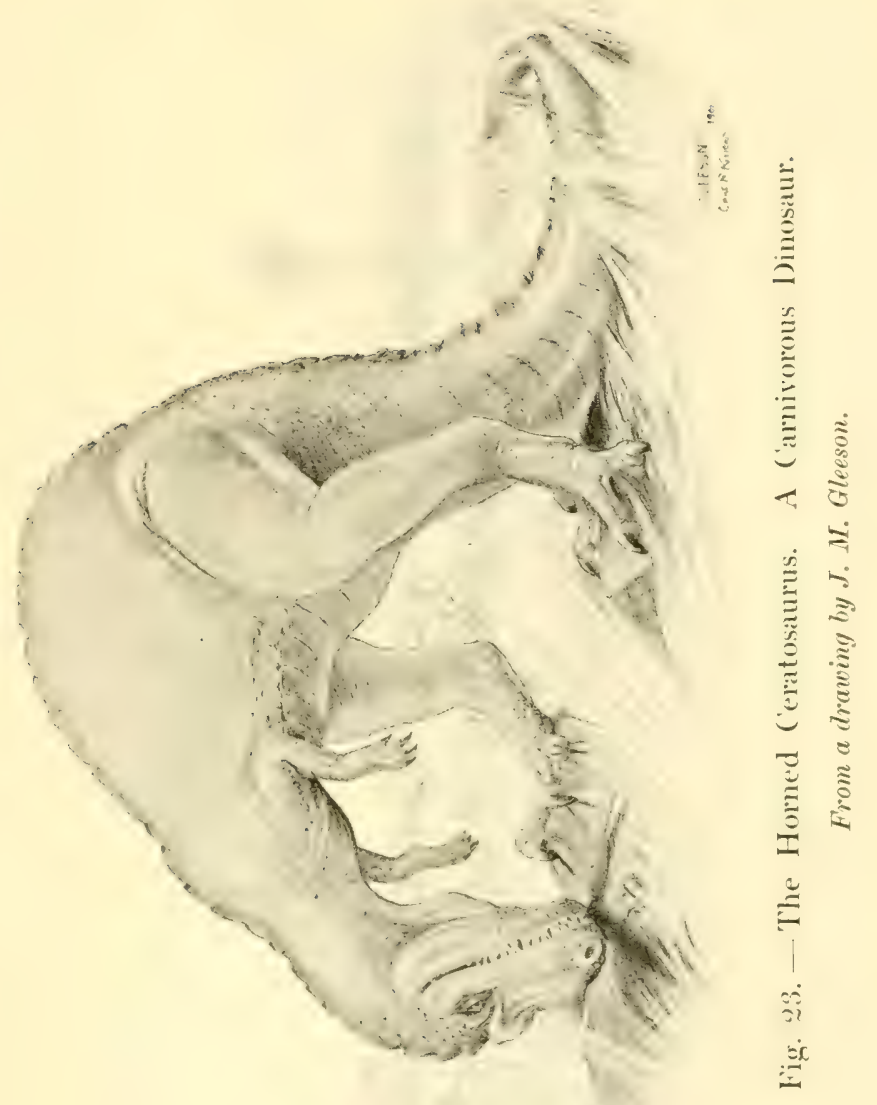



ran series of large, but thin, and sharp-edged plates standing on edge, so that their backs looked like the bottom of a boat provided with a number of little centreboards. Just how these plates were arranged is not decided beyond a peradventure, but while originally figured as having them in a single series down the back it seems much more probable that they formed parallel rows.

The largest of these plates were two feet in height and length, and not more than an inch thick, except at the base, where they were enlarged and roughened to give a firm hold to the thick skin in which they were imbedded. lie it remembered, too, that these plates and spines were doubtless covered with horn, so that they were even longer in life than as we now see them. The tail spines varied in length, according to the species, from eight or nine inches to nearly three feet, and some of them have a diameter of six inches at the base. They were swung by a tail eight to ten feet long, and as a visitor was heard to remark, one wouldn't like to be about such an animal in fly time. 
Such were some of the strange and mighty animals that once roamed this continent from the valley of the Connecticut, where they literally left their footprints on the sands of time, to the Rocky Mountains, where the ancient lakes and rivers became cemeteries for the entombment of their bones.

'The labor of the collector has gathered their fossil remains from many a Western canyon, the skill of the preparator has removed them from their stony sepulchres and the study of the anatomist has restored them as they were in life.

\section{REFERENCES.}

Most of our large muscums have on extibition fine specimens of many Dinosaurs, comprising skulls, limbs, and large portions of their sheletons. The American IIuscum of Natural History, New York, has the largest and finest display. The first actual skelcton of a Dinosaur to be mounted in this country zas the splendid Claosaurus at the I'ale University Muscum, where other striking pieces are also to be seen. The mounting of this Claosaurus, which is 99 feet long and 13 feet high, took an entive year. The United States National Muscum is 


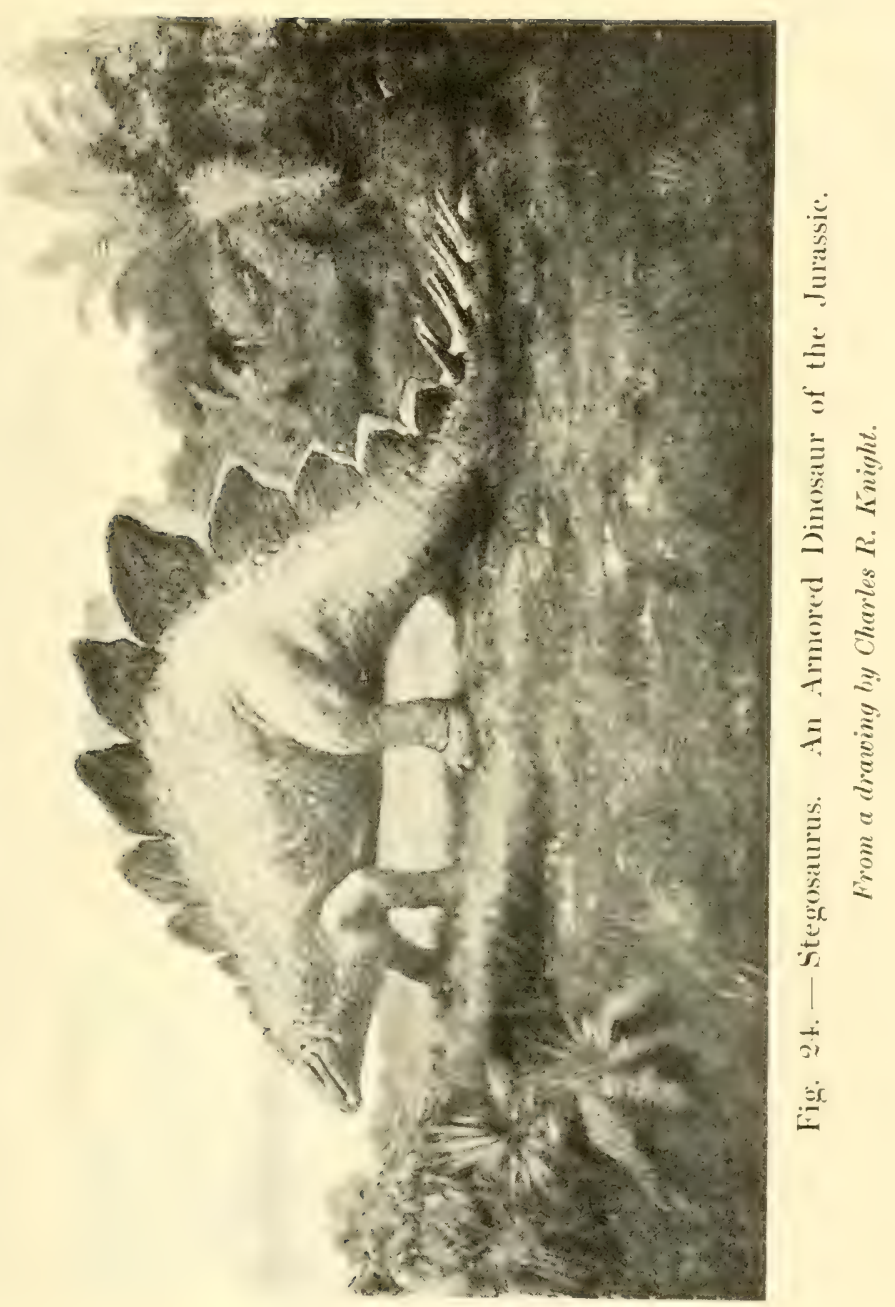



particularly rich in examples of the great, horned Triceratops, while the Carnegie Museum, Pittsburgh, hus the best Diplodocus. The Field Columbian Muscum and the Universities of Wyoming and Colorado all hate good collections.

The largest single bone of a Dinosaur is the thigh bone of a Brontosaurus in the Field Columbian Museum, this measuring 6 feet 8 inches in l'ngth. The height of a complete hind leg in the American Muscum of Natural History is 10 fect, while a single claw measures 6 by 9 inches. The skeleton of Triceratops restored in papiermache for the Pan-American Erposition measured si feet from tip of nose to end of tail and was 10 fect 6 inches to the top of the back-bone over the hips, this being the highest point. The head in the I'nited States National Muscum used as a model is 5 feet 6 inches long in a straight line and \& feet 3 inches across the frill. There is a stull in the Iale Lniversity Museum eien larger than this.

Articles relating to Dinosaurs are mostly technical in their nature and scattered through zarious scientific journals. The most accessible probably is "The Dinosaurs of North America," by Professor O. C. . Marsh, published as part of the sirtenth anmul report of the L'nited States Geological Survey. This contains many figures of the skulls, bones, and entire shelctons of many Dinosaurs. 


\section{ANIMALS OF THE PAST}

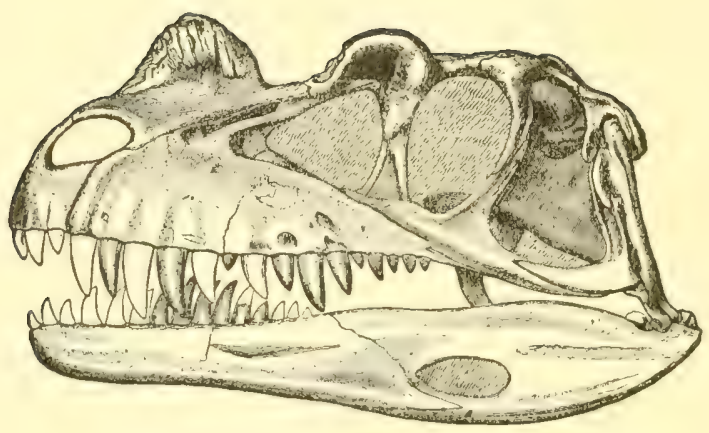

Fig. 25. - Skull of Ceratosaurus.

From a specimen in the United States National Museum. 


\section{VII}

READING THE RIDDLES OF THE ROCKS

"And the first Morning of Creation wrote

What the Last Dann of Reckoning shall read."

It is quite possible that the reader may wish to know something of the manner in which the specimens described in these pages have been gathered, how we acquire our knowledge of Brontosaurus, Claosaurus, or any of the many other "sauruses," and how their restorations have been made.

There was a time, not so very long ago, when fossils were looked upon as mere sports of Nature, and little attention paid to them; later their true nature was recognized, though they were merely gathered haphazard as occasion might offer. But now, and for many years past, the fossil-bearing rocks of many parts of the world have been systematically worked, and from the material thus obtained 
we have acquired a great deal of information regarding the inhabitants of the ancient world. This is particularly true of our own western country, where a vast amount of collecting has been done, although very much remains to be done in the matter of perfecting this knowledge, and hosts of new animals remain to be discovered. For this information we are almost as much indebted to the collector who has gathered the needed material, and the preparator whose patience and skill have made it available for study, as to the palæontologist who has interpreted the meaning of the bones.

To collect successfully demands not only a knowledge of the rocks in which fossils occur and of the localities where they are best exposed to view, but an eye quick to detect a piece of bone protruding from a rock or lying amongst the shale, and, above all, the ability to work a deposit to advantage after it has been found. 'The collector of living animals hies to regions where there is plenty for bird and beast to eat and drink, but the collector of extinct animals cares little for what is on the 
surface of the earth; his great desire is to see as much as possible of what may lie beneath. So the prospector in search of fossils betakes himself to some region where the ceaseless warfare waged by water against the dry land has scamed the face of the earth with countless gullics and canyons, or carved it into slopes and blufts in which the edges of the bonebearing strata are exposed to riew, and along these he skirts, ever on the look-out for some projecting bit of bone. 'The country is an almost shadeless desert, burning hot by day, uncomfortably cool at night. Wrater is scarce, and when it can be found, often has little to commend it save wetness; but the collector is buoyed up through all this with the hope that he may discorer some creature new to science that shall not only be bigger and uglier and stranger thin any heretofore found, but shall be the long-sought form needed for the solution of some difficult problem in the history of the past.

Now collecting is a lottery, differing from most lotteries, however, in that while some of the returns may be pretty small, there are few 
absolute blanks and some remarkably large prizes, and every collector hopes that it may fall to his lot to win one of these, and is willing to work long and arduously for the chance of obtaining it.

It may give some idea of the chances to say that some years ago Dr. Wortman spent almost an entire season in the field without success, and then, at the eleventh hour, found the now famous skeleton of Phenacodus, or that a party from Princeton actually camped within 100 yards of a rich deposit of rare fossils and yet failed to discover it.

Let us, however, suppose that the reconnoissance has been successful, and that an outcrop of bone has been found, serving like a tombstone carven with strange characters to indicate the burial-place of some primeval monster. l'ossibly Nature long ago rifled the grave, washing away much of the skeleton, and leaving little sare the fragments visible on the surface; on the other hand, these pieces may form part of a complete skeleton, and there is no way to decide this important question save by actual excavation. The manner of disinterment va- 
ries, but much depends on whether the fossil lies in comparatively loose shale or is imbedded in the solid rock, whether the strata are level or dip downward into the hillside. If, unfortunately, this last is the case, it necessitates a careful shoring up of the excavation with props of cotton-wood or such boards as may have been brought along to box specimens, or it may eren be necessary to run a short tunnel in order to get at some coveted bone. Should the specimen lie in shale, as is the case with most of the large reptiles that have been collected, much of that work may be done with pick and shorel; but if it is desirable or necessary to work in firm rock, drills and hammers, wedges, even powder, may be needed to rend from Nature her long-kept secrets. In any event, a detailed plan is made of the excavation, and each piece of bone or section of rock duly recorded therein by letter and number, so that later on the relation of the parts to one another may be known, or the various sections assembled in the work-room exactly as they lay in the quarry. Bones which lie in loose rock are often, one might say usually, more or less 
broken, and when a bone three, four, or even six feet long, weighing anywhere from 100 to 1,000 pounds, has been shattered to fragments the problem of removing it is no easy one. But here the skill of the collector comes into play to treat the fossil as a surgeon treats a fractured limb, to cover it with plaster bandages, and brace it with splints of wood or iron so that the specimen may not only be taken from the ground but endure in safety the coming journey of a thousand or more miles. For simpler cases or lighter objects strips of sacking, or even paper, applied with flour and water, suffice, or pieces of sacking soaked in thin plaster may be laid over the bone, first covering it with thin paper in order that the plaster jacket may simply stiffen and not adhere to it. Collecting has not always been carried on in this systematic manner, for the development of the present methods has been the result of years of experience; formerly there was a mere skimming-over of the surface in what Professor Marsh used to term the potato-gathering style, but now the effort is made to remore specimens intact, often imbedded in large masses 

of rock, in order that all parts may be preserved.

We will take it for granted that our specimens have safely passed through all perils by land and water, road and rail; that they have been quarried, boxed, carted orer a roadless country to the nearest railway, and have withstood 2,000 miles of jolting in a freight-car. The first step in reconstruction has been taken; the problem, now that the boxes are reposing on the work-room floor, is to make the blocks of stone give up the secrets they have guarded for ages, to free the bones from their enveloping matrix in order that they may tell us something of the life of the past. 'The method of doing this raries with the conditions under which the material has been gathered, and if from hard clay, chalk, or shale, the process, though tedious enough at best, is by no means so difficult as if the specimens are imbedded in solid rock. In this case the fragments from a given section of quarry must be assembled according to the plan which has been carefully made as the work of exhumation progressed, all pieces containing bone must be 
stuck together, and weak parts strengthened with gum or glue. Now the mass is attacked with hammer and chisel, and the surrounding matrix slowly and carefully cut away until the contained bone is revealed, a process much simpler and more expeditious in the telling than in the actuality; for the preparator may not use the heary tools of the ordinary stonecutter: sometimes an awl, or even a glover's needle, must suffice him, and the chips cut off are so small and such care must be taken not to injure the bone that the work is really tedious. 'This may, perhaps, be better appreciated by saying that to clean a single vertebra of such a huge Dinosaur as Diplodocus may require a month of continuous labor, and that a score of these big and complicated bones, besides others of simpler structure, are included in the backbone. The finished specimen weighs over 120 pounds, while as originally collected, with all the adherent rock, the weight was twice or thrice as great. Such a mass as this is comparatively small, and sometimes huge blocks are taken containing entire skulls or a number of bones, and not infre- 
quently weighing a ton. The largest single specimen is a skull of Triceratops, collected by Mr. J. 13. Hatcher, which weighed, when boxed, 3,650 pounds.

Or, as the result of some mishap, or through the work of an inexperienced collector, a valuable specimen may arrive in the shape of a box full of irregular fragments of stone compared with which a dissected map or an oldfashioned Chinese puzzle is simplicity itself, and one may spend hours looking for some piece whose proper location gires the clew to an entire section, and days, even, may be consumed before the task is completed. While this not only tries the patience, but the eyes as well, there is, nevertheless, a fascination about this work of fashioning a bone out of scores, possibly liundreds, of fragments, and watching the irregular bits of stone shaping themselres into a mosaic that forms a portion of some creature, possibly quite new to science, and destined to bear a name as long as itself. And thus, after many days of toil, the bone that millions of years before sank into the mud of some old lake-bottom or was 
buried in the sandy shoals of an ancient river, is brought to light once more to help tell the tale of the creatures of the past.

One bone might convey a great deal of information; on the other hand it might reveal very little; for, while it is very painful to say so, the popular impression that it is possible to reconstruct an animal from a single bone, or tell its size and habits from a tooth is but partially correct, and sometimes " the eminent scientist" has come to grief even with a great many bones at his disposal. Did not one of the ablest anatomists describe and figure the hip-bones of a Dinosaur as its shoulder-blade, and another, equally able, reconstruct a reptile " hind side before," placing the head on the tail! 'This certainly sounds absurd enough; but just as absurd mistakes are made by men in other walks of life, often with far more deplorable results.

Before passing to the restoration of the $\mathrm{ex}$ terior of animals it may be well to say something of the manner in which the skeleton of an extinct animal may be reconstructed and the meaning of its various parts interpreted. 
For the adjustment of the muscles is dependent on the structure of the skeleton, and putting on the muscles means blocking out the form, details of external appearance being supplied by the skin and its accessories of hair, scales, or horns. Let us suppose in the present instance that we are dealing with one of the great reptiles known as Triceratops whose remains are among the treasures of the National Museum at $W$ ashington, for the reconstruction of the big beast well illustrates the methods of the palixontologist and also the troubles by which he is beset. Moreorer, this is not a purely imaginary case, but one that is very real, for the skeleton of this animal which was shown at Buffalo was restored in papier-maché in exactly the manner indicated. W' have a goodly number of bones, but by no means an entire skeleton, and yet we wish to complete the skeleton and incidentally to form some idea of the creature's habits. Now we can interpret the past only by a knowledge of the present, and it is by carefully studying the skeletons of the animals of to-day that we can learn to read the meaning of the symbols of 
bones left by the animals of a million yesterdays. 'Thus we find that certain characters distinguish the bone of a mammal from that of a bird, a reptile, or a fish, and these in turn from one another, and this constitutes the A $\mathrm{B}$ C of comparative anatomy. And, in a like manner, the bones of the various divisions of these main groups have to a greater or less extent their own distinguishing characteristics, so that by first comparing the bones of extinct animals with those of creatures that are now living we are enabled to recognize their nearest existing relative, and then by comparing them with one another we learn the relations they bore in the ancient world. But it must be borne in mind that some of the early beasts were so very different from those of to-day that until pretty much their entire structure was known there was nothing with which to compare odd bones. Had but a single incomplete specimen of Triceratops come to light we should be very much in the dark concerning him; and although remains of some thirty individuals have been discovered, these have been so imperfect that we are very far from 
having all the information we need. A great part of the head, with its formidable looking horns, is present, and although the nose is gone, we know from other specimens that it, too, was armed with a knob, or horn, and that the skull ended in a beak, something like that of a snapping turtle, though formed by a separate and extra bone; similarly the end of the lower jaw is lacking, but we may be pretty certain that it ended in a beak, to match that of the skull. 'The large leg-bones of our specimen are mostly represented, for these being among the more solid parts of the skeleton are more frequently preserved than any others, and though some are from one side and some from another, this matters not. If the hind legs were disproportionately long it would indicate that our animal often or habitually walked erect, but as there is only difference enough between the fore and hind limbs to enable Triceratops to browse comfortably from the ground we would naturally place him on all fours, even were the skull not so large as to make the creature too top-heavy for any other mode of locomotion. Were the limbs very 
small in comparison with the other bones, it would obviously mean that their owner passed his life in the water. For a skeleton has a twofold meaning, it is the best, the most enduring, testimony we have as to an animal's place in nature and the relationships it sustains to the creatures that lived with it, before it, and after it. More than this, a skeleton is the solution of a problem in mechanics, the problem of carrying a given weight and of adaptation to a given mode of life. 'Thus the skeleton varies according as a creature dwells on land, in the water, or in the air, and according as it feeds on grass or preys upon its fellows.

And so the mechanies of a skeleton afford us a clew to the habits of the living animal. Something, too, may be gathered from the structure of the leg-bones, for solid bones mean either a sluggish animal or a creature of more or less aquatic habits, while hollow bones emphatically declare a land animal, and an active one at that; and this, in the case of the Dinosaurs, hints at predatory habits, the ability to catch and eat their defenceless and more sluggish brethren. A claw, or, better yet, a tooth, 
may confirm or refute this hint; for a blunt claw could not be used in tearing prey limb from limb, nor would a double-edged tooth, made for rending flesh, serve for champing grass.

But few bones of the feet, and especially the fore feet, are present, these smaller parts of the skeleton having been washed away before the ponderous frame was buried in the sand, and the best that can be done is to follow the law of probabilities and put three toes on the hind foot and five on the fore, two of these last without claws. 'The single blunt round claw among our bones shows, as do the teeth, that 'Triceratops was herbivorous; it also pointed a little downward, and this tells that in the living animal the sole of the foot was a thick, soft pad, somewhat as it is in the elephant and rhinoceros, and that the toes were not entirely free from one another. 'There are less than a dozen vertebre and still fewer ribs, besides half a barrelful of pieces, from which to reconstruct a backbone twenty feet long. That the ribs are part from one side and part from another matters no more than it did in the case of the leg-bones; but the backbone presents a 
more difficult problem, since the pieces are not like so many checkers - all made after one pattern - but each has an individuality of its own. 'The total number of vertebra must be guessed at (perhaps it would sound better to say estimated, but it really means the same), and knowing that some sections are from the front part of the vertebral column and some from the back, we must fill in the gaps as best we may. The ribs offer a little aid in this task, giving certain details of the vertebræ, while those in turn tell something about the adjoining parts of the ribs. We finish our Triceratops with a tail of moderate length, as indicated by the rapid taper of the few vertebra available, and from these we gather, too, that in life the tail was round, and not flattened, and that it neither served for swimming nor for a balancing pole. And so, little by little. have been pieced together the fragments from which we have derived our knowledge of the past, and thus has the palæontologist read the riddles of the rocks.

'To make these dry bones live again, to clothe them with flesh and reconstruct the 


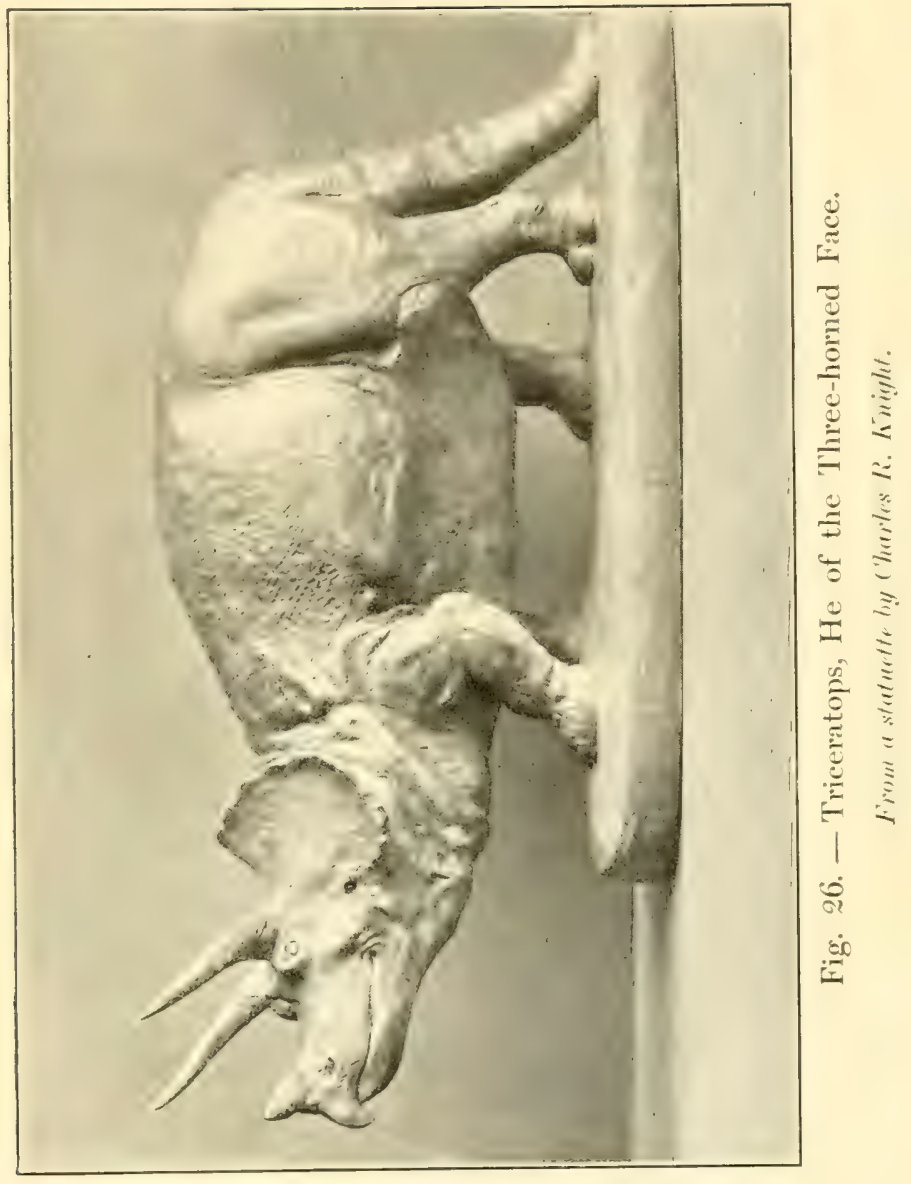



creature as he was or may have been in life, is, to be honest, very largely guesswork, though to make a guess that shall come anywhere near the mark not only demands a thorough knowledge of anatomy - for the basis of all restoration must be the skeleton but calls for more than a passing acquaintance with the cxternal appearance of living animals. And while there is nothing in the bones to tell how an animal is, or was, clad, they will at least show to what group the creature belonged, and, that known, there are certain probabilities in the case. A bird, for example, would certainly be clad in feathers. Going a little farther, we might be pretty sure that the feathers of a water-fowl would be thick and close; those of strictly terrestrial birds, such as the ostrich and other flightless forms, lax and long. These as general propositions; of course, in special cases, one might easily come to grief, as in dealing with birds like penguins, which are particularly adapted for an aquatic life, and have the feathers highly modified. 'These birds depend upon their fat, and not on their feathers, for warmth, and so 
their feathers have become a sort of cross between scales and hairs. Hair and fur belong to mammals only, although these creatures show much variety in their outer covering. 'The thoroughly marine whales have discarded furs and adopted a smooth and slippery skin,* well adapted to movement through the water, relying for warmth on a thick undershirt of blubber. 'The earless seals that pass much of their time on the ice have just enough hair to keep them from absolute contact with it, warmth again being provided for by blubber. 'The fur seals, which for several months in the year dwell largely on land, have a coat of fur and hair, although warmth is mostly furnished, or rather kept in, by fat.

No reptile, therefore, would be covered with

* The reader is warned that this is a mere figure of speech, for, of course, the process of adaptation to surroundings is passive, not active, although there is a most unfortunate tendency among uriters on crolution, and particularly on mimicry, to speak of it as active. The writer believes that no animal in the first stages of mimicry, consciously mimics or endeavors to resemble another animal or any part of its surroundings, but a habit at first accidental may in time become more or less conscious. 
feathers, neither, judging from those we know to-day, would they be clad in fur or hair; but, such corerings being barred out, there remain a great variety of plates and scales to choose from. Folds and frills, crests and dewlaps, like beauty, are but skin deep, and, being thus superficial, ordinarily leave no trace of their former presence, and in respect to them the reconstructor must trust to his imagination, with the law of probabilities as a check rein to his fancy. 'This law would tell us that such ornaments must not be so placed as to be in the way, and that while there would be a possibility - one might even say probability - of the great, short-headed, iguana-like Dinosaurs having dewlaps, that there would be no great likelihood of their possessing ruffs such as that of the Australian Chlamydosaurus (mantled lizard) to flap about their ears. Eren Stegosaurus, with his bizarre array of great plates and spines, kept them on his back, out of the way. Such festal ornamentation would, howerer, more likely be found in small, active creatures, the larger beasts contenting themselves with plates and folds. 
Spines and plates usually leave some trace of their existence, for they consist of a super. structure of skin or horn, built on a foundation of bone; and while even horn decomposes too quickly to "petrify," the bone will become fossilized and changed into enduring stone. But while this affords a pretty sure guide to the general shape of the investing hom, it does not give all the details, and there may have been ridges and furrows and sculpturing that we know not of.

Knowing, then, what the probabilities are, we have some guide to the character of the covering that should be placed on an animal, and if we may not be sure as to what should be done, we may be pretty certain what should not.

For example, to depict a Dinosaur with smooth, rubbery hide walking about on dry land would be to riolate the probabilities, for only such exclusively aquatic creatures as the whales among mammals, and the salamanders among batrachians, are clothed in smooth, shiny skin. There might, however, be reason to suspect that a creature largely aquatic in its habits did occasionally venture on land, as, for 
instance, when vertebra that seem illy adapted for carrying the weight of a land animal are found in company with huge limb-bones and massive feet we may feel reasonably certain that their owner passed at least a portion of his time on terra firma.

So much for the probabilities as to the covering of animals known to us only by their fossil remains; but it is often possible to go beyond this, and to state certainly how they were clad. For while the chances are small that any trace of the covering of an extinct animal, other than bony plates, will be preserved, Nature does now and then seem to have relented, and occasionally some animal settled to rest where it was so quickly and quietly covered with fine mud that the impression of small scales, feathers, or even smooth skin, was preserved; curiously enough, there seems to be scarcely any record of the imprint of hair. Then, too, it is to be remembered that while the chances were very much against such preservation, in the thousands or millions of times creatures died the millionth chance might come uppermost. 
Silhouettes of those marine reptiles, the Ichthyosaurs, have been found, probably made by the slow carbonization of animal matter, showing not only the form of the body and tail, but revealing the existence of an unsuspected back fin. And yet these animals were apparently clad in a skin as thin and smooth as that of a whale. Impressions of feathers were known long before the discovery of Archæopteryx; a few have been found in the Green River and Florissant shales of Wyoming, and a Hesperornis in the collection of the State University of Kansas shows traces of the existence of long, soft feathers on the legs and very clear imprints of the scales and reticulated skin that covered the tarsus. From the Chalk of Kansas, too, came the example of 'Tylosaur, showing that the back of this animal was decorated with the crest shown in Mr. Knight's restoration, one not unlike that of the modern iguana. From the Laramie sandstone of Montana Mr. Hatcher and Mr. Butler have obtained the impressions of portions of the skin of the great Dinosaur, Thespesius, which show that the covering of this animal consisted largely, if not 
READING RIDDLES OF THE ROCKS 133

entirely, of small, irregularly hexagonal horny scutes, slightly thickened in the centre. The quarries of lithographic stone at Solenhofen have yielded a few specimens of flying reptiles, pterodactyls, which not only verify the correctness of the inference that these creatures possessed membranous wings, like the bats, but show the exact shape, and it was sometimes very curious, of this membrane. And each and all of these wonderfully preserved specimens serve both to check and guide the restorer in his task of clothing the animal as it was in life.

And all this help is needed, for it is an easy matter to make a wide-sweeping deduction, apparently resting on a good basis of fact, and yet erroneous. Remains of the Mammoth and Woolly Rhinoceros, found in Siberia and Northern Europe, were thought to indicate that at the period when these animals lived the climate was mild, a very natural inference, since the elephants and rhinoceroses we now know are all inhabitants of tropical climes. But the discovery of more or less complete specimens makes it evident that the climate 
was not particularly mild; the animals were simply adapted to it; instead of being naked like their modem relatives, they were dressed for the climate in a woolly covering. We think of the tiger as prowling through the jungles of India, but he ranges so far north that in some localities this beast preys upon reindecr, which are among the most northern of large mammals, and there the tiger is clad in fairly thick fur.

When we come to coloring a reconstructed animal we have absolutely no guide, unless we assume that the larger a creature the more soberly will it be colored. 'The great land animals of to-day, the elephant and rhinoceros, to say nothing of the aquatic hippopotamus, are very dully colored, and while this sombre coloration is to-day a protection, rendering these animals less easily seen by man than they otherwise would be, yet at the time this color was developing man was not nor were there enemies sufficiently formidable to menace the race of elephantine creatures.

For where mere size furnishes sufficient protection one would hardly expect to find pro- 
READING RIDDLES OF THE ROCKS 135

tective coloration as well, unless indeed a creature preyed upon others, when it might be advantageous to enable a predatory animal to steal upon its prey.

Color often exists (or is supposed to) as a sexual characteristic, to render the male of a species attractive to, or readily recognizable by, the female, but in the case of large animals mere size is quite enough to render them conspicuous, and possibly this may be one of the factors in the dull coloration of large animals.

So while a green and yellow Triceratops would undoubtedly have been a conspicuous feature in the Cretaceous landscape, from what we know of existing animals it seems best to curb our fancy and, so far as large Inosaurs are concerned, employ the colors of a Rembrandt rather than those of a sign painter.

Aids, or at least hints, to the coloration of extinct animals are to be found in the coloration of the young of various living species, for as the changes undergone by the embryo are in a measure an epitome of the changes undergone by a species during its evolution, so the brief color phases or markings of the young 
are considered to represent the ordinary coloring of distant ancestors. Young thrushes are spotted, young ostriches and grebes are irregularly striped, young lions are spotted, and in restoring the early horse, or Hyracothere, Professor Osborn had the animal represented as faintly striped, for the reason that zebras, the wild horses of to-day, are striped, and because the ass, which is a primitive type of horse, is striped over the shoulders, these being hints that the earlier horse-like forms were also striped.

Thus just as the skeleton of a Dinosaur may be a composite structure, made up of the bones of a dozen individuals, and these in turn mosaics of many fragments, so may the semblance of the living animal be based on a fact, pieced out with a probability and completed by a bit of theory.

\section{REFERENCES}

There is a large series of restorations of extinct animals, prepared by Mr. Charles R. Knight, under the direction of Professor Osborn, in the Hall of Palaontology of the American ILuscum of Natural History, 
and these are later to be reprodued and issued in portfolio form.

Should the rader visit Princeton, he may see in the muscum there a mumber of $B$. Waterhouse IIawkins's creations - creations is the proper word - which are of interest as examples of the early work in this line.

The "Report of the Smithsonian Institution for $1900 "$ contains an article on "The Restoration of Eritinct Animals," pages 4r9-492, which includes a number of plates showing the progress that has becn made in this direction.

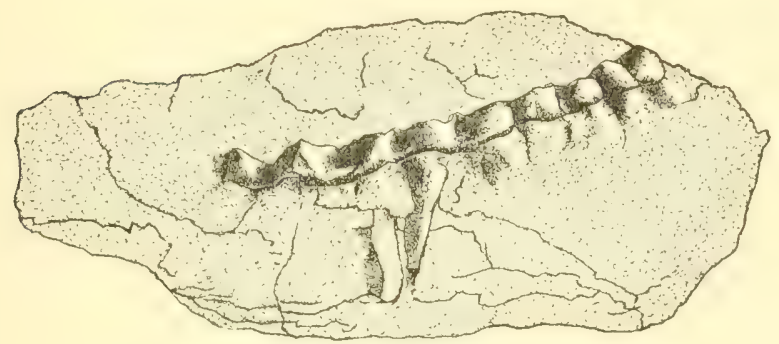

Fig. 27. - A Hint of Buried Treasures. 


\section{VIII}

\section{FEATHERED GIANTS}

"There were giants in the earth in those days."

Nearly every group of animals has its giants, its species which tower above their fellows as Goliath of Gath stood head and shoulders above the Philistine hosts; and while some of these are giants only in comparison with their fellows, belonging to families whose members are short of stature, others are sufficiently great to be called giants under any circumstances. Some of these giants live to-day, some have but recently passed away, and some ceased to be long ages before man trod this earth. 'The most gigantic of mammals - the whales - still survive, and the elephant of today suffers but little in comparison with the mammoth of yesterday ; the monstrous Dinosaurs, greatest of all reptiles - greatest, in fact, of all animals that have walked the 
earth-flourished thousands upon thousands of years ago. As for birds, some of the giants among them are still living, some existed long geologic periods ago, and a few have so recently ranished from the scene that their memory still lingers amid the haze of tradition. 'The best known among these, as well as the most recent in point of time, are the Moas of New Zealand, first brought to notice by the Rev. IV. Colenso, later on Bishop of New Zealand, one of the many missionaries to whom Science is under obligations. Early in 1838, Bishop Colenso, while on a missionary visit to the East Cape region, heard from the natives of $W$ aiapu tales of a monstrous bird, called Moa, having the head of a man, that inhabited the mountain-side some eighty miles away. 'This mighty bird, the last of his race, was said to be attended by two equally huge lizards that kept guard while he slept, and on the approach of man wakened the Moa, who immediately rushed upon the intruders and trampled them to death. None of the Maoris had seen this bird, but they had seen and somewhat irreverently used for making parts 
of their fishing tackle, bones of its extinct relatives, and these bones they declared to be as large as those of an ox.

About the same time another missionary, the Rev. Richard 'Taylor, found a bone ascribed to the Moa, and met with a very similar tradition among the natives of a near-by district, only, as the foot of the rainbow moves away as we move toward it, in his case the bird was said to dwell in quite a different locality from that given by the natives of East Cape. While, however, the Maoris were certain that the Moa still lived, and to doubt its existence was little short of a crime, no one had actually seen it, and as time went on and the bird still remained unseen by any explorer, hope became doubt and doubt certainty, until it even became a mooted question whether such a bird had existed within the past ten centuries, to say nothing of having lived within the memory of man.

But if we do not know the living birds, their remains are scattered broadcast over hillside and plain, concealed in caves, buried in the mud of swamps, and from these we gain a good 


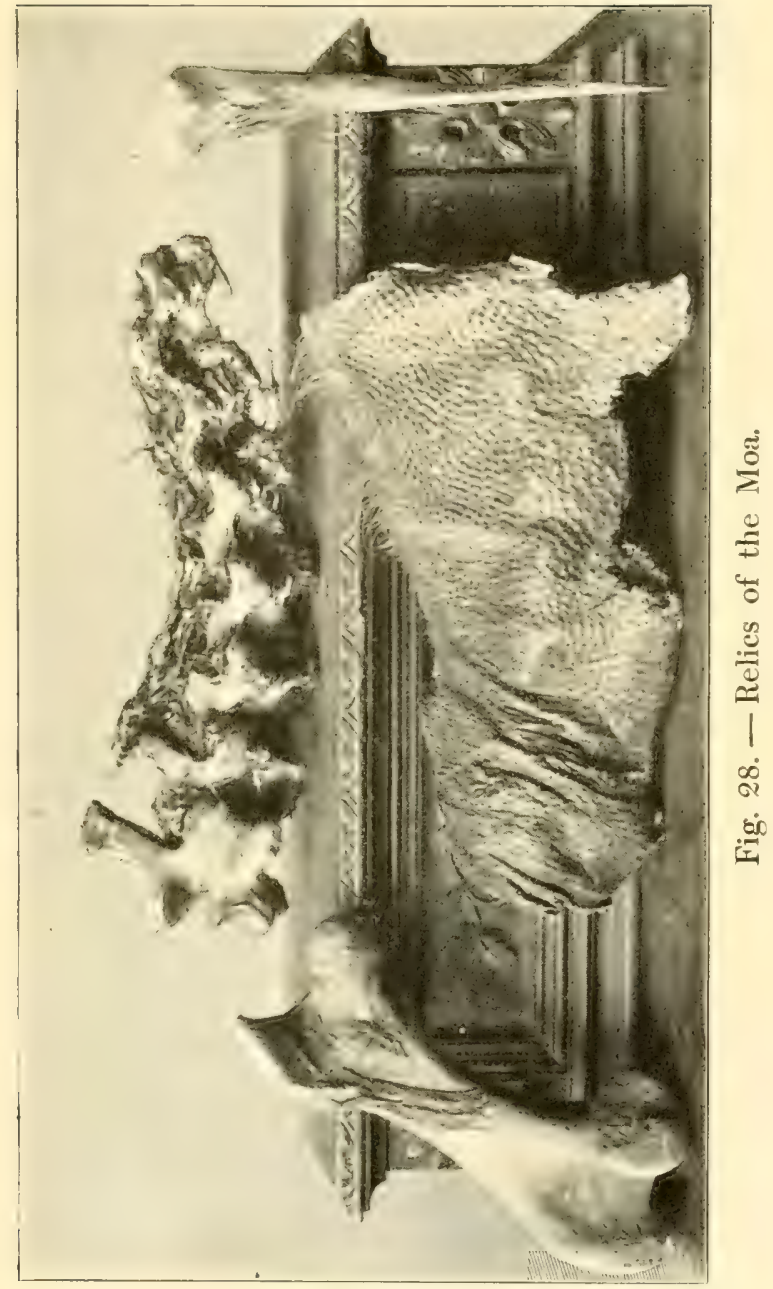



idea of their size and structure, while chance has even made it possible to know something; of their color and general appearance. This chance was the discovery of a few specimens, preserved in exceptionally dry caves on the South Island, which not only had some of the bones still united by ligaments, but patches of skin clinging to the bones, and bearing numerous feathers of a chestnut color tipped with white. These small, straggling, rusty feathers are not much to look at, but when we reflect that they have been preserved for centuries without any care whaterer, while the buffalo bugs have devoured our best Smyrna rugs in spite of all possible precautions, our respect for them increases.

From the bones we learn that there were a great many kinds of Moas, twenty at least, ranging in size from those little larger than a turkey to that giant among giants, Dinornis maximus, which stood at least ten feet high,*

* The height of the Moas, and even of some species of Epyornis. is often stated to be trelve or fourteen feet, but such a height can only be obtained by placing the skeleton in a wholly unnatural attitude. 
or two feet higher than the largest ostrich, and may well claim the distinction of being the tallest of all known birds. We also learn from the bones that not only were the Moas flightless, but that many of them were absolutely wingless, being devoid even of such vestiges of wings as we find in the Cassowary or Apteryx. But if Nature deprived these birds of wings, she made ample amends in the matter of legs, those of some species, the Elephant-footed Moa, Pachyornis elephantopus, for example, being so massively built as to cause one to wonder what the owner used them for, although the generally accepted theory is that they were used for scratching up the roots of ferns on which the Moas are believed to have fed. And if a blow from an irate ostrich is sufficient to fell a man, what must have been the kicking power of an able-bodied Moa? Beside this bird the ostrich would appear as slim and graceful as a gazelle beside a prize ox.

The Mloas were confined to New Zealand, some species inhabiting the North Island, some the South, very few being common to both, and from these peculiarities of distribution 
geologists deduce that at some early period in the history of the earth the two islands formed one, that later on the land subsided, leaving the islands separated by a strait, and that since this subsidence there has been sufficient time for the development of the species peculiar to each island. Although Moas were still numerous when man made his appearance in this part of the world, the large deposits of their bones indicate that they were on the wane, and that natural causes had already reduced the feathered population of these islands. A glacial period is believed to have wrought their destruction, and in one great morass, abounding in springs, their bones occur in such enormous numbers, layer upon layer, that it is thought the birds sought the place where the flowing springs might afford their feet at least some respite from the biting cold, and there perished miserably by thousands.

What Nature spared man finished, and legends of Moa hunts and Moa feasts still lingered among the Maoris when the white man came and began in turn the extermination of the Maori. 'The theory has been advanced, 
with much to support it, that the big birds were eaten off the face of the earth by an earlier race than the Maoris, and that after the extirpation of the Moas the craving for flesh naturally led to cannibalism. But by whomsoever the destruction was wrought, the result was the same, the habitat of these feathered giants knew them no longer, while multitudes of charred bones, interspersed with fragments of eggshells, bear testimony to former barbaric feasts.

It is a far cry from New Zealand to Madagascar, but thither must we go, for that island was, pity we cannot say is, inhabited by a race of giant birds from whose eggs it has been thought may have been hatched the Roc of Sindbad. Arabian tales, as we all know, locate the Roc either in Madagascar or in some adjacent island to the north and east, and it is far from unlikely that legends of the Epyornis, backed by the substantial proof of its enormous eggs, may have been the slight foundation of fact whereon the story-teller erected his structure of fiction. True, the Roc of fable was a gigantic bird of prey capable of 
bearing away an elephant in its talons, while the Epyornis has shed its wings and shrunk to dimensions little larger than an ostrich, but this is the inevitable result of closer acquaintance and the application of a two-foot rule.

Like the Moa the Epyornis seems to have lived in tradition long after it became extinct, for a French history of Madagascar, published as early as 1658 makes mention of a large bird, or kind of ostrich, said to inhabit the southern end of the island. Still, in spite of bones having been found that bear evident traces of the handiwork of man, it is possible that this and other reports were due to the obrious necessity of having some bird to account for the presence of the eggs.

'The actual introduction of the Apyornis to science took place in 1834, when a French trareller sent Jules Verreaux, the ornithologist, a sketch of a huge egg, saying that he had seen two of that size, one sawed in twain to make bowls, the other, traversed by a stick, serving in the preparation of rice uses somewhat in contrast with the proverbial fragility of egg-shells. A little later another traveller 
procured some fragments of egg-shells, but it was not until 1851 that any entire eggs were obtained, when two were secured, and with a few bones sent to France, where Geoffroy St. Hilaire bestowed upon them the name of Epyornis maximus (the greatest lofty bird). Maximus the eggs remain, for they still hold the record for size; but so far as the bird that is supposed to have laid them is concerned, the name was a little premature, for other and larger species subsequently came to hand. Between the Eyornithes and the Moas Science has had a hard time, for the supply of big words was not large enough to go around, and some had to do duty twice. In the way of generic names we have Dinornis, terrible bird; Apyornis, high bird; Pachyornis, stout bird; and Brontornis, thunder bird, while for specific names there are robustus, maximus, titan ; gravis, heavy; immanis, enormous; crassus, stout; ingens, great; and elephantopus, elephant-footed - truly a goodly array of largesounding words. But to return to the big eggs! Usually we look upon those of the ostrich as pretty large, but an ostrich egg meas- 
ures $4 \frac{1}{2}$ by 6 inches, while that of the AEyornis is 9 by 13 inches; or, to put it another way, it would hold the contents of six ostrichs' eggs, or one hundred and forty-eight hens' eggs, or thirty thousand humming birds' eggs; and while this is rery much smaller than a waterbutt, it is still as large as a bucket, and one or two such eggs might suffice to make an omelet for Gargantua himself.

The size of an egg is no safe criterion of the size of the bird that laid it, for a large bird may lay a small egg, or a small bird a large one. Comparing the egg of the great Moa with that of our Epyornis one might think the latter much the larger bird, say twelve feet in height, when the facts in the case are that while there was no great difference in the weight of the two, that difference, and a superiority of at least two feet in height, are in favor of the bird that laid the smaller egg. The record of large eggs, however, belongs to the Apteryx, a New Zealand bird smaller than a hen, though distantly related to the Moas, which lays an egg about one-third of its own weight, measuring 3 by 5 inches; per- 
haps it is not to be wondered at that the bird lays but two.

Although most of the eggs of these big birds that have been found have literally been unearthed from the muck of swamps, now and then one comes to light in a more interesting manner as, for example, when a perfect egg of Apyornis was found afloat after a hurricane, bobbing serenely up and down with the waves near St. Augustine's Bay, or when an egg of the Moa was exhumed from an ancient Maori grave, where for years it had lain unharmed, safely clasped between the skeleton fingers of the occupant. So far very few of these huge eggs have made their way to this country, and the only egg of Epyornis now on this side of the water is the property of a private individual.

Most recent in point of discovery, but oldest in point of time, are the giant birds from Patagonia, which are burdened with the name of Phororhacida, a name that originated in an error, although the error may well be excused. 'The first fragment of one of these great birds to come to light was a portion of the lower jaw, and this was so massive, so un-bird-like, 


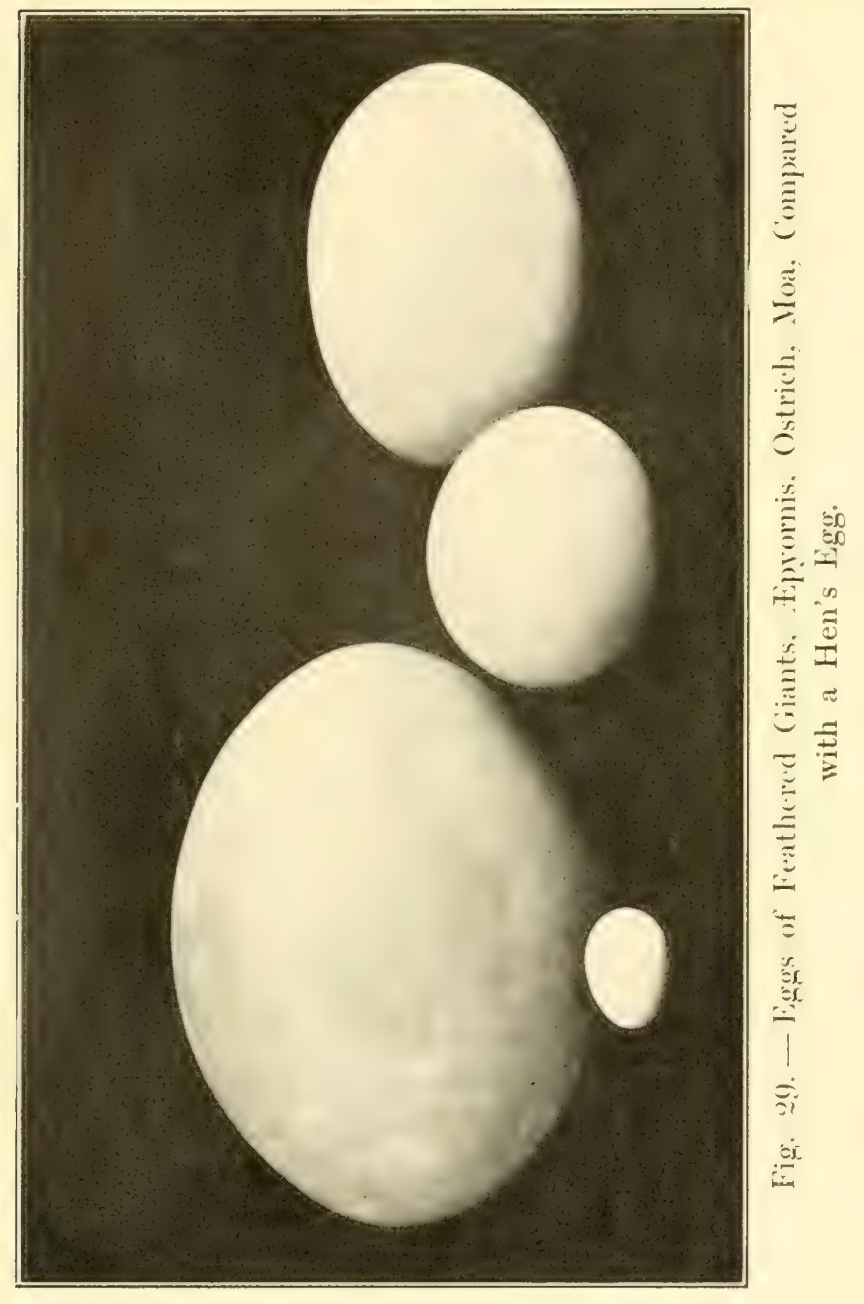



that the finder dubbed it Phororhacos, and so it must remain.

It is a pity that all the large names were used up before this group of birds was discovered, and it is particularly unfortunate that Dinornis, terrible bird, was applied to the rooteating Moas, for these Patagonian birds, with their massive limbs, huge heads and hooked beaks, were truly worthy of such a name; and although in nowise related to the eagles, they may in habit have been terrestrial birds of prey. Not all the members of this family are giants, for as in other groups, some are big and some little, but the largest among them might be styled the Daniel Iambert of the feathered race. Brontornis, for example, the thunder bird, or as the irreverent translate it, the thundering big bird, had leg-bones larger than those of an ox, the drumstick measuring 30 inches in length by $2 \frac{1}{2}$ inches in diameter, or $4 \frac{1}{4}$ inches across the ends, while the tarsus, or lower bone of the leg to which the toes are attached, was $16 \frac{1}{2}$ inches long and $5 \frac{1}{2}$ inches wide where the toes join on. Bear this in mind the next time you see a large turkey, or compare these bones 
with those of an ostrich : but lest you may forget, it may be said that the same bone of a fourteen-pound turkey is 5.1 inches long, and one inch wide at either end, while that of an ostrich measures 19 inches long and 2 inches across the toes, or 3 at the upper end.

If Brontornis was a heary-limbed bird, he was not without near rivals among the Moas, while the great Phororhacos, one of his contemporaries, was not only nearly as large, but quite unique in build. Imagine a bird seven or eight feet in height from the sole of his big, sharp-clawed feet, to the top of his huge head, poise this head on a neck as thick as that of a horse, arm it with a beak as sharp as an icepick and almost as formidable, and you have a fair idea of this feathered giant of the ancient pampas. The head indeed was truly colossal for that of a bird, measuring 23 inches in length by 7 in depth, while that of the racehorse Lexington, and he was a good-sized horse, measures 22 inches long by $5 \frac{1}{2}$ inches deep. The depth of the jaw is omitted because we wish to make as good a case as possible for the bird, and the jaw of a horse is so 
deep as to give him an undue advantage in that respect.

Wre can only speculate on the food of these great birds, and for aught we know to the contrary they may have caught fish, fed upon carrion, or used their powerful feet and huge
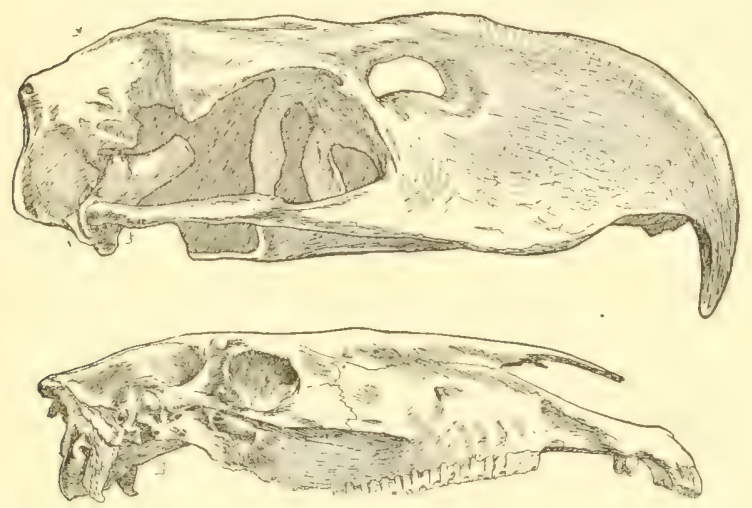

Fig. 30. - Skull of Phororhacos Compared with that of the Race-horse Lexington.

beaks for grubbing roots; but if they were not more or less carnivorous, preying upon such reptiles, mammals and other birds as came within reach, then nature apparently made a mistake in giving them such a formidable equipment of beak and claw. So far as habits 


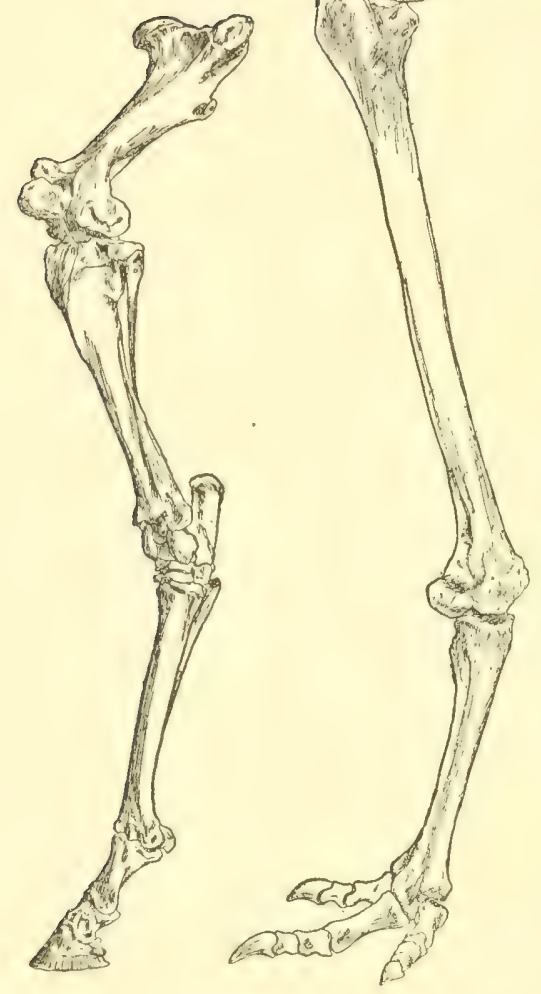

Fig. 31. - Leg of a Horse Compared with that of the Giant Moa.

go we might be justified in calling them cursorial birds of prey.

We really know very little about these Patagonian giants, but they are interesting not only from their great size and astounding skulls, but because of the early age (Miocene) at which they lived and because in spite of their bulk they are in nowise related to the ostriches, but belong near the heron family. As usual, we have no idea why they became extinct, 
but in this instance man is guiltless, for they lived and died long before he made his appearance, and the ever-convenient hypothesis "change of climate" may be responsible for their disappearance.

Something, perhaps, remains to be said concerning the causes which seem to have led to the development of these giant birds, as well as the reasons for their flightless condition and peculiar distribution, for it will be noticed that, with the exception of the African and South American ostriches the great flightless birds as a rule are, and were, confined to uninhabited or sparsely populated islands, and this is equally true of the many small, but equally flightless birds. It is a seemingly harsh law of nature that all living beings shall live in a more or less active struggle with each other and with their surroundings, and that those creatures which possess some slight advantage over their fellows in the matter of speed, or strength, or ability to adapt themselves to surrounding conditions, shall prosper at the expense of the others. In the power of flight, birds have a great safeguard against changes of 
climate with their accompanying variations in the supply of food, and, to a lesser extent, against their various enemies, including man. This power of flight, acquired early in their geological history, has enabled birds to spread orer the length and breadth of the globe as no other group of animals has done, and to thrive under the most rarying conditions, and it would seem that if this power were lost it must sooner or later work harm. Now to-day we find no great wingless birds in thickly populated regions. or where heasts of prey abound; the ostriches roam the desert wastes of Arabia, Africa and South America where men are few and sarage beasts scarce, and against these is placed a fleetness of foot inherited from ancestors who acquired it before man was. The heary cassowaries dwell in the thinly inhabited, thickly wooded islands of Malaysia, where again there are no large carnirores and where the dense regetation is some safeguard against man; the emu comes from the Australian plains. where also there are no four-footed enemies * and where his ancestors

* The dingo, or native dog, is not forgotten, but, like man, it is a comparatively recent animal. 
dwelt in peace before the advent of man. And the same things are true of the Moas, the Apyornithes, the flightless birds of Patagonia, the recent dodo of Mauritius and the solitaire of Rodriguez, each and all of which flourished in places where there were no men and practically no other enemies. Hence we deduce that absence of enemies is the prime factor in the existence of flightless birds, * although presence of food is an essential, while isolation, or restriction to a limited area, plays an important part by keeping together those birds, or that race of birds, whose members show a tendency to disuse their wings. It will be seen that such combinations of circumstances will most naturally be found on islands whose geological history is such that they have had no connection with adjacent continents, or such a very ancient connection that they were not then peopled with beasts of prey, while subsequently their distance from other countries has prevented them from receiving such

* Note that in Tasmania, which is very near Australia, both in space and in the character of its animals, there are two carnivorous mammals, the Tasmanian "Wolf" and the Tasmanian Devil, and no fightless birds. 
population by accident in recent times and has also retarded the arrival of man.

Once established, flightlessness and size play into one another's hands; the flightless bird has no limit placed on its size * while granted a food supply and immunity from man; the larger the bird the less the necessity for wings to escape from four-footed foes. So long as the climate was favorable and man absent, the big, clumsy bird might thrive, but upon the coming of man, or in the face of any unfarorable change of climate, he would be at a serious disadrantage and hence whenever either of these two factors has been brought to bear against them the feathered giants have vanished.

\section{REFERENCES}

There is a fine collection of mounted skicletons of rarious species of Mors in the Muscum of Comparatize Zoology at Cambridge, Mass., and another in the Americun Mruscum of Nutural History, New York. A few

* While we do not know the limit of size to a flying creature, none has as yet been found whose wings would spread over twenty feet from tip to tip, and it is evident that wings larger than this rould demand great strength for their manipulation. 
other slicletons and mumerous bones are to be found in other institutions, but the author is not aware of any egg being in this country. Specimens of the Epyornis are rare in this country, but Mr. Robert Gilfort, of Orange, $N$. J., is the possessor of a iery fine egg. A number of egges hate been sold in London, the prices ranging from $£ 200$ down to $\mathfrak{f}_{4}$ '. , this last being much less than price's paid for egges of the greut ank. But then, the great auk is somechut of a fuel, and there are just cnough eggs in existence to bring one into the market every little while. Besides, the number of egges of the great ank is a fixed quantity, while no one knows how many more of Epyornis remuin to be discosered in the stitumps of Madagascar. No specimens of the grigrantic Patagonian birds are now in this country, but a fine example of one of the smaller forms, Pelycornis, including the only breast-bone yet found, is in the Muscum of Princeton University.

The largest known tibia of a Moa, the longest birdbone known, is in the collection of the C'anterbury Museum, Christchurch, New Zeuland ; it is 3 feet 3 inches long. This, howerer, is exceptional, the measurements of the leg-bones of an ordinary Dinornis marimus being as follows: Femur, 18 inches; tibia, 3.2 inches; tarsus, 19 inches, a total of is feet 9 inches. The egg measures $10 \frac{1}{2}$ by $6 \frac{1}{2}$ inches.

There is plenty of literuture, and rery interesting 
litcrature, about the Moas, but, unfortumately, the best of it is not always accessible, being contained in the "New Zealand Journal of Science" and the "Transactions of the New Zealand Institute." The rolume of "Transactions" for 1893, being vol. xxvi., contains a zery full list of articles relating to the Moas, compiled by Mr. A. Hamilton; it will be found to commence on page :2s9. There is a good article on Moa in Newton's "Dictionary of Birds," a book that should be in ezery library.

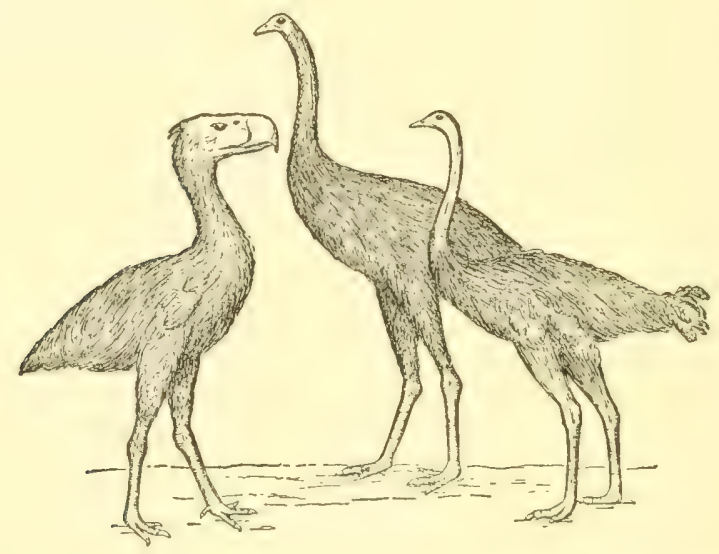

Fig. 32. - The Three Giants, Phororhacos, Moa, Ostrich. 


\section{IX}

\section{THE ANCESTRY OF THE HORSE}

"Said the little Eohippus

I am going to be a horse

And on my middle finger-nails

To run my earthly course."

The American whose ancestors came over in the "Mayflower" has a proper pride in the length of the line of his descent. 'The Englishman whose genealogical tree sprang up at the time of William the Conqueror has, in its eight centuries of growth, still larger occasion for pluming himself on the antiquity of his family. But the pedigree of eren the latter is a thing of yesterday when compared with that of the horse, whose family records, according to Professor Osborn, reach backward for something like $2,000,000$ years. And if, as we have been told, "it is a good thing to have ancestors, but sometimes a little hard on the ancestor," in this 
instance at least the founders of the family have every reason to regard their descendants with undisguised pride. For the horse family started in life in a small way, and the first of the line, the Hyracotherium, was " a little animal no bigger than a fox, and on five * toes he scampered orer 'Tertiary rocks," in the age called Eocene, because it was the morning of life for the great group of mammals whose culminating point was man. At that time, western North America was a country of many lakes, for the most part comparatively shallow, around the reedy margins of which moved a host of animals, quite unlike those of to-day, and yet foreshadowing them, the forerunners of the rhinoceros, tapir, and the horse.

'The early horse - we may call him so by courtesy, although he was then rery far from being a true horse - was an insignificant little creature, apparently far less likely to succeed in life's race than his bulky competitors, and yet, by making the most of their opportunities, * Four, to be exact; but we prefer to sacrifice the foot of the Hyracothere rather than to take liberties with one of the feet of Mrs. Stetson's poem. 
his descendants have survived, while most of theirs have dropped by the wayside; and finally, by the aid of nirn, the horse has be-

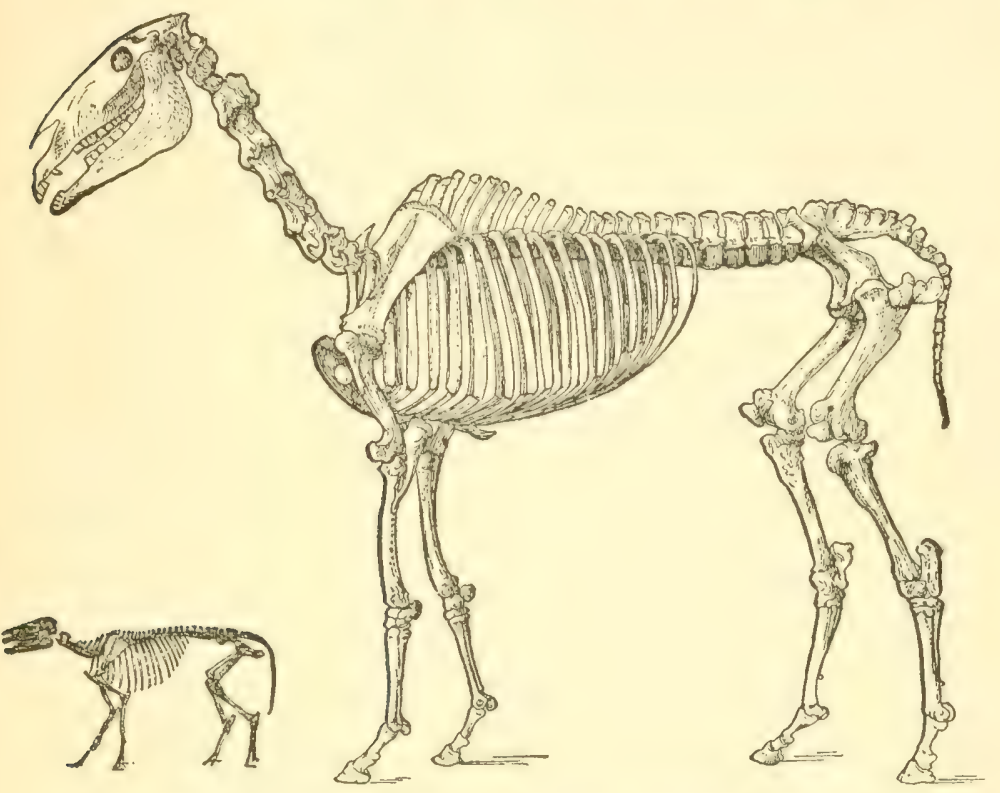

Fig. 33. - Skeleton of the Modern Horse and of His Eocene Ancestor.

come spread orer the length and breadth of the habitable globe.

Now right here it may be asked, How do we know that the little Hyracothere was the 
progenitor of the horse, and how can it be shown that there is any bond of kinship between him and, for example, the great French Percheron? 'There is only one way in which we can obtain this knowledge, and but one method by which the relationship can be shown, and that is by collecting the fossil remains of animals long extinct and comparing them with the bones of the recent horse, a branch of science known as Palæontology. It has taken a very long time to gather the necessary evidence, and it has taken a vast amount of hard work in our western 'Territories, for "the country that is as hot as Hades, watered by stagnant alkali pools, is almost invariably the richest in fossils." Likewise it has called for the expenditure of much time and more patience to put together some of this petrified evidence, fragmentary in every sense of the word, and get it into such shape that it could be handled by the anatomist. Still, the work has been done, and, link by link, the chain has been constructed that unites the horse of to-day with the horse of very many yesterdays.

The very first links in this chain are the re- 
mains of the bronze age and those found among the ruins of the ancient Swiss lake dwellings; but earlier still than these are the bones of horses found abundantly in northern Europe, Asia, and America. 'The individual bones and teeth of some of these horses are scarcely distinguishable from those of to-day, a fact noted in the name, Equus firtermus, applied to one species; and when teeth alone are found, it is at times practically impossible to say whether they belong to a fossil horse or to a modern animal. But when enough scattered bones are gathered to make a fairly complete skeleton, it becomes evident that the fossil horse had a proportionately larger head and smaller feet than his existing relative, and that he was a little more like an ass or zebra, for the latter, spite of his gay coat, is a near relative of the lowly ass. Moreover, primitive man made sketches of the primitive horse, just as he did of the mammoth, and these indicate that the horse of those days was something like an orergrown Shetland pony, low and heavily built, largeheaded and rough-coated. For the old cavedwellers of Europe were intimately acquainted 
with the prehistoric horses, using them for food, as they did almost every animal that fell beneath their flint arrows and stone axes. And if one may judge from the abundance of bones, the horses must have roamed about in bands, just as the horses escaped from civilization roam, or have roamed, over the pampas of South America and the prairies of the West.

The horse was just as abundant in North America in Pleistocene time as in Europe; but there is no evidence to show that it was contemporary with early man in North America, and, even were this the case, it is generally believed that long before the discovery of America the horse had disappeared. And yet, so plentiful and so fresh are his remains, and so much like those of the mustang, that the late Professor Cope was wont to say that it almost seemed as if the horse might have lingered in Texas until the coming of the white man. And Sir William Flower wrote: "There is a possibility of the animal having still existed, in a wild state, in some parts of the continent remote from that which was first visited by the Spaniards, where they were certainly 
unknown. It has been suggested that the horses which were found by Cabot in I La I'lata in 1530 cannot have been introduced."

Still we have not the least little bit of positive proof that such was the case, and although the site of many an ancient Indian village has been carefully explored, no bones of the horse have come to light, or if they have been found, bones of the ox or sheep were also present to tell that the village was occupied long after the advent of the whites. It is also a curious fact that within historic times there have been no wild horses, in the true sense of the word, unless indeed those found on the steppes north of the Sea of Azof be wild, and this is very doubtful. But long before the dawn of history the horse was domesticated in Europe, and Cæsar found the Germans, and even the old Britons, using war chariots drawn by horses for the first use man secms to have made of the horse was to aid him in killing off his fellow-man, and not until comparatively modern times was the animal employed in the peaceful arts of agriculture. The immediate predecessors of these horses were considerably 
smaller, being about the size and build of a pony, but they were very much like a horse in structure, save that the teeth were shorter. As they lived during Pliocene times, they have been named "Pliohippus."

Going back into the past a step farther, though a pretty long step if we reckon by years, we come upon a number of animals very much like horses, save for certain cranial peculiarities and the fact that they had three toes on each foot, while the horse, as every one knows, has but one toe. Now, if we glance at the skeleton of a horse, we will see on either side of the canon-bone, in the same situation as the upper part of the little toes of the Hippotherium, as these three-toed horses are called, a long slender bone, termed by veterinarians the splint bone; and it requires no anatomical training to see that the bones in the two animals are the same. 'The horse lacks the lower part of his side toes, that is all, just as man will very probably some day lack the last bones of his little toe. We find an approach to this condition in some of the Hippotheres even, known as Protohippus, in which the side toes 
are quite small, foreshadowing the time when they shall have disappeared entirely. It may also be noted here that the splint bones of the horses of the bronze age are a little longer than those of existing horses, and that they are never united with the large central toe, while nowadays there is something of a tendency for the three bones to fuse into one, although part of this tendency the writer believes to be due to inflammation set up by the strain of the pulling and hauling the animal is now called upon to do. Some of these three-toed Hippotheres are not in the direct line of ancestry of the horse, but are side branches on the family tree, having become so highly specialized in certain directions that no further progress horseward was possible.

Backward still, and the bones we find in the Miocene strata of the West, belonging to those ancestors of the horse to which the name of Mesohippus has been given because they are midway in time and structure between the horse of the past and present, tell us that then all horses were small and that all had three toes on a foot, while the fore feet bore 
even the suggestion of a fourth toe. From this to our Eocene Hyracothere with four toes is only another long-time step. We may go even beyond this in time and structure, and carry back the line of the horse to animals

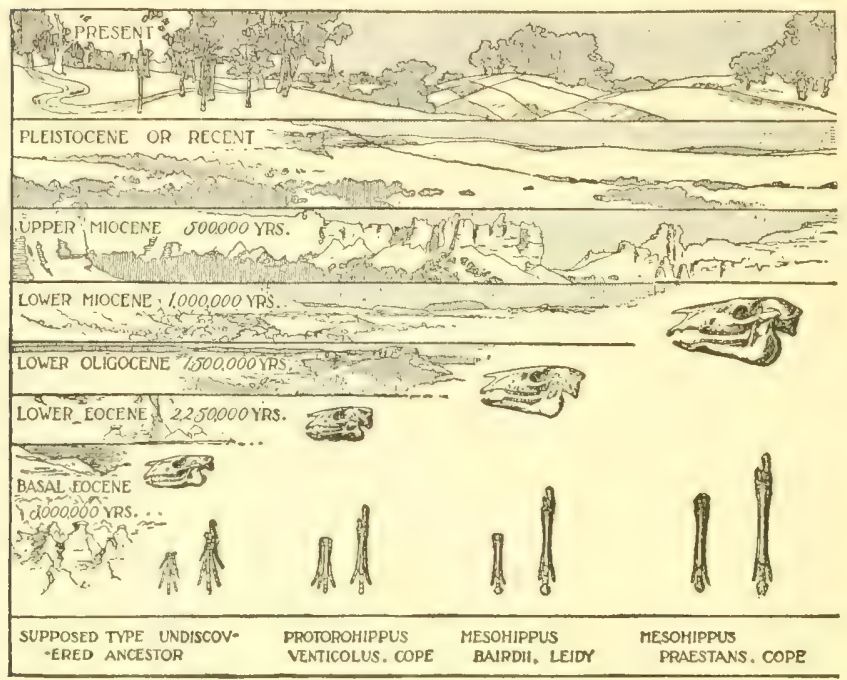

Fig. 34. - The Development

which only remotely resembled him and had five good toes to a foot; but while these contained the possibility of a horse, they made no show of it.

Increase in size and decrease in number of 
the toes were not the only changes that were required to transform the progeny of the $\mathrm{Hy}$ racothere into a horse. 'These are the most evident; but the increased complexity in the structure of the teeth was quite as important.

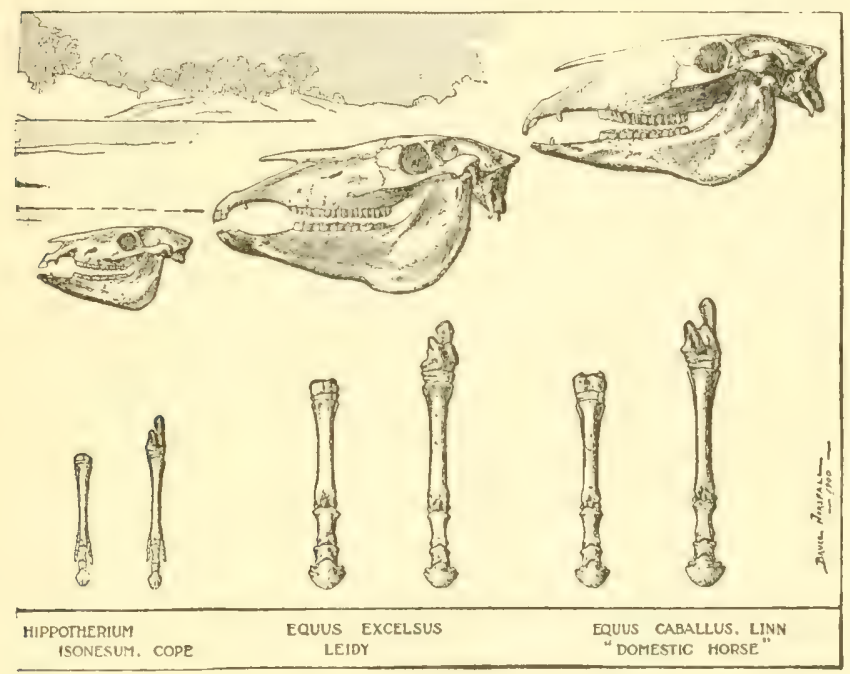

of the Horse.

The teeth of gnawing animals have often been compared to a chisel which is made of a steel plate with soft iron backing, and the teeth of a horse, or of other grass-eating animals, are simply an elaboration of this idea. The hard 
enamel, which represents the steel, is set in soft dentine, which represents the iron, and in use the dentine wears away the faster of the two, so that the enamel stands up in ridges, each tooth becoming, as it is correctly termed, " a grinder." In a horse the plates of enamel form curred, complex, irregular patterns; bat as we go back in time, the patterns become less and less elaborate, until in the Hyracothere, standing at the foot of the family tree, the teeth are very simple in structure. Moreover, his teeth were of limited growth, while those of the horse grow for a considerable time, thus compensating for the wear to which they are subjected.

We have, then, this direct evidence as to the genealogy of the horse, that between the little Eocene IIyracothere and the modern horse we can place a series of animals by which we can pass by gradual stages from one to the other, and that as we come upward there is an increase in stature, in the complexity of the teeth, and in the size of the brain. At the same time, the number of toes decreases, which tells that the animals were 
developing more and more speed; for it is a rule that the fewer the toes the faster the animal : the fastest of birds, the ostrich, has but two toes, and one of these is mostly ornamental; and the fastest of mammals, the horse, has but one.

- All breeders of fancy stock, particularly of pigeons and poultry, recognize the tendency of animals to revert to the forms whence they were derived and reproduce some character of a distant ancestor ; to "throw back," as the breeders term it. If now, instead of reproducing a trait or feature possessed by some ancestor a score, a hundred, or perhaps a thousand years ago, there should reappear a characteristic of some ancestor that flourished 100,000 years back, we should have a seeming abnormality, but really a case of reversion; and the more we become acquainted with the structure of extinct animals and the development of those now living, the better able are we to explain these apparent abnormalities.

Bearing in mind that the two splint bones of the horse correspond to the upper portions of the side toes of the Hippotherium and 
Mesohippus, it is easy to see that if for any reason these should develop into toes, they would make the foot of a modern horse appear like that of his distant ancestor. While such a thing rarely happens, yet now and then nature apparently does attempt to reproduce a horse's foot after the ancient pattern, for occasionally we meet with a horse having, instead of the single toe with which the average horse is satisfied, one or possibly two extra toes. Sometimes the toe is extra in every sense of the word, being a mere duplication of the central toe; but sometimes it is an actual development of one of the splint bones. No less a personage than Julius Casar possessed one of these polydactyl horses, and the reporters of the Daily Roman and the Tiberian Gazette doubtless wrote it up in good journalistic I atin, for we find the horse described as having feet that were almost human, and as being looked upon with great awe. While this is the most celebrated of extra-toed horses, other and more plebeian individuals have been much more widely known through having been exhibited throughout the country under such 
titles as "Clique, the horse with six feet," "the eight-footed Cuban horse," and so on ; and possibly some of these are familiar to readers of this page.

So the collateral evidence, though scanty, bears out the circumstantial proof, derived from fossil bones, that the horse has developed from a many-toed ancestor; and the evidence points toward the little Hyracothere as being that ancestor. It remains only to show some good reason why this derclopment, should have taken place, or to indicate the forces by which it was brought about. IVe have heard much about "the survival of the fittest," a phrase which simply means that those animals best adapted to their surroundings will survive, while those ill adapted will perish. But it should be added that it means also that the animals must be able to adapt themselves to changes in their environment, or to change with it. Living beings cannot stand still indefinitely; they must progress or perish. And this seems to have been the cause for the extinction of the huge quadrupeds that flourished at the time of the three-toed Miocene 
horse. 'They were adapted to their environment as it was; but when the western mountains were thrust upward, cutting off the moist winds from the Pacific, making great changes in the rainfall and climate to the eastward of the Rocky Mountains, these big beasts, slow of foot and dull of brain, could not keep pace with the change, and their race vanished from the face of the earth. 'The day of the little Hyracothere was at the beginning of the great series of changes by which the lake country of the West, with its marshy flats and rank vegetation, became transformed into dry uplands sparsely clad with fine grasses. On these dry plains the more nimblefooted animals would have the advantage in the struggle for existence; and while the fourtoed foot would keep its owner from sinking in soft ground, he was handicapped when it became a question of speed, for not only is a fleet animal better able to flee from danger than his slower fellows, but in time of drouth he can cover the greater extent of territory in search of food or water. So, too, as the rank rushes gave place to fine grasses, often 
browned and withered beneath the summer's sun, the complex tooth had an advantage orer that of simpler structure, while the cuttingteeth, so completely developed in the horse family, enabled their possessors to crop the grass as closely as one could do it with scissors. Likewise, up to a certain point, the largest, most powerful animal will not only conquer, or escape from, his enemies, but prevail over rivals of his own kind as well, and thus it came to pass that those early members of the horse fumily who were preëminent in speed and stature, and harmonized best with their surroundings, outstripped their fellows and transmitted these qualities to their progeny, until, as a result of long ages of natural selection, there was developed the modem horse. The rest man has done: the heary, slow-paced dray horse, the fleet trotter, the huge Percheron, and the diminutive pony are one and all the recent products of artificial selection. 


\section{REFERENCES.}

The best collection of fossil horses, and one specially arranged to illustrate the line of descent of the modern horse, is to be found in the American Muscum of Natural History, New Iork, but some good specimens, of particular interest because they were described by Professor Marsh and studied by Huxley are in the Yale Lniversity Museum. They are referred to in Hualey's "American Addresses; Lectures on Evolution" "The Horse," by Sir W. H. Flower, discusses the horse in a popular manner from various points of view and contains numerous references to books and articles on the subject from which anyone wishing for further information could obtain it. 


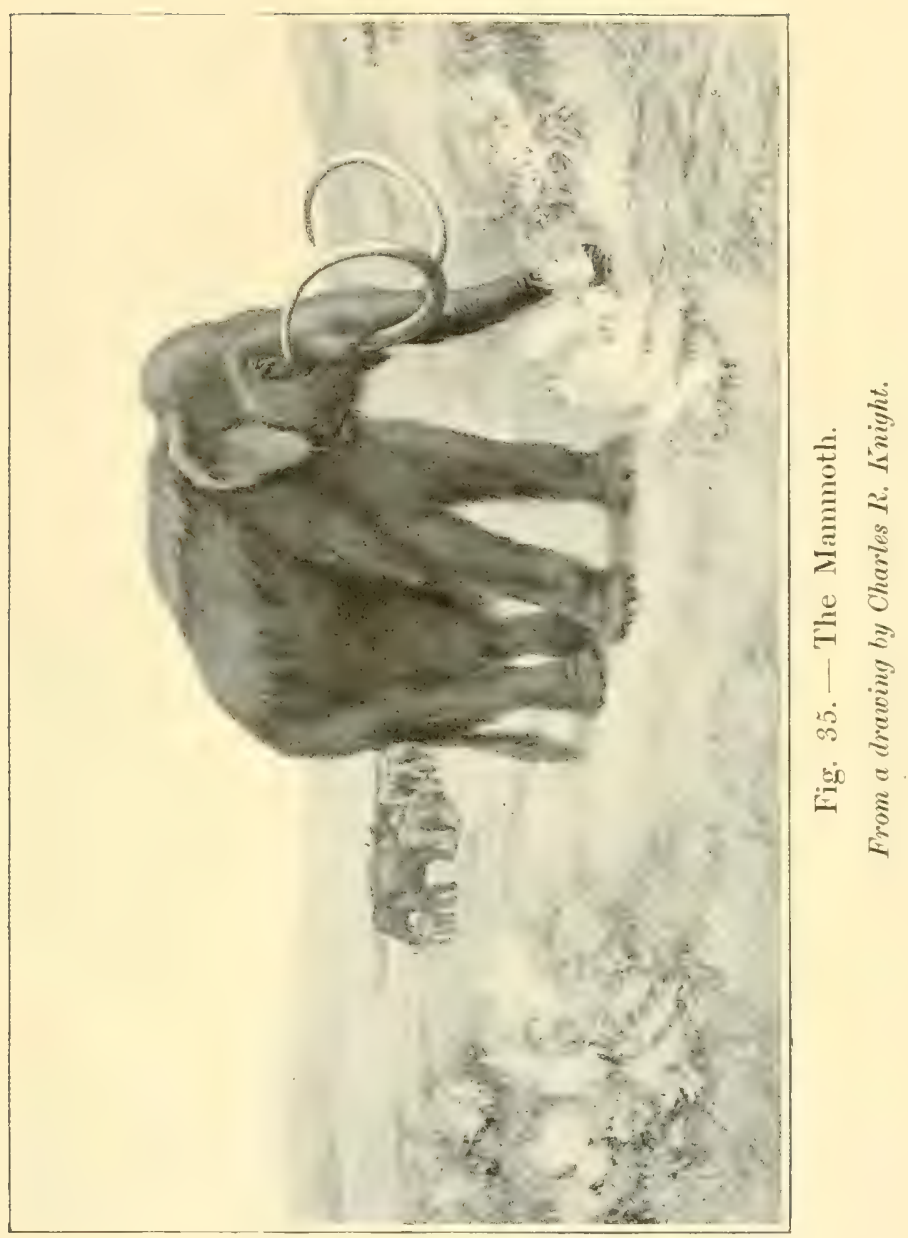





\section{X \\ THE MAMMOTH}

"His legs were as thick as the bole of the beech, His tusks as the buttonwood white, While his lithe trunk wound like a sapling around An oak in the whirlwind's might."

In the October number of McClure's Magazine for 1899 was published a short story, "The Killing of the Mammoth," by "H. Tulieman," which, to the amazement of the editors, nas taken by many readers not as fiction, but as a contribution to natural history. Immediately after the appearance of that number of the magasine, the authorities of the Smithsonian Institution, in which the author had located the remains of the beast of his fancy, were beset with visitors to see the stuffed mammoth, and the daily mail of the Magazine, as well as that of the Smithsonian Institution, was, filled with inquivies for more information and for requests to settle wagers as to whether it was a true story or not. The contribution in question was printed purely as fiction, with no idea of misleading the public, and was entitled a story in the table of contents. Te doubt if amy nriter of realistic fiction ever had a more general and convincing proof of' success.

\section{Aвout three centuries ago, in 1696, a Russian, one Ludloff by name, described some bones


belonging to what the Tartars called "Mamantu "; later on, Blumenbach pressed the common name into scientific use as "Mammut," and Cuvier gallicized this into "Mammouth," whence by an easy transition we get our familiar mammoth. We are so accustomed to use the word to describe anything of remarkable size that it would be only natural to suppose that the name Mammoth was given to the extinct elephant because of its extraordinary bulk. Exactly the reverse of this is true, however, for the word came to have its present meaning because the original possessor of the name was a huge animal. The Siberian peasants called the creature "Mamantu," or "ground-dweller," because they believed it to be a gigantic mole, passing its life beneath the ground and perishing when by any accident it saw the light. 'The reasoning that led to this belief was very simple and the logic very good; no one had ever seen a live Mamantu, but there were plenty of its bones lying at or near the surface; consequently if the animal did not live above the ground, it must dwell below.

To-day, nearly every one knows that the 
mammoth was a sort of big, hairy elephant, now extinct, and nearly every one has a general idea that it lived in the North. There is some uncertainty as to whether the mammoth was a mastodon, or the mastodon a mammoth, and there is a great deal of misconception as to the size and abundance of this big beast. It may be said in passing that the mastodon is only a second or third cousin of the mammoth, but that the existing elephant of Asia is a very near relative, certainly as near as a first cousin, possibly a very great grandson. Popularly, the mammoth is supposed to have been a colossus somewhere from twelve to twenty feet in height, beside whom modern elephants would seem insignificant; but as " trout lose much in dressing," so mammoths shrink in measuring, and while there were doubtless Jumbos among them in the way of individuals of exceptional magnitude, the majority were decidedly under Jumbo's size. The only mounted mammoth skeleton in this country, that in the Chicago Academy of Sciences, is one of the largest, the thigh-bone measuring five feet one inch in length, or a foot more than that of Jumbo; 
and as Jumbo stood eleven feet high, the rule of three applied to this thigh-bone would give the living animal a height of thirteen feet eight inches. 'The height of this specimen is given as thirteen feet in its bones, with an estimate of fourteen feet in its clothes; but as the skeleton is obviously mounted altogether too high, it is pretty safe to say that thirteen feet is a good, fair allowance for the height of this animal when alive. As for the majority of mammoths, they would not average more than nine or ten feet high. Sir Samuel Baker tells us that he has seen plenty of wild African elephants that would exceed Jumbo by a foot or more, and while this must be accepted with caution, since unfortunately he neglected to put a tape-line on them, yet Mr. Thomas Baines did measure a specimen twelve feet high. This, coupled with Sir Samuel's statement, indicates that there is not so much difference between the mammoth and the elephant as there might be. This applies to the mammoth par excellence, the species known scientifically as Elephas primigenius, whose remains are found in many parts of the North- 
ern Hemisphere and occur abundantly in Siberia and Alaska. There were other elephants than the mammoth, and some that exceeded him in size, notably Elephas meridionalis of southern Europe, and Elephas columbi of our Southern and Western States, but even the largest cannot positively be asserted to have exceeded a height of thirteen feet. 'Tusks offer convenient terms of comparison, and those of an average fully grown mammoth are from eight to ten feet in length; those of the famous St. Petersburg specimen and those of the huge specimen in Chicago measuring respectively nine feet three inches, and nine feet eight inches. So far as the writer is aware, the largest tusks actually measured are two from Alaska, one twelve feet ten inches long, weighing 190 pounds, reported by Mr. Jay Beach; and another eleven feet long, weighing 200 pounds, noted by Mr. 'T. I. Brevig. Compared with these we have the big tusk that used to stand on Fulton Street, New York, just an inch under nine feet long, and weighing $18+$ pounds, or the largest shown at Chicago in 1893, which was seven feet six 
inches long, and weighed 176 pounds. The largest, most beautiful tusks, probably, ever seen in this country were a pair brought from Zanzibar and displayed by Messrs. 'Tiffany \& Company in 1900 . 'The measurements and weights of these were as follows : length along outer curve, ten feet and three-fourths of an inch, circumference one foot, eleven inches, weight, 224 pounds; length along outer curve, ten feet, three and one-half inches, circumference two feet and one-fourth of an inch, weight, 239 pounds.

For our knowledge of the external appearance of the mammoth we are indebted to the more or less entire examples which have been found at various times in Siberia, but mainly to the noted specimen found in 1799 near the Lena, embedded in the ice, where it had been reposing, so geologists tell us, anywhere from 10,000 to 50,000 years. How the creature gradually thawed out of its icy tomb, and the tusks were taken by the discoverer and sold for ivory; how the dogs fed upon the flesh in summer, while bears and wolves feasted upon it in winter; how the animal was within an 
ace of being utterly lost to science when, at the last moment, the mutilated remains were rescued by Mr. Adams, is an old story, often

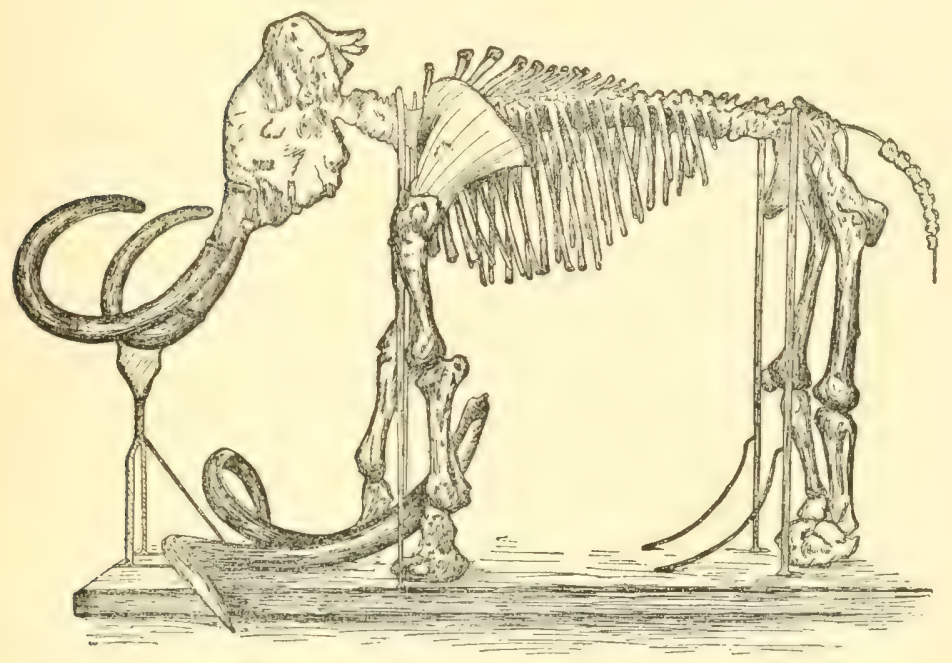

Fig. 36. - Skeleton of the Mammoth in the Royal Museum of St. Petersburg.

told and retold. Suffice it to say that, besides the bones, enough of the beast was preserved to tell us exactly what was the covering of this 
ancient elephant, and to show that it was a creature adapted to withstand the northern cold and fitted for living on the branches of the birch and hemlock.

The exact birthplace of the mammoth is as uncertain as that of many other great characters; but his earliest known resting-place is in the Cromer Forest Beds of England, a country inhabited by him at a time when the German Ocean was dry land and Great Britain part of a peninsula. Here his remains are found today, while from the depths of the North Sea the hardy trawlers hare dredged hundreds, aye thousands, of mammoth teeth in company with soles and turbot. If, then, the mammoth origated in western Europe, and not in that great graveyard of fossil elephants, northern India, eastward he went spreading over all Europe north of the Pyrenees and Alps, sare only Scandinavia, whose glaciers offered no attractions, scattering his bones abundantly by the wayside to serve as marvels for future ages. Strange indeed have been some of the tales to which these and other elephantine remains have given rise when they came to light in the 
good old days when knowledge of anatomy was small and credulity was great. 'The least absurd theory conceming them was that they were the bones of the elephants which IIannibal brought from Africa. Occasionally they were brought forward as irrefutable evidences of the deluge; but usually they figured as the bones of giants, the most famous of them being known as 'Teutobochus, King of the Cimbri, a lusty warrior said to have had a height of nineteen feet. Somewhat smaller, but still of respectable height, fourteen feet, was "Littell Johne" of Scotland, whereof Hector Boece wrote, concluding, in a moralizing tone, " Be quilk (which) it appears how extravegant and squaire pepill grew in oure regioun afore they were effeminat with lust and intemperance of mouth." More than this, these bones have been rencrated in Greece and Rome as the remains of pagan heroes, and later on worshipped as relics of Christian saints. Did not the church of Valencia possess an elephant tooth which did duty as that of St. Christopher, and, so late as $\mathbf{1 7 8 9}$, was not a thigh-bone, figuring as the arm-bone of a saint, carried in 
procession through the streets in order to bring rain?

Out of Europe eastward into Asia the mammoth took his way, and haring peopled that vast region, took advantage of a land comnection then existing between Asia and North America and walked over into Alaska, in company with the forerumners of the bison and the ancestors of the mountain sheep and Alaskan brown bear. Still eastward and southward he went, until he came to the Atlantic coast, the latitude of southern New York roughly marking the southern boundary of the broad domain over which the mammoth roamed undisturbed.* Not that of necessity all this vast area was occupied at one time; but this was the range of the mammoth during Pleistocene time, for over all this region his bones and tecth are found in greater or less abundance and in varying conditions of preservation. In regions like parts of Siberia and Alaska, where

* This must be taken as a very general statement, as the distinction between and habitats of Elephas primigenins and Elephas columbi, the southern mammoth, are not satisfactorily determined; moreover, the two species overlap through a wide area of the West and Northwest. 
the bones are entombed in a wet and cold, often icy, soil, the bones and tusks are almost as perfectly preserved as though they had been deposited but a score of years ago, while remains so situated that they have been subjected to varying conditions of dryness and moisture are always in a fragmentary state. As previously noted, several more or less entire carcasses of the mammoth have been discovered in Siberia, only to be lost; and, while no entire animal has so far been found in Alaska, some day one may yet come to light. 'That there is some possibility of this is shown by the discovery, recorded by Mr. Dall, of the partial skeleton of a mammoth in the bank of the Yukon with some of the fat still present, and although this had been partially converted into adipocere, it was fresh enough to be used by the natives for greasing, not their boots, but their boats. And up to the present time this is the nearest approach to finding a live mammoth in Alaska.

As to why the mammoth became extinct, we know absolutely nothing, although various theories, some much more ingenious than plaus- 
ible, have been advanced to account for their extermination - they perished of starvation; they were overtaken by floods on their supposed migrations and drowned in detachments; they fell through the ice, equally in detachments, and were swept out to sea. But all we can safely say is that long ages ago the last one perished off the face of the earth. Strange it is, too, that these mighty beasts, whose bulk was ample to protect them against four-footed foes, and whose woolly coat was proof against the cold, should have utterly vanished. 'They ranged from England eastward to New York, almost around the world ; from the Alps to the Arctic Ocean; and in such numbers that to-day their tusks are articles of commerce, and fossil ivory has its price current as well as wheat. Mr. Boyd Dawkins thinks that the mammoth was actually exterminated by early man, but, even granting that this might be true for southern and western Europe, it could not be true of the herds that inhabited the wastes of Siberia, or of the thousands that flourished in Mlaska and the western United States. So far as man is concerned, 
the mammoth might still be living in these localities, where, before the discovery of gold drew thousands of miners to Alaska, there were vast stretches of wilderness wholly untrodden by the foot of man. Neither could this theory account for the disappearance of the mastodon from North America, where that animal covered so vast a stretch of territory that man, unaided by nature, could have made little impression on its numbers. 'That many were swept out to sea by the flooded rivers of Siberia is certain, for some of the low islands off the coast are said to be formed of sand, ice, and bones of the mammoth, and thence, for hundreds of years, have come the tusks which are sold in the market beside those of the African and Indian elephants.

That man was contemporary with the mammoth in southern Europe is fairly certain, for not only are the remains of the mammoth and man's flint weapons found together, but in a few instances some primeval Landseer graved on slate, ivory, or reindeer antler a sketchy outline of the beast, somewhat impressionistic perhaps, but still, like the work of a true artist, 
preserving the salient features. We see the curved tusks, the snaky trunk, and the shaggy coat that we know belonged to the mammoth, and we may feel assured that if early man did not conquer the clumsy creature with fire and flint, he yet gazed upon him from the safe vantage point of some lofty tree or inaccessible rock, and then went home to tell his wife and neighbors how the animal escaped because his bow missed fire. 'That man and mammoth lived together in North America is uncertain; so far there is no evidence to show that they did, although the absence of such evidence is no proof that they did not. 'That any live mammoth has for centuries been seen on the Alaskan tundras is utterly improbable, and on Mr. C. H. Townsend seems to rest the responsibility of having, though quite unintentionally, introduced the Alaskan Live Mammoth into the columns of the daily press. It befell in this wise: Among the raried duties of our revenue marine is that of patrolling and exploring the shores of arctic Alaska and the waters of the adjoining sea, and it is not so many years ago that the cutter Corrin, if memory serves 
aright, held the record of farthest north on the Pacific side. On one of these northern trips, to the Kotzebue Sound region, famous for the abundance of its deposits of mammoth bones, * the Corwin carried Mr. 'Townsend, then naturalist to the United States Fish Commission. At Cape Prince of Wales some natives came on board bringing a few bones and tusks of the mammoth, and upon being questioned as to whether or not any of the animals to which they pertained were living, promptly replied that all were dead, inquiring in turn if the white men had ever seen any, and if they knew how these animals, so vastly larger than a reindeer, looked.

Fortunately, or unfortunately, there was on board a text-book of geology containing the well-known cut of the St. Petershurg mammoth, and this was brought forth, greatly to the edification of the natives, who were delighted at recognizing the curved tusks and the bones they knew so well. Next the na-

* Elephant Point, at the mouth of the Buckland River, is so named from the numbers of mammoth bones which have accumulated there. 
tives wished to know what the outside of the creature looked like, and as Mr. 'Townsend had been at Ward's establishment in Rochester when the first copy of the Stuttgart restoration was made, he rose to the emergency, and made a sketch. 'This was taken ashore, together with a copy of the cut of the skeleton that was laboriously made by an Innuit sprawled out at full length on the deck. Now the Innuits, as Mr. 'Townsend tells us, are great gadabouts, making long sledge journeys in winter and equally long trips by boat in summer, while each season they hold a regular fair on Kotzebue Sound, where a thousand or two natives gather to barter and gossip. On these journeys and at these gatherings the sketches were no doubt passed about, copied, and recopied, until a large number of Innuits had become well acquainted with the appearance of the mammoth, a knowledge that naturally they were well pleased to display to any white visitors. Also, like the Celt, the Alaskan native delights to give a "soft answer," and is always ready to furnish the kind of information desired. Thus in due time the news- 
paper man learned that the Alaskans could make pictures of the mammoth, and that they had some knowledge of its size and habits; so with inference and logic quite as good as that of the 'Tungusian peasant, the reporter came to the conclusion that somewhere in the frozen wilderness the last survivor of the mammoths must still be at large. And so, starting on the Pacific coast, the Live Mammoth story wandered from paper to paper, until it had spread throughout the length and breadth of the United States, when it was captured by Mr. Tukeman, who with much artistic color and some realistic touches, transferred it to McClure's Magazine, and - unfortunately for the officials thereof - to the Smithsonian Institution.

And now, once for all, it may be said that there is no mounted mammoth to awe the visitor to the national collections or to any other; and yet there seems no good and conclusive reason why there should not be. True, there are no live mammoths to be had at any price; neither are their carcasses to be had on demand; still there is good reason to believe 
that a much smaller sum than that said to have been paid by Mr. Conradi for the mammoth which is not in the Smithsonian Institution, would place one there.* It probably could not be done in one year; it might not be possible in five years; but should any man of means wish to secure enduring fame by showing the world the mammoth as it stood in life, a hundred centuries ago, before the dawn of even tradition, he could probably accomplish the result by the expenditure of a far less sum than it would cost to participate in an international yacht race.

* Since these lines vere written another fine example of the Mammoth has been discovered in Siberia and even now (Oct., 1901) an expedition is on its nay to secure the shin and skeleton for the Academy of Natural Sciences at St. Petersburg. 


\section{REFERENCES}

The mounted skeleton of the mammoth in the muscum of the Chicago Academy of Science is still the only one on cxhibition in the Lnited States; this specimen is probably the Southern Mammoth, Elephas columbi, a species, or race, characterized by its great size and the coarse structure of the tecth. Remains of the mammoth are common enough but, save in Alasta, they are usually in a poor state of preserzation or consist of isolated bones or tecth. A great many shicletons of mammoth haze been found by gold miners in Alasta, and with proper care some of these could undoubtedly hate been secured. Naturally, howezer, the miners do not fed like taking the time and trouble to exhume bones whose value is uncertain, while the cost of transportation precludes the bringing out of many specimens.

Some reports of mammoths have been based on the bones of whales, including a skull that was figured in the daily papers.

Almost ezery museum has on exhibition tecth of the mammoth, and there is a skull, though from a small individual, of the Southern Mammoth in the American Museum of Natural History, New York.

The tusk obtained by Mr. Beach and mentioned in the text still holds the record for mammoth tusk's. The 
greatest development of tusks occurred in Elephas ganesa, a species found in Pliocene deposits of the Siwalik Hills, India. This species appears not to have excecded the existing elephant in bulk, but the tushs are twelte feet nine inches long, and two feet two inches in circumfercne. How the animal ever carried them is a mystery, both on account of their size and their enormons leverage. As for tecth, an upper grinder of Elephas columbi in the United Stutes National Muscum is ten and onc-half inches high, nine inches wide, the grinding face being eight by five inches. This tooth, which is unusually perfect, retaining the outer covering of cement, came from Afton, Indian Territory, and weighs a little ower fiftecn pounds. The lower tooth, shown in Fig. 3S, is twelve inches long, and the grinding fuce is nine by three and one-half inches; this is also from Elephas columbi. Grinders of the Northern Mammoth are smaller, and the plates of enamel thimer, and closer to one another. Mr. F. E. Andrews, of Gunsight, Texas, reports having found a femur, or thigh-bone five feet four inches long, and a humerus measuring four fect three inches, these being the largest bones on record indicating an animal fourteen feet high.

There is a vast amount of literature relating to the mammoth, some of it very untrustworthy. A list of all discoveries of specimens in the flesh is given by Nordens- 
kiold in "The Voyage of the V'ga," and "The LIammoth and the Flood," by Sir Henry Hozorth, is a mine of information. Mr. Tozinsend's "Alaska Lize-1Lammoth Story" may be found in "Forest and Stream" for August 14, 1897.

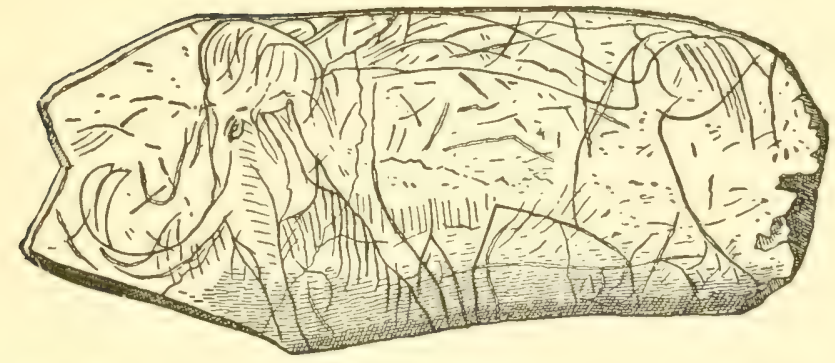

Fig. 37. - The Nammoth as Engraved by a Primitive Artist on a Piece of Mammoth Tusk. 


\section{XI}

\section{THE MASTODON}

\section{" . . . who shall place}

A limit to the giant's unchained strength?"

The name mastodon is given to a number of species of fossil elephants differing from the true elephants, of which the mammoth is an example, in the structure of the teeth. In the mastodons the crown, or grinding face of the tooth, is formed by more or less regular $\Lambda$-shaped cross ridges, covered with enamel, while in the elephants the enamel takes the form of narrow, pocket-shaped plates, set upright in the body of the tooth. Moreover, in the mastodons the roots of the teeth are long prongs, while in the elephants the roots are small and irregular. A glance at the cuts will show these distinctions better than they can be explained by words. Back in the past, however, we meet, as we should if there is any truth 
in the theory of evolution, with elephants having an intermediate pattern of teeth.

'There is usually, or at least often, another point of difference between elephants and mastodons, for many of the latter not only had tusks in the upper, but in the lower jaw, and these are never found in any of the true elephants. The lower tusks are longer and larger
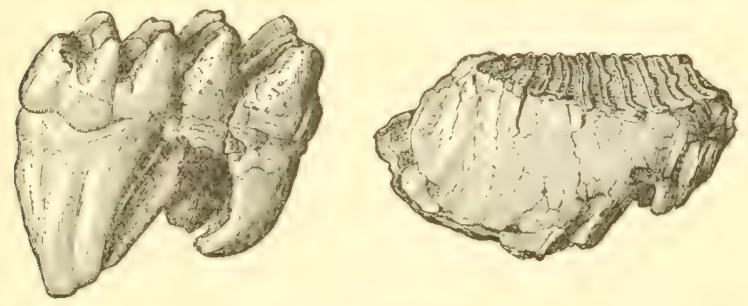

Fig. 38. - Tooth of Mastodon and of Mammoth.

in the earlier species of mastodon than in those of more recent age and in the latest species, the common American mastodon, the little lower tusks were usually shed early in life. These afford some hints of the relationships of the mastodon; for in Europe are found remains of a huge beast well called Dinotherium, or terrible animal, which possessed lower tusks only, and these, instead of sticking out 
from the jaw are bent directly downwards. No perfect skull of this creature has yet been found, but it is believed to have had a short trunk. For a long time nothing but the skull was known, and some naturalists thought the mimal to have been a gigantic manatee, or sea cow, and that the tusks were used for tearing food from the bottom of rivers and for anchoring the animal to the bank, just as the walrus uses his tusks for digging clams and climbing out upon the ice. In the first restorations of Dinotherium it is represented lying amidst reeds, the feet concealed from view, the head alone visible, but now it is pictured as standing erect, for the discovery of massive legbones has definitely settled the question as to whether it did or did not have limbs.

'There is another hint of relationship in the upper tusks of the earlier mastodons, and this is the presence of a band of enamel rumning down each tusk. In all gnawing animals the front, cutting teeth are formed of soft dentine, or ivory, faced with a plate of enamel, just as the blade of a chisel or plane is formed of a plate of tempered steel backed with soft iron; 
the object of this being the same in both tooth and chisel, to keep the edge sharp by wearing away the softer material. In the case of the chisel this is done by a man with a grindstone, but with the tooth it is performed automatically and more pleasantly by the gnawing of food. In the mastodon and elephant the tusks, which are the representatives of the cutting teeth of rodents, are wide apart, and of course do not gnaw anything, but the presence of these enamel bands hints at a time when they and their owner were smaller and differently shaped, and the teeth were used for cutting. 'Thus, great though the disparity of size may be, there is a suggestion that through the mastodon the elephant is distantly related to the mouse, and that, could we trace their respective pedigrees far enough, we might find a common ancestor.

'This presence of structures that are apparently of no use, often worse than useless, is regarded as the survival of characters that once served some good purpose, like the familiar buttons on the sleeve or at the back of a man's coat, or the bows and ruffles on a woman's 
dress. We are told that these are put on "to make the dress look pretty," but the student regards the bows as vestiges of the time when there were no buttons and hooks and eyes had not been invented, and dresses were tied together with strings or ribbons. As for ruffles, they took the place of flounces, and flounces are vestiges of the time when a young woman wore the greater part of her wardrobe on her back, putting on one dress above another, the bottoms of the skirts showing like so many flounces. So buttons, ruffles, and the vermiform appendix of which we hear so much all fall in the category of restigial structures.

Where the mastodons originated, we know not: Señor Ameghino thinks their ancestors are to be found in Patagonia, and he is very probably wrong; Professor Cope thought they came from Asia, and he is probably right; or they may have immigrated from the convenicnt Antarctica, which is called up to account for various facts in the distribution of animals.*

* During the past year, 1901, Mr. C. W. Andrens of the British Muscum has discovered in Egypt a small and primitive species of mastodon, also the remains of another animal which he 
Neither cio we at present know just how many species of mastodons there may have been in the Western Hemisphere, for most of them are known from scattered teeth, single jaws, and odd bones, so that we cannot tell just what differences may be due to sex or individual variation. It is certain, however, that several distinct kinds, or species, have inhabited various parts of North Amcrica, while remains of others occur in South America. T'Th mastodon, however, the one most recent in point of time, and the best known because its remains are scattered far and wide over pretty much the length and breadth of the United States, and are found also in southern and western Canada, is the well-named Mastodon americanus, ${ }^{*}$ and unless otherwise specified this alone will be meant when the name mastodon is used. In some localities the mastodon seems to have abounded, but between the Hudson and Connecticut Rivers indications of its former pres

thinks may be the long sought ancestor of the elephant family, which includes the mammoth and mastodon.

* This has also been called giganteus and ohioticus, but the name americanus claims priority, and should therefore be used. 
ence are rare, and east of that they are practically wanting. 'The best preserved specimens come from Ulster and Orange Counties, New York, for these seem to have furnished the animal with the best facilities for getting mired. Just west of the Catskills, parallel with the valley of the Hudson, is a series of meadows, bogs, and pools marking the sites of swamps that came into existence after the recession of the mighty ice-sheet that long covered eastern North America, and in these many a mastodon, seeking for food or water, or merely wallowing in the mud, stuck fast and perished miserably. And here to-day the spade of the farmer as he sinks a ditch to drain what is left of some beaver pond of bygone days, strikes some bone as brown and rugged as a root, so like a piece of water-soaked wood that nine times out of ten it is taken for a fragment of tree-trunk.

The first notice of the mastodon in North America goes back to 1712, and is found in a letter from Cotton Mather to Dr. Woodward (of England?) written at Boston on November $17 \mathrm{th}$, in which he speaks of a large work in 
manuscript entitled Biblia Americana, and gives as a sample a note on the passage in Genesis (VI. 4) in which we read that "there were giants in the earth in those days." We are told that this is confirmed by "the bones and teeth of some large animal found lately in Albany, in New England, which for some reason he thinks to be human; particularly a tooth brought from the place where it was found to New York in $\mathbf{1 7 0 5}$, being a very large grinder, weighing four pounds and three quarters; with a bone supposed to be a thigh-bone, seventeen feet long," the total length of the body being taken as serenty-five feet. 'Thus bones of the mastodon, as well as those of the mammoth, have done duty as those of giants.

And as the first mastodon remains recorded from North America came from the region west of the Hudson, so the first fairly complete skeleton also came from that locality, secured at a very considerable outlay of money and a still more considerable expenditure of labor by the exertions of C. IV. Peale. This specimen was described at some length by Rembrandt Peale in a privately printed pam- 
phlet, now unfortunately rare, and described in some respects better than has been done by any subsequent writer, since the points of difference between various parts of the mastodon and elephant were clearly pointed out. 'This skeleton was exhibited in London, and afterwards at Peale's Museum in Philadelphia where, with much other valuable material, it was destroyed by fire.

Struck by the evident crushing power of the great ridged molars, Peale was led to believe that the mastodon was a creature of carnivorous habits, and so described it, but this error is excusable, the more that to this day, when the mastodon is well known, and its description published time and again in the daily papers, finders of the teeth often consider them as belonging to some huge beast of prey.

Since the time of Peale several fine specimens have been taken from Ulster and Orange Counties, among them the well-known "Warren Mastodon," and there is not the slightest doubt that many more will be recovered from the meadows, swamps, and pond holes of these two counties. 


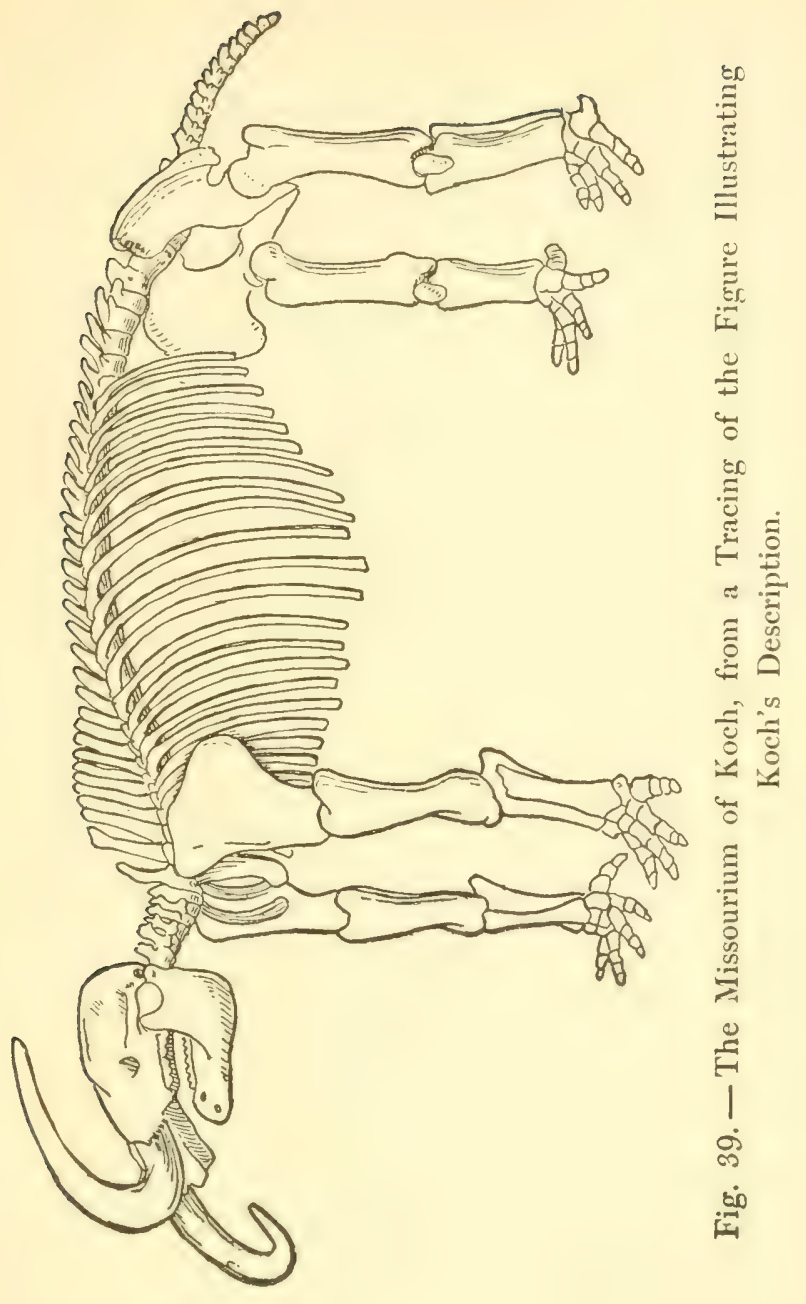


'The next mastodon to appear on the scene was the so-called Missourium of Albert Koch, which he constructed somewhat as he did the Hydrarchus (see p. 61) of several individuals pieced together, thus forming a skeleton that was a monster in more ways than one. 'To heighten the effect, the curved tusks were so placed that they stood out at right angles to the sides of the head, like the swords upon the axles of ancient war chariots. Like Peale's specimen this was exhibited in London, and there it still remains, for, stripped of its superfluous bones, and remounted, it may now be seen in the British Museum.

Many a mastodon has come to light since the time of Koch, for while it is commonly supposed that remains of the animal are great rarities, as a matter of fact they are quite common, and it may safely be said that during the seasons of ditching, draining, and well-digging not a week passes without one or more mastodons being unearthed. Not that these are complete skeletons, very far from it, the majority of finds are scattered teeth, crumbling tusks, or massive leg-bones, but still the 
mastodon is far commoner in the museums of this country than is the African elephant, for at the present date there are eleven of the former to one of the latter, the single skeleton of African elephant being that of Jumbo in the American Museum of Natural History. If one may judge by the abundance of bones, mastodons must have been very numerous in some farored localities such as parts of Michigan, Florida, and Missouri and about lig Bone Lick, Ky. I'erhaps the most noteworthy of all deposits is that at Kimmswick, about twenty miles south of St. Louis, where in a limited area Mr. I. IV. Beehler has exhumed bones representing several hundred individuals, varying in size from a mere baby mastodon up to the great tusker whose wornout teeth proclaim that he had reached the limit of even mastodonic old age. The spot where this remarkable deposit was found is at the foot of a bluff near the junction of two little streams, and it seems probable that in the days when these were larger the spring floods swept down the bodies of animals that had perished during the winter to ground in 
an eddy beneath the bluff. Or as the place abounds in springs of sulphur and salt water it may be that this was where the animals assembled during cold weather, just as the moas are believed to have gathered in the swamps of New Zealand, and here the weaker died and left their bones.

The mastodon must have looked very much like any other elephant, though a little shorter in the legs and somewhat more heavily built than either of the living species, while the head was a trifle flatter and the jaw decidedly longer. The tusks are a variable quantity, sometimes merely bowing outwards, often curving upwards to form a half circle; they were never so long as the largest mammoth tusks, but to make up for this they were a shade stouter for their length. As the mastodon ranged well to the north it is fair to suppose that he may have been covered with long hair, a supposition that seems to be borne out by the discovery, noted by Rembrandt Peale, of a mass of long, coarse, woolly hair buried in one of the swamps of Ulster County, New York. And with these facts in mind, aided by photo- 


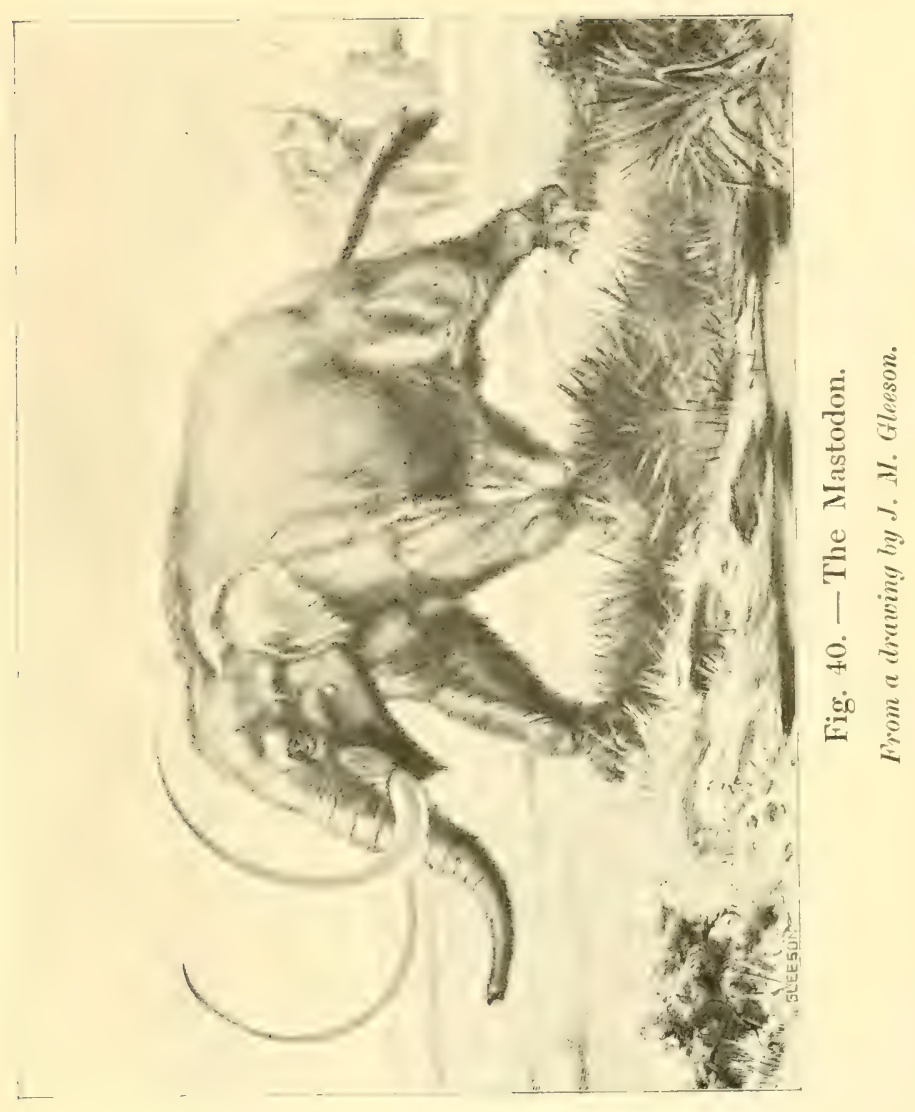



graphs of various skeletons of mastodons, Mr. Gleeson made the restoration which accompanies this chapter.

As for the size of the mastodon, this, like that of the mammoth, is popularly much overestimated, and it is more than doubtful if any attained the height of a full-grown African elephant. 'The largest femur, or thigh-bone, that has come under the writer's notice was one he measured as it lay in the earth at Kimmswick, and this was just four feet long, three inches shorter than the thigh-bone of Jumbo. Several of the largest thigh-bones measured show so striking an unanimity in size, between 46 and 47 inches in length, that we may be pretty sure they represent the average old "bull" mastodon, and if we say that these animals stood ten feet high we are probably doing them full justice. An occasional tusk reaches a length of ten feet, but seren or eight is the usual size, with a diameter of as many inches, and this is no larger than the tusks of the African elephant would grow if they had a chance. It is painful to be obliged to scale down the mastodon as we have 
just done the mammoth, but if any reader knows of specimens larger than those noted, he should by all means publish their measurements.*

The disappearance of the mastodon is as difficult to account for as that of the mammoth, and, as will be noted, there is absolutely no evidence to show that man had any hand in it. Neither can it be ascribed to change of climate, for the mastodon, as indicated by the wide distribution of its bones, was apparently adapted to a great diversity of climates, and was as much at home amid the cool swamps of Michigan and New York as on the warm savannas of Florida and Louisiana. Certainly the much used, and abused, glacial epoch cannot be held accountable for the extermination of the creature, for the mastodon came into New York after the recession of the great ice-sheet, and tarried to so late a date that bones buried in

* As skeletons are sometimes mounted, they stand a full foot or more higher at the shoulders than the amimal stood in life, this being caused by raising the body until the shoulder-blades are far below the tips of the vertebra, a position they never assume in life. 
the swamps retain much of their animal matter. So recent, comparatively speaking, has been the disappearance of the mastodon, and so fresh-looking are some of its bones, that Thomas Jefferson thought in his day that it might still be living in some part of the then unexplored Northwest.

It is a moot question whether or not man and the mastodon were contemporaries in North America, and while many there be who, like the writer of these lines, believe that this was the case, an expression of belief is not a demonstration of fact. 'The best that can be said is that there are scattered bits of testimony, slight though they are, which seem to point that way, but no one so strong by itself that it could not be shaken by sharp crossquestioning and enable man to prove an alibi in a trial by jury. For example, in the great bone deposit at Kimmswick, Mo., Mr. Bechler found a flint arrowhead, but this may have lain just over the bone-bearing layer, or have got in by some accident in excavating. How easily a mistake may be made is shown by the report sent to the United States National Museum of 
many arrowheads associated with mastodon bones in a spring at Ifton, Indian 'Territory. This spring was investigated, and a few mastodon bones and flint arrowheads were found, but the latter were in a stratum just above the bones, although this was overlooked by the first diggers.* Koch reported finding charcoal and arrowheads so associated with mastodon bones that he inferred the animal to have been destroyed by fire and arrows after it became mired. It has been said that Koch could have had no object in disseminating this report, and hence that it may be credited, but he had just as much interest in doing this as he did in fabricating the IIydrarchus and the Missourium, and his testimony is not to be considered seriously. It seems to be with the mastodon much as it is with the sea-serpent; the latter never appears to a naturalist, remains of the former are never found by a trained observer

* This locality has just been carefully investigated by Mr. II. H. Holmes of the L'nited States National Museum who found bones of the mastodon and Southern Mammoth associated with arrowheads. But he also found fresh bones of bison, horse, and nolf, showing that these and the arrowheads had simply sunk to the level of the older deposit. 
associated with indications of the presence of man. Perhaps an exception should be made in the case of Professor J. M. Clarke, who found fragments of charcoal in a deposit of muck under some bones of mastodon.

We may pass by the so-called "Elephant Mound," which to the eye of an unimaginative observer looks as if it might have been intended for any one of several beasts; also, with bated breath and due respect for the bitter controversy waged orer them, pass we by the elephant pipes. 'There remains, then, not a bit of man's handiwork, not a piece of pottery, engraved stone, or scratched bone that can unhesitutingly be said to have been wrought into the shape of an elephant before the coming of the white man. 'T'rue, there is "The Lenape Stone," found near Doyleston, P'a., in 1872, a gorget graven on one side with the representation of men attacking an elephant, while the other bears a number of figures of various animals. The good faith of the finder of this stone is unimpeachable, but it is a curious fact that, while this gorget is elaborately decorated on both sides, no similar stone, out of all that 
have been found, bears any image whatsoever. On the other hand, if not made by the aborigines, who made it, why was it made, and why did nine years elapse between the discovery of the first and sceond portions of the broken ornament? 'These are questions the reader may decide for himself; the author will only say that to his mind the drawing is too elaborate, and depicts entirely too much to have been made by a primitive artist. A much better bit of testimony seems to be presented by a fragment of Fulgur shell found near Hollyoak, Del., and now in the United States National Museum, which bears a very rudely scratched image of an animal that may have been intended for a mastodon or a bison. This piece of shell is undeniably old, but there is, unfortunately, the uncertainty just mentioned as to the animal depicted. 'The familiar legend of the Big Buffislo that destroyed animals and men and defied even the lightnings of the Great Spirit has been thought by some to have originated in a tradition of the mastodon handed down from ancient times; but why consider that the mastodon is meant? Why 
not a legendary bison that has increased with years of story-telling? And so the co-existence of man and mastodon must rest as a case of not proven, although there is a strong probability that the two did live together in the dim ages of the past, and some day the evidence may come to light that will prove it beyond a peradventure. If scientific men are charged with obstinacy and unwarranted incredulity in declining to accept the testimony so far presented, it must be remembered that the evidence as to the existence of the sea serpent is far stronger, since it rests on the testimony of eye-witnesses, and yet the creature himself has never been seen by a trained observer, nor has any specimen, not a scale, a tooth, or a bonc, ever made its way into any museum.

\section{REFERENCES}

There are at least cleven mounted skeletons of the Irastodon in the L'nited Stutes, and the writer trusts he may be pardoned for mentioning only those which are most accessible. Thesc are in the American Muscum of Nutural History, Ncw Iork; the State Museum, Al- 
bany, N. I. ; Field Columbian Muscum, Chicago ; Carnegie MLuseum, Pittsburg; IInseum of Comparative Zoïlogy, Cambridge, Irass. There is no mounted skclcton in the United States National Museum, nor has there ever been.

The heaviest pair of tuskis is in the possession of T.O. Tuttle, Seneca, Mich., and they are nine and one-half inches in diameter, and a little over eight feet long; very few tusks, however, reach cight inches in diameter. The thigh-bone of an old male mastodon measures from forty-fice to forty-six and one-half inches long, the humerus from thirty-five to forty inches. The height of the mounted skicleton is of little zalue as an indication of size, since it depends so much upon the manner in which the skeleton is mounted. The grinders of the mastodon hate three cross ridges, save the last, which has four, and a final elciation, or hecl. This does not apply to the teeth of zery young animals. The presence or absence of the last grinder will show whether or not the animal is of full age and size, while the amount of wear indicates the comparative age of the specimen.

The skeleton of the " Warren Mastodon" is described at length by Dr. J. C. Warren, in a quarto zolume entitled "Mastodon Giganteus." There is much information in a little book by J. P. MacLean, "Mrastodon, Mammoth, and Man," but the reader must not accept all its statements unhesitatingly. The first volume, 188\%, 
of the New Seribner's Magazine contains an article on "American Elephant LIyths," by Professor W. B. Scott, but he is under an crroncous impression regarding the size of the mastodon, and photographes of the Maya carings show that their resemblane to elephants has been caraggerated in the wood cuts. The story of the Lenape Stone is told at length by H. C. Mereer in "The Lenape Stone, or the Indian and the Mammoth."

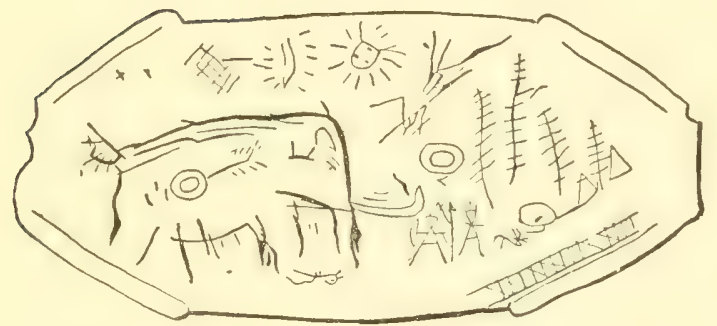

Fig. 41. - The Lenape Stone, Reduced. 


\section{XII}

\section{WHY DO ANIMALS BECOME EXTINCT?}

\section{"And Sultan after Sultan with his Pomp}

Abode his destined Hour and went his way."

IT is often asked "why do animals become extinct?" but the question is one to which it is impossible to give a comprehensive and satisfactory reply; this chapter does not pretend to do so, merely to present a few aspects of this complicated, many-sided problem.

In very many cases it may be said that actual extermination has not taken place, but that in the course of evolution one species has passed into another; species may have been lost, but the race, or phylum endures, just as in the growth of a tree, the twigs and branches of the sapling disappear, while the tree, as a whole, grows onward and upward. This is what we see in the horse, which is the living representative of an unbroken line reaching 220 
WHY DO ANIMALS BECOME EXTINCT? 221 back to the little Eocene Hyracothere. So in a general way it may be said that much of what at the first glance we might term extinction is really the replacement of one set of animals by another better adapted to surrounding conditions.

Again, there are many cases of animals, and particularly of large animals, so peculiar in their make up, so very obviously adapted to their own special surroundings that it requires little imagination to see that it would have been a difficult matter for them to have responded to even a slight change in the world about them. Such great and necessarily sluggish brutes as Brontosaurus and Diplodocus, with their tons of flesh, small heads, and feeble teeth, were obviously reared in easy circumstances, and unfitted to succeed in any strenuous struggle for existence. Stegosaurus, with his bizarre array of plates and spines, and hugeheaded Triceratops, had evidently carried specialization to an extreme, while in turn the carnivorous forms must have required an abundant supply of slow and easily captured prey.

Coming down to a more recent epoch, when 
the big Titanotheres flourished, it is easy to see from a glance at their large, simple teeth that these beasts needed an ample provision of coarse vegetation, and as they seem never to have spread far beyond their birthplace, climatic change, modifying even a comparatively limited area, would suffice to sweep them out of existence. To use the epitaph proposed by P'rofessor Marsh for the tombstone of one of the Dinosaurs, many a beast might say, "I, and my race perished of over specialization." 'I'o revert to the horse it will be remembered that this very fate is believed to have overtaken those almost horses the European Hippotheres; they reached a point where no further progress was possible, and fell by the wayside.

'There is, however, still another class of cases where species, families, orders, even, seem to have passed out of existence without sufficient cause. Those great marine reptiles, the Ichthyosaurs, of Europe, the Plesiosaurs and Mosasaurs, of our own continent, seem to have been just as well adapted to an aquatic life as the whales, and even better than the seals, and we can see no reason why Columbus should 
not have found these creatures still disporting themselves in the Gulf of Mexico. The best we can do is to fall back on an unknown "law of progress," and say that the trend of life is toward the replacement of large, lower animals by those smaller and intellectually higher.

But rchy there should be an allotted course to any group of animals, why some species come to an end when they are seemingly as well fitted to endure as others now living, we do not know, and if we say that a time comes when the germ-plasm is incapable of further subdivision, we merely express our ignorance in an unnecessary number of words. The mammoth and mastodon have already been cited as instances of animals that have unaccountably become extinct, and these examples are chosen from among many on account of their striking nature. 'The great ground sloths, the Mylodons, Megatheres, and their allies, are another case in point. At one period or another they reached from Oregon to Virginia, Florida, and Patagonia, though it is not claimed that they covered all this area at one time. And, while it may be freely admitted 
that in some portions of their range they may have been extirpated by a change in food-supply, due in turn to a change in climate, it seems preposterous to claim that there was not at all times, somewhere in this vast expanse of territory, a climate mild enough and a food-supply large enough for the support of even these huge, sluggish creatures. We may evoke the aid of primitive man to account for the disappearance of this race of giants, and we know that the two were coeval in Patagonia, where the sloths seem to have played the rôle of domesticated animals, but again it seems incredible that early man, with his flint-tipped spears and arrows, should have been able to slay even such slow beasts as these to the very last individual.

Of course, in modern times man has directly exterminated many animals, while by the introduction of dogs, cats, pigs, and goats he has indirectly not only thinned the ranks of animals, but destroyed plant life on an enormous scale. But in the past man's capabilities for harm were infinitely less than now, while of course the greatest changes took place before 
man even existed, so that, while he is responsible for the great changes that have taken place in the world's flora and fauna during recent times, his influence, as a whole, has been insignificant. 'Thus, while man exterminated the great northern sea-cow, Rytina, and Pallas's cormorant on the Commander Islands, these animals were already restricted to this circumscribed area* by natural causes, so that man but finished what nature had begun. 'The extermination of the great auk in European waters was somewhat similar. 'There is, however, this unfortunate difference between extermination wrought by man and that brought about by natural causes : the extermination of species by nature is ordinarily slow, and the place of one is taken by another, while the destruction wrought by man is rapid, and the gaps he creates remain unfilled.

Not so very long ago it was customary to account for changes in the past life of the globe by earthquakes, rolcanic outbursts, or

* It is possible that the cormorant may always have been confined to this one spot, hut this is probably not the case with the sea-cow. 
cataclysms of such appalling magnitude that the whole face of nature was changed, and entire races of living beings swept out of existence at once. But it is now generally conceded that while catastrophes have occurred, yet, vast as they maly have been, their effects were comparatively local, and, while the life of a limited region may have been ruthlessly blotted out, life as a whole was but little affected. 'The eruption of Krakatoa shook the earth to its centre and was felt for hundreds of miles around, yet, while it caused the death of thousands of living beings, it remains to be shown that it produced any efiect on the life of the region taken in its entirety.

Changes in the life of the globe have been in the main slow and gradual, and in response to correspondingly slow changes in the level of portions of the earth's crust, with their farreaching effects on temperature, climate, and regetation. Animals that were what is termed plastic kept pace with the altering conditions about them and became modified, too, while those that could not adapt themselves to their surroundings died out. 
WHY DO ANIMALS BECOME EXTINCT? Q2?

How slowly changes may take place is shown by the occurrence of a depression in the Isthmus of Panama, in comparatively recent geologic time, permitting free communication between the Atlantic and Pacific, a sort of natural inter-oceanic canal. And yet the alterations wrought by this were, so to speak, superficial, affecting only some species of shore fishes and invertebrates, having no influence on the animals of the deeper waters. Again, on the Pacific coast are now found a number of shells that, as we learn from fossils, were in Pliocene time common on both coasts of the United States, and Mr. Dall interprets this to mean that when this continent was rising, the steeper shore on the Pacific side permitted the shell-fish to move downward and adapt themselves to the ever changing shore, while on the Atlantic side the drying of a wide strip of level sea-bottom in a relatively short time exterminated a large proportion of the less active mollusks. And in this instance "relatively short" means positively long ; for, compared to the rise of a continent from the ocean's bed, the flow of a glacier is the rapid rush of a mountain torrent. 
Then, too, while a tendency to vary seems to be inherent in animals, some appear to be vastly more susceptible than others to outside influences, to respond much more readily to any change in the world about them. In fact, Irofessor Cook has recently suggested that the inborn tendency to variation is sufficient in itself to account for evolution, this tendency being either repressed or stimulated as external conditions are stable or variable.

The more uniform the surrounding conditions, and the simpler the animal, the smaller is the liability to change, and some animals that dwell in the depths of the ocean, where light and temperature vary little, if any, remain at a standstill for long periods of time.

The genus I ingula, a small shell, traces its ancestry back nearly to the base of the Ordovician system of rocks, an almost inconceivable lapse of time, while one species of brachiopod shell endures unchanged from the 'Trenton Limestone to the Lower Carboniferous. In the first case one species has been replaced by another, so that the shell of to-day is not ex actly like its very remote ancestor, but that 
WHY DO ANIMALS BECOME EXTINCT? 229

the type of shell should have remained unchanged when so many other animals have arisen, flourished for a time, and perished, means that there was slight tendency to variation, and that the surrounding conditions were uniform. Says Professor Brooks, speaking of Lingula: " The everlasting hills are the type of vencrable antiquity; but I ingula has seen the continents grow up, and has maintained its integrity unmored by the convulsions which have given the crust of the earth its present form."

Many instances of sudden but local extermination might be adduced, but among them that of the tile-fish is perhaps the most striking. 'This fish, belonging to a tropical family having its headquarters in the Gulf of Mexico, was discovered in 1879 in moderately deep water to the southward of Massachusetts and on the edge of the Gulf Stream, where it was taken in considerable numbers. In the spring of 1882 vessels arriving at New York reported having passed through great numbers of dead and dying fishes, the water being thickly dotted with them for miles. From samples brought 
in, it was found that the majority of these were tile-fish, while from the reports of various vessels it was shown that the area covered by dead fish amounted to somewhere between $\mathbf{5 , 0 0 0}$ and 7,500 square miles, and the total number of dead was estimated at not far from $\iota$ billion. This enormous and widespread destruction is believed to have been caused by an unwonted duration of northerly and easterly winds, which drove the cold arctic current inshore and southwards, chilling the warm belt in which the tilefish resided and killing all in that locality. It was thought possible that the entire race might have been destroyed, but, while none were taken for many years, in 1899 and in 1900 a number were caught, showing that the species was beginning to reoccupy the waters from which it had been driven years before.

The effect of any great fall in temperature on animals specially adapted to a warm climate is also illustrated by the destruction of the Manatees in the Sebastian River, Florida, by the winter of 1894-95, which came very near exterminating this species. Readers may remember that this was the winter that wrought 
such haroc with the blue-birds, while in the vicinity of Washington, D. C., the fish-crows died by hundreds, if not by thousands.

Fishes may also be exterminated over large areas by outbursts of poisonous gases from submarine volcanoes, or more rarely by some vast lava flood pouring into the sea and actually cooking all living beings in the ricinity. And in the past these outbreaks took place on a much larger scale than now, and naturally wrought more widespread destruction.

A recent instance of local extermination is the total destruction of a humming-bird, $\boldsymbol{B} \boldsymbol{B} \%$ lona ormate, peculiar to the island of St. Vincent, by the IV est Indian hurricane of 1898 , but this is naturally extirpation on a rery small scale.

Still, the problems of nature are so involved that while local destruction is ordinarily of little importance, or temporary in its effects, it may lead to the amihilation of a species by breaking a race of animals into isolated groups, thereby leading to inbreeding and slow decline. The European bison, now confined to a part of Lithuania and a portion of the Caucasus, seems 
to be slowly but surely approaching extinction in spite of all efforts to preserve the race, and no reason can be assigned for this save that the small size of the herds has led to in-breeding and general decadence.

In other ways, too, local calamity may be sweeping in its effects, and that is by the destruction of animals that resort to one spot during the breeding season, like the fur-seals and some sea-birds, or pass the winter months in great flocks or herds, as do the ducks and elk. The supposed decimation of the Moas by severe winters has been already discussed, and the extermination of the great auk in Furopean waters was indirectly due to natural causes. 'These birds bred on the small, almost inaccessible island of Eldey, off the coast of Iceland, and when, through volcanic disturbances. this islct sank into the sea, the few birds were forced to other quarters, and as these were, unfortunately, easily reached, the birds were slain to the last one.

From the great local abundance of their remains, it has been thought that the curious short-legged Pliocene rhinoceros, Aphelops fos- 
siger, was killed off in the West by blizzards when the animals were gathered in their winter quarters, and other long-extinct animals, too, have been found under such conditions as to suggest a similar fate.

Among local catastrophes brought about by unusually prolonged cold may be cited the decimation of the fur-scal herds of the Pribilof Islands in 1834 and 18.59, when the breeding seals were prevented from landing by the presence of ice-floes, and perished by thousands. Peculiar interest is attached to this case, because the restriction of the northern fur-seals to a few isolated, long undiscovered islands, is beliered to have been brought about by their complete extermination in other localities by prehistoric man. IIad these two seasons killed all the seals, it would have been a reversal of the customary extermination by man of a species reduced in numbers by nature.

In the case of large animals another element probably played a part. 'The larger the animal, the fewer young, as a rule, does it bring forth at a birth, the longer are the intervals between births, and the slower the growth of 
the young. 'The loss of two or three broods of sparrows or two or three litters of rabbits makes comparatively little difference, as the loss is soon supplied, but the death of the young of the larger and higher mammals is a more serious matter. I factor that has probably played an important rôle in the extinction of animals is the relation that exists between rarious animals, and the relations that also exist between animals and plants, so that the existence of one is dependent on that of another. 'Thus no group of living beings, plants or animals, can be affected without in some way affecting others, so that the injury or destruction of some plant may result in serious harm to some animal. Nearly everyone is familiar with the classic example given by Darwin of the effect of cats on the growth of red clover. This plant is fertilized by bumble bees only, and if the field mice, which destroy the nests of the bees, were not kept in check by cats, or other small carnivores, their increase would lessen the numbers of the bees and this in turn would cause a dearth of clover.

The yuccas present a still more wonderful 
example of the dependence of plants on animals, for their existence hangs on that of a small moth whose peculiar structure and habits bring about the fertilization of the flower. 'The two probably dereloped side by side until their present state of inter-dependence was reached, when the extinction of the one would probably bring about that of the other.

It is this inter-dependence of living things that makes the outcome of any direct interference with the natural order of things more or less problematical, and sometimes brings about results quite different from what were expected or intended.

The gamekeepers on the grouse moors of Scotland systematically killed off all birds of prey because they caught some of the grouse, but this is beliered to have caused far more harm than good through permitting weak and sickly birds, that would otherwise have fallen a prey to hawks, to live and disseminate the grouse distemper.

The destruction of sheep by coyotes led the State of California to place a bounty on the heads of these animals, with the result that in 
eighteen months the State was called upon to pay out $\$ 187,485$. As a result of the war on coyotes the animals on which they fed, notably the rabbits, increased so enormously that in turn a bounty was put on rabbits, the damage these animals caused the fruit-growers being greater tham the losses among sheep-owners from the depredations of coyotes. And so, says Dr. Palmer, "In this remarkable case of legislation a large bounty was offered by a county in the interest of fruit-growers to counteract the effects of a State bounty expended mainly for the benefit of sheep-owners!"

Professor Shaler, in noting the sudden disappearance of such trees as the gums, magnolias, and tulip poplars from the Miocene flora of Europe has suggested that this may have been due to the attacks, for a series of years, of some insect enemy like the gipsy moth, and the theory is worth considering, although it must be looked upon as a possibility rather than a probability. Still, anyone familiar with the ravages of the gipsy moth in Massachusetts, where the insect was introduced by accident, can readily imagine what might have 
been the effect of some sudden increase in the numbers of such a pest on the forests of the past. 'Trees might resist the attacks of encmies and the destruction of their leaves for two or three years, but would be destroyed by a few additional seasons of defoliation.

Ordinarily the abnormal increase of any insect is promptly followed by an increase in the number of its enemies; the pest is killed off, the destroyers die of starvation and nature's balance is struck. But if by some accident, such as two or three consecutive seasons of wet, drought, or cold, the natural increase of the enemies was checked, the balance of nature would be temporarily destroyed and serious harm done. 'That such accidents may occur' is familiar to us by the damage wrought in Florida and other Southern States by the unwonted severity of the winters of 1893,1895 , and 1899.

If any group of forest trees was destroyed in the manner suggested by I'rofessor Shaler, the effects would be felt by rarious plants and animals. In the first place, the insects that fed on these trees would be forced to seek another 
source of food and would be brought into a silent struggle with forms already in possession, while the destruction of one set of plants would be to the advantage of those with which they came into competition and to the disadvantage of regetation that was protected by the shade. Finally, these changed conditions would react in various ways on the smaller birds and mammals, the general effect being, to use a well-worn simile, like that of casting a stone into a quiet pool and setting in motion ripples that sooner or later reach to every part of the margin.

It is scarcely necessary to warn the reader that for the most part this is purely conjectural, for from the nature of the case it is bound to be so. But it is one of the characteristics of educated man that he wishes to know the why and wherefore of everything, and is in a condition of mental unhappiness until he has at least formulated some theory which seems to harmonize with the visible facts. And from the few glimpses we get of the extinction of animals from natural causes we must formulate a theory to fit the continued extermina- 
WHY DO ANIMALS BECOME EXTINCT? 239 tion that has been taking place ever since living beings came into the world and were pitted against one another and against their surroundings in the silent and ceaseless struggle for existence.

THE END. 

INDEX 



\section{INDEX}

The asterisk denotes that the animal or object is figured on or opposite the page referred to.

Epyornis, egg of, 145, 148,* 147, 157

eggs found in swamps, 148 ; found floating, 148

eggs used for bowls, 145

origin of fable of Roc, 144, 145

Alaskan Live Mammoth Story, 190-193, 197

Anomœepus tracks, 39

Apteryx egg, 147

Archæopteryx, description of, 77, 78

discovery of, 77

earliest known bird, 70

restoration, $89^{*}$

specimens of, $70, * 88$

wing, $72, * 73$

Archelon, a great turtle, 54

Basilosaurus, 60

See also Zeuglodon

Beehler, L. W., 209, 213

Birds, always clad in feathers, 71,127

earliest, 70 
Birds, first intimation of, 76

rarity of fossil, 86,87

related to reptiles, 92

wings of embryonic, 73

with teeth, 79,88

Bison, European, 231

Books of reference, xix, 17, 32, 47, 69, 89, 110, 13\%, $158,1 \% 6,197,218$

Breeding of large animals, 233

Brontornis, size of leg-bones, 149

Brontosaurus, size of bones, $96,{ }^{*} 97, * 109$

Brooks, W. K., on Lingula, 229

Buffalo legend, 216

Buttons as vestigial structures, 202

Carcharodon auriculatus, 66

teeth, 66

megalodon, 65

estimated size, 66

teeth, 65, 67

Carson City footprints, 45

Casts, how formed, 10, 11

Cats and clover, 234

Cephalaspis, 24*

Ceratosaurus, habits, 106

restoration, 106 *

skull, $110^{*}$

Changes in Nature slow, 227

Cheirotherium, 43 
Chlamydosaurus, 129

Claosaurus. See Thespesius

Climate, changes in western United States, 174

Clover and cats, 234

Cold, effects of, on animals, 230, 231, 233

Cold winters, 230

Collecting fossils, 17, 112-116

Color of large land animals, 134

of young animals, 136

Covering of extinct animals sometimes indicated, 131, 132

Corotes, effect of their destruction on fruit, 236

Dill, WV. H., theory as to extinction of molluskis, 227

Dinosaurs, bones of, 109, 110

brain of, 93

collections of, 109

compared to marsupials, 95

first discovered, 90

food required by, 98

hip-bones mistaken for shoulder-blade, 120

Professor Marsh's epitaph for, 222

range, 92

recognized as new order of reptiles, 91

related to ostrich and alligator, 91

size of, $95,96,98$

tracks, ascribed to birds, 38

Dinotherium, 200 
Diplodocus, estimated weight, 99

supposed habits, 99

Egg of Apyornis, 147, 148 ; Apteryx, 147 ; Ostrich, 146; Moa, 148

Eggs, casts of, 87

Elephant, size, 180

size of tusks, 181, 182

Elephas ganesa, tusks, 196

Encrustations, 14

Extermination. See Extinction

Extinction, ascribed to great convulsions, 225

ascribed to primitive man, 188, 224.

of Dinosaurs, 221

local, 225

by man, 224, 225

of Marine Reptiles, 22\%

often unaccountable, 222, 223

of Pliocene rhinoceros, 232

sometimes evolution, 221, 226

of 'Titanotheres, 222

Feathers, imprints of, 76,132

Fishes, abundance of, 25

armored, 23, 24, 25, 28

collections of, 32

killed by cold, 230

killed by volcanoes, 231

Fish-crows, killed by cold, 231

Flesh does not petrify, 10 
Flightless birds, absent from Tasmania, 155

present distribution, 154, 155

relation between flightlessness and size, 156

Folds and frills, 129

Footprints, collections of, 47

books on, 47

See also under Tracks

Fossil birds, rarity of, 86

Fossil man, 13

Fossilization a slow process, 10

Fossils, conditions under which they are formed, 5, 7

collecting, 112-116

definition of, 1

deformation of, 16

impressions, 2, 3

not necessarily petrifactions, 2

preparation of, 117-119

why they are not more common, 5, 15, 16

Fowls, muscles of, 81

Frill of Triceratops, 102

Fur-seals killed by ice-floes, 233

Gar pikes, destruction of, 26

Giant birds, reasons for distribution and flightlessness, 153

Giant Moa, 141

leg compared with that of horse, 152*

Giant Sloth, domesticated by man, 224

struggle between, 46 
Giant Sloth, tracks at Carson City, 46

Gilfort, Robert, 157

Great Auk, extermination of, 232

Grouse on Scotch moors, 235

Hawkins, B. W., restorations by, 137

Hesperornis, description of, 80

impressions of feathers, 132

position of legs, 83, 84

restoration of, $82^{*}$

Hippotherium, 166, 167

Hoactzin, habits of, 74,75 *

Horn does not petrify, 130

Horse, abundant in Pleistocene time, 164

books on, 176

of bronze age, 163, 167

collections of fossil, 176

development of, $16 \%, 168, * 175$

differences between fossil and living, 163

early domestication, 165

evidence as to genealogy, 170-173

extra-toed, 172, 173

found in South America in 1530, 165

of Julius Cæesar, 172

none found wild in historic times, 165

Pliocene, 166

possibility of existence in America up to the time

of its discovery, 169, 170

primitive, $160,161^{*}$ 
Horse, sketched by primitive man, 163

teeth of, 170

three-toed, 166

Humming-bird, exterminated by hurricane, 231

Hydrarchus, 62*

Hyracotherium, 160, 161, * 170, 174

Ichthyosaurs, silhouettes of, 132

Iguanodons, found at Bernissart, 104

Impressions of feathers, 131

$$
\begin{aligned}
& \text { of scales, } 131 \\
& \text { of skin, } 131
\end{aligned}
$$

Inbreeding, effects of, 231, 232

Information, sources of, xvi

Innuits, habits, 192

Interdependence of animals and plants, 234, 235, 238

Ivory, fossil, 2, 4, 188, 189

Jaw of Mosasaur, 54*

of reptiles, 53

Killing of the Mammoth, story, 17\%, 193

Kimmswick, deposit of Mastodon bones, 209

Knight, Charles R., restorations by, xviii, 136

Koch's Hydrarchus, 61, 62*

Missourium, 207,* 208

Leaves, impressions of, 3, 13

Leg of Brontornis, $149^{*}$ 
Leg of the Great Brontosaurus, 96* of Giant Moa, 152*

position in Hesperornis, 83

position in ducks, 84

Lenape Stone, 215, 216, 219*

Life, earliest traces of, 21, 34

Lingula, antiquity of, 228

Professor Brooks on, 229

Loricaria, 24*

Mammoth, adapted to a cold climate, 134

Alaskan Live, Story, 190

believed to live underground, 178

bones taken for those of giants, 185

contemporary with man, 189

derivation of name, 178

description, 179

discovery of entire specimens, 183, 187

distribution, 184, 186

drawn by early man, 189, 197*

entire specimens obtainable, 194

reasons for extermination, 188

killing of the, $17 \%$

literature on, $19 \%$

misconception as to size, 179

mounted skeleton, 179

not now living, 190

preservation of remains, 187

skeletons in Alaska, 181, 195 
Mammoth, in Chicago Academy of Sciences, 179

at St. Petersburg, 183*

restoration, 176 *

size, 179, 180, 181

size of tusks, 181, 196

teeth, $196,199^{*}$

teeth dredged in North Sea, 184

tusks brought into market, 188, 189

Man contemporary with Mammoth, 189

fossil, 13

of Guadeloupe, 13

Manatees killed by cold, 230

Marsh, Prof. O. C., collection of fossil horses, 176

on Dinosaurs, 222

on toothed birds, 79,89

Miastodon, bones taken for those of giants, 205

thought to be carnivorous, 206

covering, 210

description, 210

distribution, 203, 210, 212

extinction, 212

literature, 218

and man, 215, 216

first noticed in America, 204

origin unknown, 202

remains abundant, 208, 209

remains in Ulster and Orange counties, New York, 204, 206

restoration, $210 *$ 
Mastodon, size, 211

skeletons on exhibition, 218

species, 203

teeth, 198, 199, * 218

tusks, 199, 200

Mesohippus, 167

Mimicry, not conscious, 128

Missourium of Koch, 207, * 208

Moas, collections of, $156,15 \%$

contemporary with man, 143, 144

deductions from distribution, 143

destruction of, 143, 144

discovery of bones, 140

elephant-footed, 142

feathers of, 141

Giant, 141

supposed food of, 142

legends of, 139, 140

literature, 158

scientific names, 146

size of, 141

species of, 141

Moloch, an Australian lizard, 100 *

Mosasaurs, abundance of, in Kansas, 52

books on, 69

collections of, 68

extinction of, 56

first discovery, 50

jaw of, 54 * 
Mosasaurs, range of, 49

restoration, $52 *$

size of, 49,50

Mylodon tracks at Carson City, 45

Names, scientific, reasons for using, xvi, xvii

Nature, balance of, 238

Nuts, fossil, 11

Oldest animals, 21

vertebrates, 19, 22

Ostrich egg, 147

Over-specialization, 221, 222

Peale, C. W., 205

Peale, Rembrandt, 205, 206

Pelican, mandible, 53

Penguins, depend on fat for warmth, 127

feathers highly modified, 128

swim with wings, 80

Petrified bodies, 10

Phororhacos, description of, 149

mistaken for mammal, 149

Patagonian bird, 148

related to heron family, 152

restoration, frontispiece

skull, 150, 151 *

Protohippus, 166

Pteraspis, 28 
Pterichthys, 25, 28, 32*

mistaken for crab, 25

Pterodactyls, impressions of wings, 133

from Kansas, 55

wing, 72*

Pycraft, IV. P., restoration of Archæopteryx, 89

Radiolarians, 15, 17*

Reconstruction of animals, 127, 130, 134

Reptiles, fasting powers of, 98

growth throughout life, 102

jaws, 53

Restorations, xviii

Archæopteryx, 89*

Ceratosaurus, $106 *$

Hesperornis, 82*

Mammoth, $176 *$

Mastodon, 210*

Phororhacos, fiontispiece

progress in, 137

Stegosaurus, 108 *

Thespesius, 90 *

Triceratops, $126 *$

Tylosaurus, 52*

Reversion of fancy stock, 171

Rhinoceros, exterminated by cold, 232

Roc, legend of, 144, 145

Rocks, thickness of sedimentary, 20

Ruffles on dresses, 202 
Schuchert, Charles, on collecting fossils, 17

collector of Zeuglodon bones, 63

Seals, covering of, 128

Sea-serpent, belief in, 56

possibility of existence, 57

Shaler, Professor, on changes in Miocene flora of

Europe, 236, 237

Sharks, early, 31

Great-toothed, 65

known from spines and teeth, 29

Port Jackson, 29

teeth of, 69

White, or Man-Eater, 65

Skeleton, basis of all restorations, $12 \%$

best testimony of animal's relationships, 124

information to be derived from, 120, 122, 123,

124, 125, 126, 127

a problem in mechanics, 102, 124

reconstruction of, 120

relation of, to exterior of animal, 121, 127

of Triceratops, 103, * 121

Spines and plates, 130

Stegosaurus, description of, 106

restoration of, $108 *$

Survival of the fittest, 173

Teeth, birds with, 79

of gnawing animals, 169, 200

of grass-eaters, 169 
'Teeth, of horse, 170

of mammoth, 198, 199*

of mastodon, 198, $199^{*}$

of sharks, 29, 30

of 'Thespesius, 105

Thespesius, abundance of, 104, 105

brain of, 93

(Same as Claosaurus)

engulfed in quicksand, 8

impressions of skin, 132

restoration of, $90 *$

teeth of, 105

at Yale, 109

Tiger, preying on reindeer, 134

Tile-fish, destruction of, 230

Titanichthys, 28, 29

Toothed birds, collections of, 88

discovery of, 79

Townsend C. H., 190-192

Tracks, ascribed to birds, 38

ascribed to giants, 45

animals known from, 41

collections of, 47

of Connecticut Valley, 37

deductions from, 44

of Dinosaurs, 38, ${ }^{*} 40,{ }^{*} 41,47^{*}$

discovery in England and America, 3\%, 42

how formed, 35,40

at Hastings, 44 
Tracks, of Mylodon, 46

$$
\text { of worms, 3, } 33
$$

Triceratops, brain, 94

broken horn, 102

description, 100, 101

restoration, $126^{*}$

skeleton, $103^{*}$

'Tufa, 14

Tukeman, killing of the Mammoth, 17\%, 193

Variation in animals, 228

Vertebrates, oldest, 22

Vestigial structures, 201, 202

Volcanic outbursts, 231, 232

Webster, F. S., on destruction of gar pikes, 26

White, C. A., on the nature and uses of fossils, 17

White Shark, 65

Wings, 71, 72,* 73

of embryonic birds, 73

Wood, fossil, 9, 10

Worm trails, 3, 33

Yucca, fertilization, 235

Zeuglodon, abundance of remains, 60

same as Basilosaurus

description, 58, 63

habits, 59 
Zeuglodon, Koch's restoration, 62

name, 58, 69

once numerous, 60

size, 58

specimen of, 68

structure of bones, 64

teeth, 58, 69* 





SMITHSONIAN INSTITUTION LIBRARIES 